Government of Islamic Republic of Afghanistan

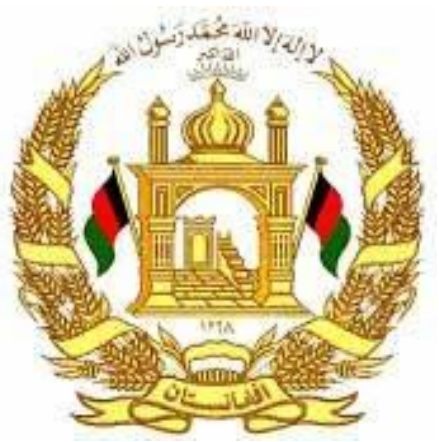

\title{
AGRICULTURE AND RURAL DEVELOPMENT
} CLUSTER

\section{NATIONAL PRIORITY PROGRAM TWO}

National Comprehensive Agriculture Production and Market Development Program 


\section{Table of Contents}

List of Acronyms ........................................................................................................................4

EXECUTIVE SUMMARY .........................................................................................6

1 Background .................................................................................................................6

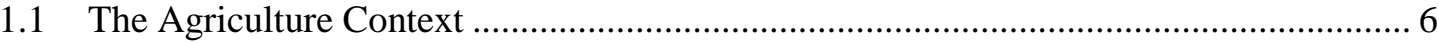

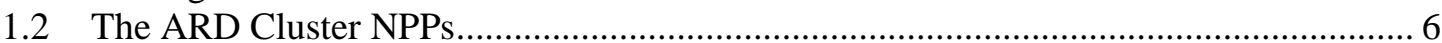

2 NPP-2 Scope, Objectives and Component Overview..............................................8

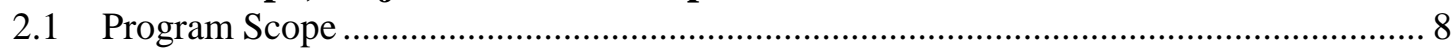

2.2 Program Goal, Objectives and Expected Results....................................................... 8

2.3 Component One: Food for Life ..................................................................................... 9

2.3.1 Component Goal, Objectives and Expected Results............................................... 9

2.3.2 Sub-Component 1: Data and Information Base.................................................... 10

2.3.3 Sub-Component 2: Cereals, Legumes and Oilseeds............................................... 10

2.3.4 Sub-Component 4: Horticulture ………………………………………………... 11

2.3.5 Sub-Component 4: Livestock .......................................................................... 11

2.3.6 Sub-Component 5: Food Nutrition ………………………………………….. 12

2.3.7 Sub-Component 6: Emergency Preparedness and Response …………………….. 12

2.3.8 Sub-Component 7: Dry Land Farming............................................................. 12

2.3.9 Sub-Component 8: Integrated Pest Management ................................................... 13

2.3.10 FFL Implementation Framework...………………………………………… 13

2.4 Component Two: Enterprise and Market Development …………………………….... 15

2.4.1 Component Goal, Objectives and Expected Results .............................................. 15

2.4.2 Sub-Component 1: Integrated Rural Economic Development and Marketing ....... 16

2.4.3 Sub-Component 2: Rural Enterprise Development ............................................... 16

2.4.4 Sub-Component 3: Sustainable Agriculture Credit ................................................ 16

2.4.5 Sub-Component 4: Afghanistan Land Authority..................................................... 17

2.4.6 EMD Implementation Framework ………………………………………………... 17

3 Program Governance Structure …………….........................................................17

4 Monitoring \& Evaluation ........................................................................................18

5 Linkages and Synergies among NPPs ..................................................................19

6 Cross-Cutting Issues ...................................................................................................20

7 Challenges, Constraints and Solutions................................................................21

8 Budget Summary Table.........................................................................................22

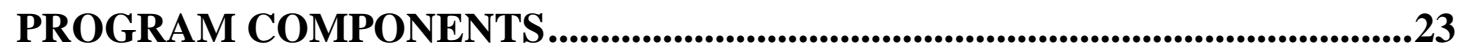

1 Component One: Food For Life ..............................................................................23

$1.1 \quad$ FFL Goal, Objectives and Expected Results............................................................ 23

1.1.1 FFL within Food Security and Nutrition Framework....................................... 24

1.1.2 FFL Time Framework ................................................................................ 24

1.2 Situation Analysis …………………………………………………………. 25

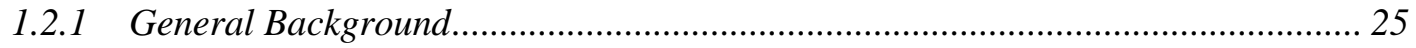

1.2.2 Food Insecurity and Poverty........................................................................... 26

1.2.3 Key Agricultural Growth and Development Issues .......................................... 27

1.2.4 Potential Options for Agricultural Growth and Enhanced Food Security .............. 29

1.2.5 Cultivation of Narcotic Crops and the Illicit Economy .............................................. 31

1.3 Implementation and Governance ................................................................................ 31 


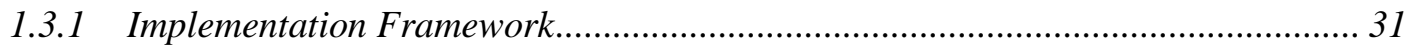

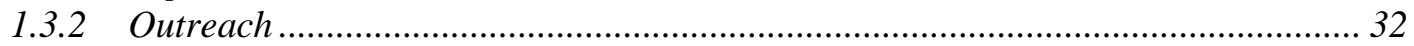

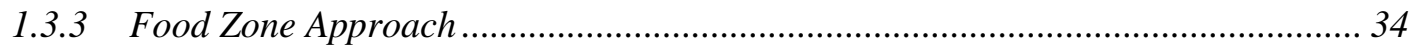

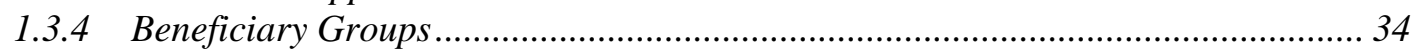

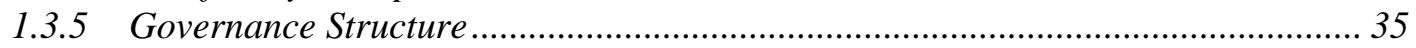

1.3.6 Technical Assistance, Change Management and Capacity Building …….............. 36

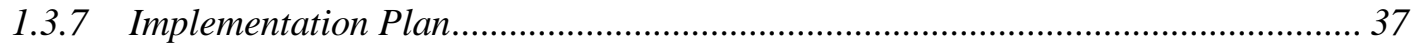

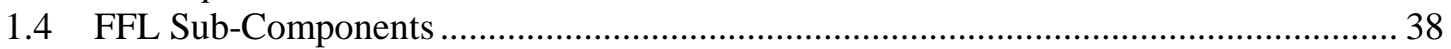

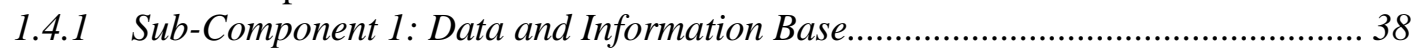

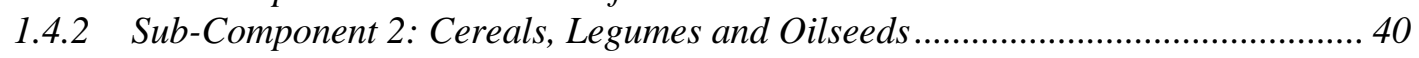

1.4.3 Sub-Component 3: Horticulture ........................................................................... 45

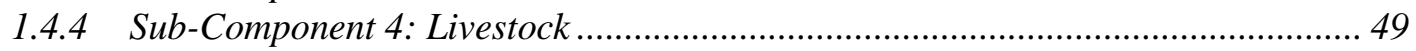

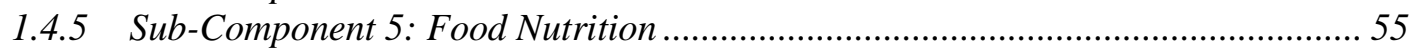

1.4.6 Sub-Component 6: Emergency Preparedness and Response ................................ 59

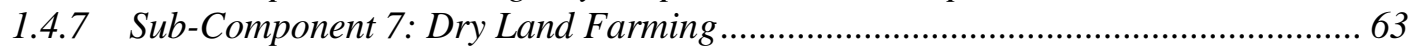

1.4.8 Sub-Component 8: Integrated Pest Management .................................................. 65

2 Component Two: Enterprise and Market Development .......................................70

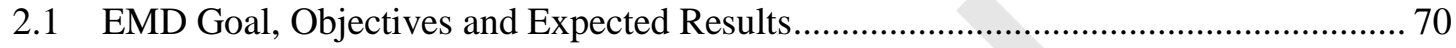

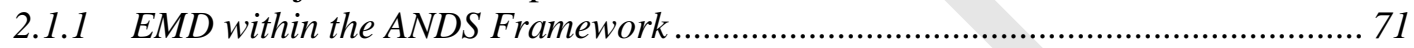

2.1.2 Policy Development for the ARD Sector .............................................................. 71

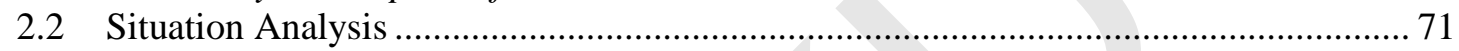

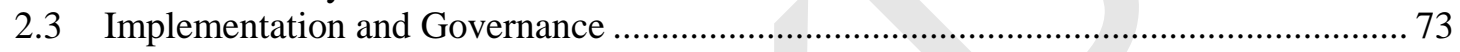

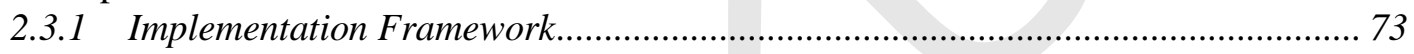

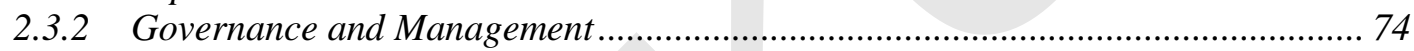

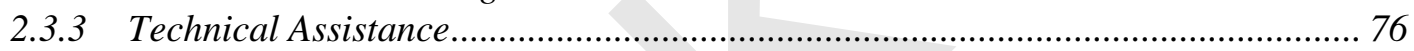

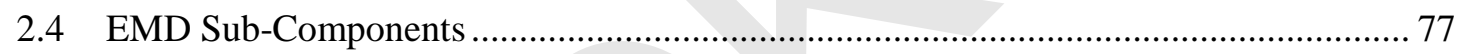

2.4.1 Sub-Component 1: Integrated Rural Economic Development and Marketing ........ 78

2.4.2 Sub-Component 2: Rural Enterprise Development ................................................. 79

2.4.3 Sub-Component 3: Sustainable Agriculture Credit ............................................. 81

2.4.4 Sub-Component 4: Afghanistan Land Authority ................................................ 83

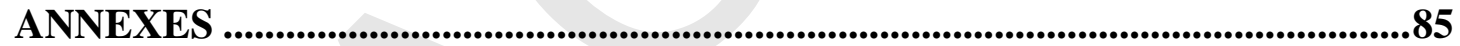

1 Annex: Component Budgets ......................................................................................85

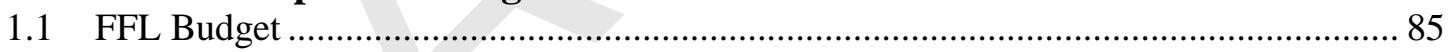

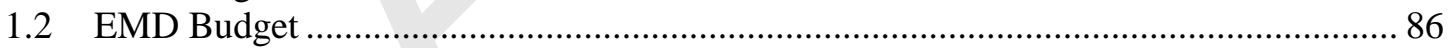

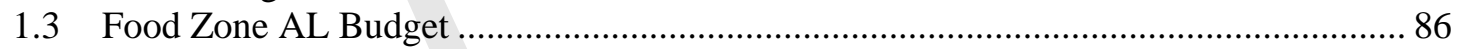

2 Annex: Component Logical Frameworks..................................................................87

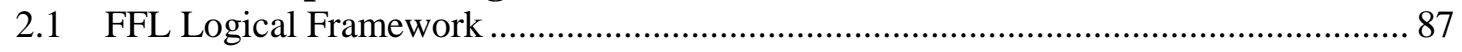

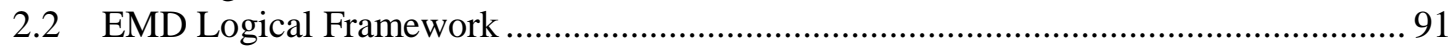

3 Annex: Monitoring \& Evaluation Framework .............................................93

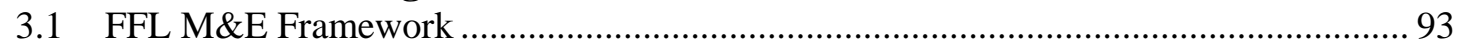

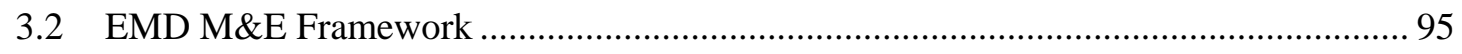

4 Annex: NPP Linkages..........................................................................................99

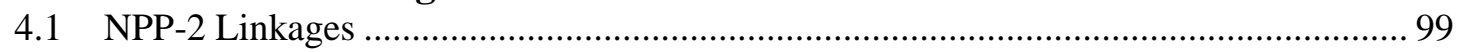

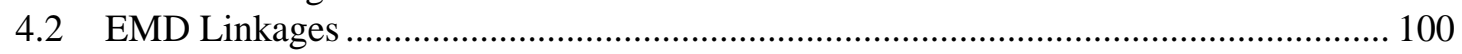

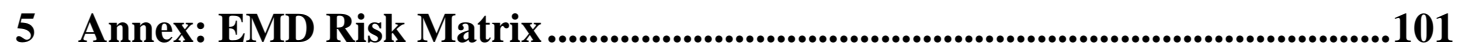

6 Annex: Comprehensive Strategic Framework for Food and Nutrition Security .......................................................................................................................................102 


\section{List of Acronyms}

\begin{tabular}{|c|c|c|c|}
\hline ACE & Agriculture Credit Enhancement programme & JCMB & Joint Coordination \& Monitoring Board \\
\hline $\mathrm{ADF}$ & Agriculture Development Fund & JDAI & Joint Development Associates International \\
\hline Ag Depots & Agriculture Depots & JICA & Japan International Cooperation Agency \\
\hline AI & Artificial Insemination & $\mathrm{Kg}$ & Kilogram \\
\hline ALA & Afghanistan Land Authority & MAIL & $\begin{array}{l}\text { Ministry of Agriculture, Irrigation and } \\
\text { Livestock }\end{array}$ \\
\hline ANDMA & $\begin{array}{l}\text { Afghan National Disaster Management } \\
\text { Authority }\end{array}$ & $M \& E$ & Monitoring and Evaluation \\
\hline ANDS & Afghanistan National Development Strategy & $\mathrm{MCN}$ & Ministry of Counter Narcotics \\
\hline ARD & Agriculture and Rural Development & MDG & Millennium Development Goals \\
\hline AREDP & $\begin{array}{l}\text { Afghanistan Rural Enterprise Development } \\
\text { Programme }\end{array}$ & MEW & Ministry of Energy and Water \\
\hline ASAP & Accelerating Sustainable Agriculture Project & MFI & Microfinance Institution \\
\hline BRF & Badam bagh Research Farm & MICS & Multiple Indicator Cluster Survey \\
\hline $\mathrm{CA}$ & Conservation Agriculture & MIS & Management Information System \\
\hline CARD-F & $\begin{array}{l}\text { Comprehensive Agriculture and Rural } \\
\text { Development Facility }\end{array}$ & MoCI & Ministry of Commerce and Industry \\
\hline $\mathrm{CDC}$ & Community Development Council & $\mathrm{MoF}$ & Ministry of Finance \\
\hline CGIAR & $\begin{array}{l}\text { Consultative Group on International } \\
\text { Agricultural Research }\end{array}$ & MoJ & Ministry of Justice \\
\hline CHAMP & $\begin{array}{l}\text { Commercial Horticulture and Agricultural } \\
\text { Marketing Programme }\end{array}$ & MoM & Ministry of Mines \\
\hline CIMMYT & $\begin{array}{l}\text { International Maize and Wheat Improvement } \\
\text { Centre }\end{array}$ & $\mathrm{MoPH}$ & Ministry of Public Health \\
\hline CMAM & $\begin{array}{l}\text { Community-based Management of Acute } \\
\text { Malnutrition }\end{array}$ & MRRD & $\begin{array}{l}\text { Ministry of Rural Rehabilitation \& } \\
\text { Development }\end{array}$ \\
\hline CPI & Consumer Price Index & MT & Metric Tons \\
\hline $\mathrm{CSO}$ & Central Statistics Organization & NABDP & National Area Based Development Programme \\
\hline DAIL & Department of Agriculture in Provinces & NADF & National Agriculture Development Framework \\
\hline DFID & $\begin{array}{l}\text { Department for International Development } \\
\text { (UK) }\end{array}$ & NALP & National Alternative Livelihood Policy \\
\hline DLF & Dry Land Farming & NAIP & $\begin{array}{l}\text { National Agricultural Information System } \\
\text { Project }\end{array}$ \\
\hline DLFU & Dry Land Farming Unit & NDCS & National Drug Control Strategy \\
\hline DOCs & Denomination of Controlled Origin & NDMC & National Disaster Management Committee \\
\hline DRR & Disaster Risk Reduction & NEI & Nutrition \& Education International \\
\hline EDP & Economic Development Package & NFI & Non Financial Institution \\
\hline ERDA & Energy for Rural Development of Afghanistan & NEPA & National Environmental Protection Agency \\
\hline EU & European Union & NGO & Non Governmental Organization \\
\hline FAAHM & $\begin{array}{l}\text { Food, Agriculture and Animal Husbandry } \\
\text { Information Management and Policy Unit }\end{array}$ & NPP & National Priority Program \\
\hline FAO & Food and Agriculture Organization & NRDS & National Rice Development Strategy \\
\hline FCOMAIL & French Cooperation Office for MAIL & NRM & Natural Resources Management \\
\hline FEWSNET & Famine Early Warning System Network & NRVA & National Risk \& Vulnerability Assessment \\
\hline FFS & Farmer Field School & OCHA & $\begin{array}{l}\text { UN Office for Coordination of Humanitarian } \\
\text { Affairs }\end{array}$ \\
\hline FNS & Food and Nutrition Security & PPQD & Plant Protection \& Quarantine Department \\
\hline FZ & Food Zone & & \\
\hline GDP & Gross Domestic Product & PS & Private Sector \\
\hline GGC & Growing Greener Cities & RMLSP & $\begin{array}{l}\text { Rural Microfinance and Livestock Support } \\
\text { Programme }\end{array}$ \\
\hline GIRoA & Government of Islamic Republic of & RIPA & Rice-based Agriculture Development in \\
\hline
\end{tabular}




\section{Afghanistan}

GIS

Geographic Information Systems

GL-CRSP Global Livestock Collaborative Research Support Program

$\mathrm{Ha}$ Hectare

HLP Horticulture and Livestock Project

ICARDA International Centre for Agricultural Research in the Dry Areas

ICRISAT International Crops Research Institute for the Semi-Arid Tropics

IDEW-NEW Incentives Driving Economic Alternatives North, East \& Wes

IFAD International Fund for Agriculture Development

IMC Inter Ministerial Committee

IPM Integrated Pest Management

\section{Afghanistan}

SAES

SheshamBagh Agriculture Experiment Station

SGR Strategic Grain Reserves

SMEs Small and Medium Enterprise

SWI System for wheat Intensification

ULV Ultra Low Volume

USAID United States Agency for International Development

USDA United States Department of Agriculture

VFU Veterinary Facility Unit

VSLA Village Savings and Loan Association

WFP World Food Program 


\section{EXECUTIVE SUMMARY}

\section{Background}

\subsection{The Agriculture Context}

Agriculture and rural life play a predominant role in the Afghan economy and society. It is estimated that more than $80 \%$ of people live in rural areas, around $50 \%$ of the labour force is engaged in primary agricultural production, and agriculture accounts for around $32 \%$ of the GDP. Due to long periods of conflict and recurring droughts, there has been a steady annual decline of $3.5 \%$ in licit production between 1978 and 2004, and a rise in illicit drug crops. Livestock herds also decreased between 1997 and 2004, partly due to the migration of herdsmen to neighbouring countries. Crop production started rebounding by the mid-2000s, and livestock numbers also increased as owners and their animals returned to the country.

The 2007-2008 NRVA Survey reported that up to 70\% of Afghans are food insecure, and high food prices, political instability and natural disasters constantly push and hold millions of people into highrisk food insecurity. Low levels of dietary intake make malnourishment a further concern. Additional fruit and vegetable consumption is needed as Afghans consume roughly a quarter of the WHO minimum guideline, which is on average met in other Asian developing countries. The 2007-2008 NRVA also revealed that 9 million (or $36 \%$ of the country's population), mostly in the rural areas, live below the national poverty line. Another $20 \%$ of the people live just above that line.

As a result of low levels of agriculture and livestock production and productivity, the agriculture sector produces insufficient and highly variable amounts of the nation's primary staple crops, namely wheat, rice, maize, and legumes, and the same being true for vegetables and fruits. There is also only a limited level of commercialisation, investment and business entrepreneurship in the licit agriculture sector, leading to limited cash incomes and employment earnings from crop and livestock production and related activities. As such, the licit agriculture sector currently lacks the necessary dynamism in production and productivity and markets to sufficiently address issues of farming and rural poverty, unemployment and underemployment, providing viable alternatives to the cultivation of illicit crops, and alleviating national and household food insecurity.

Agriculture, however, has the potential to further grow, address self-sufficiency issues and contribute to food security, notably by tackling the sector's low production and productivity and creating on and off-farm jobs across value chains. Exploiting this growth potential implies improving the sub-optimal productivity that still affects subsistence and landless farmers, and further promoting the entrepreneurial capacity of semi-commercial farmers. However, to achieve increased production in agriculture and economic growth that makes a significant impact on rural areas, agriculture production needs to grow at a steady average rate of at least $5 \%$ per annum over the next decade. There are significant opportunities for economic growth through improved processing and marketing of this increase in produce, creating employment and income opportunities. Therefore, improving production and on and off-farm income, and ensuring availability of sufficient food supply are major components in strengthening the contribution of the agricultural sector to achieve economic growth and poverty reduction. To ensure agricultural sustainability while exploiting the full potential of licit agricultural production in the rural areas, strong public programs along with the development of the private sector must be considered as the key to capacity building and development efforts.

\subsection{The ARD Cluster NPPs}

The Agriculture and Rural Development (ARD) Cluster's policies, strategies and priorities draw from overarching policies, strategies and priorities set at national level, and are driven down to National Priority Program (NPP) level and their constituent elements. As such, the Components and SubComponents of different NPPs are directly influenced by national priorities relating back to the Afghanistan National Development Strategy (ANDS) and the MDGs. Furthermore, within ARD 
Cluster NPPs, Cluster strategies and priorities are used in identifying work plans, determining financial allocations, and identifying implementation models. In the latter case, established district and community level institutions, notably Community Development Committees (CDCs) and farmers' organizations, already take responsibility for identifying local priorities, as well as taking on varying degrees of implementation or oversight responsibility.

The four NPPs in the ARD Cluster address different aspects of agriculture and rural development, but they do so in a way that is complementary rather than competitive. NPP Components and SubComponents are individually complementary within the NPPs, while they are collectively adding value to the overall Cluster approach. This holistic approach to achieving sustainable equitable growth in the rural economy helps reduce the cost of delivery, and increase community leadership and ownership. It does so in part by promoting investments that are appropriate to need, that contribute to developing local skills that increasingly support inclusive and equitable outcomes, and ensure that maintenance of the value of past and existing investment becomes increasingly important. This comprehensive approach and complementary nature of the NPP Components and Sub-Components is also expected to strengthen and diversify licit rural incomes, thus reducing the dependency of subsistence and marginal farmers on cultivation of narcotic crops, as stated in the National Alternative Livelihood Policy (NALP).

The overarching vision of the ARD Cluster is 'to build prosperous rural and pastoral communities' which the 4 NPPs contribute to via their individual goals:

\section{NPP-1: National Water and Natural Resources Development Program}

Goal: To ensure effective utilisation, together with proper management, of existing water and other natural resources to accelerate agricultural productivity and provide safe drinking water and a hygienic environment, with viable rural energy options for rural prosperity.

\section{NPP-2: National Comprehensive Agriculture Production and Market Development Program}

Goal: To improve sustainable agriculture production and productivity and increase on and off-farm enterprises, contributing to food security, inclusive economic growth and reduced dependency of subsistence and marginal farmers and labourers on narcotic crops.

\section{NPP-3: National Rural Access Program}

Goal: To promote equitable economic growth by providing year-round access to basic services and facilities in rural Afghanistan.

\section{NPP-4: Strengthening Local Institutions Program}

Goal: To establish a productive, participatory partnership between the Government and the people it serves using three major vehicles that focus on community-based governance for development.

Furthermore, a complementary approach by ARD Cluster ministries to supporting delivery of objectives within and beyond the ARD NPPs reflects governance models applied within the Cluster. Increasing levels of inter-Ministry engagement are evident, including through an Inter-Ministerial Committee (IMC) and technical working groups. Continuing oversight of the four ARD Cluster NPPs is to be strengthened through quarterly meetings of Cluster Ministers and Deputy Ministers to set priorities, approve work plans and financial allocations, assess progress and recommend action to further strengthen the quality or pace of delivery. More formal and regular engagement with the international community is also planned. 


\section{Program Overview}

\subsection{Program Scope}

From improved production and productivity on the farm, to the factory, to the domestic markets, and finally to exports, agricultural economic growth requires the strengthening or development of new 'value chains'. To this end, The National Comprehensive Agriculture Production and Market Development Program aims to improve the provision of agriculture services, strengthen on and offfarm enterprises, and create a better enabling and regulatory environment for subsistence farmers, semi-commercial and commercial food producers, which will help to increase levels of production beyond subsistence with an approach to sustainable access to nutritious and safe foods and contributing to economic growth. Furthermore, the two Components of the program jointly facilitate the strengthening, provision and diversification of licit rural livelihoods, with a particular focus on subsistence and marginal farmers and labourers, thereby supporting reduction in poppy production in $\mathrm{CN}$-priority provinces. It focuses notably on research and extension services, improved agricultural production methods, alternative livelihoods, agriculture infrastructure development, access to credit and land, enterprise and market development.

Through this program, new crops and technologies will be introduced; agricultural and livestock production will be strengthened, with a particular emphasis on staple crops and nutritious foods to ensure contribution towards food security and emergency preparedness; farmers will have increased access to inclusive credit and inclusive land tenure; better rural infrastructure, such as food storage and processing facilities, will be developed for increasing value-added; and business development services will promote private sector growth. The intent of this proposed approach is to create close linkages between farmers and extension and research services, public and private supporting programs for inputs and outputs, and domestic and global markets.

In addition to delivering targeted and integrated interventions, NPP-2 will also focus on developing evidence-based policy recommendations that enhance and promote the development of an enabling environment for agriculture development and economic growth. As such, it notably aims to strengthen the capacity of ARD Cluster ministries in their respective roles of policy formulation, regulation and program implementation. Overall, these recommendations will serve to enhance policy capacity of the ARD Cluster in the areas of policy formulation, need assessment, information management systems, regulation and oversight, programme design, and monitoring and evaluation functions. These specific functions will be coordinated at the Cluster level, through the IMC and ARD governance mechanisms.

\subsection{Program Goal, Objectives and Expected Results}

The overall Goal of NPP-2 is 'to improve sustainable agriculture production and productivity and increase on and off-farm enterprises, contributing to food security, inclusive economic growth and reduced dependency of subsistence and marginal farmers and labourers on narcotic crops".

NPP-2 is divided into two separate but complementary Components: (1) Food for Life (FFL) and (2) Enterprise and Market Development (EMD), including a counter-narcotics mainstreaming approach. The program is based on the common vision of the ARD Cluster and has been developed in line with ANDS criteria and the Kabul Conference process, targeting national coverage, job creation, scalability and ability to attract private investment. Furthermore, although each Component has its own set of specific objectives and outcomes, they serve to facilitate overall consolidated objectives and expected results, and together form the foundation of a sector-wide approach to agriculture and rural development. Over time, the coordination at Cluster level and integration of capacities and mechanisms within Ministry structure at the centre and provinces for implementation will help reduce the compartmentalization of project-based approaches and enhance the integration of NPP-2 Components and Sub-Components in order to further strengthen policy consistency and delivery effectiveness.

NPP-2 defines 4 overall Objectives to demonstrate the integrated approach to sustainable agriculture production, food security and market development, and consequently reduce dependency on cultivation of narcotic crops: 
- $\quad$ Objective 1: Strengthen delivery of agriculture inputs, mechanization, research and extension services through public and private sector service providers;

- $\quad$ Objective 2: Strengthen licit agricultural production and productivity, with particular emphasis on staple crops, to ensure contribution to food security, emergency preparedness and improving rural livelihoods;

- Objective 3: Improve the quality, quantity and value of agricultural production and commercialization systems, and subsequent linkages to domestic and export markets; and

- $\quad$ Objective 4: Strengthen the regulatory and enabling environment for agricultural and rural development, including public policy capacity and key sector reforms.

The Program is expected to achieve the following $\underline{\text { Results }}$ over 3 years:

- $\quad$ Sustained growth in legal rural incomes and employment by $28 \%$;

- Increase agricultural production and productivity by $20 \%$ over 5 years;

- Credit system to farmers fully operational with at least US\$90 million of credit;

- Decreased local market prices within $10 \%$ of the price in the nearest town;

- Afghanistan Strategic Grain Reserve fully operational with at least 200,000 MT capacity;

- $\quad 15,000$ hectares of new land area coming into productive use;

- Establishment of new community enterprises increased by $30 \%$; and

- $18 \%$ voluntary reduction (not including eradication) in cultivation of opium poppy.

Components 1 (FFL) and 2 (EMD) are envisaged to have a longer life than the proposed 3-year budget cycle, with an outlook on achievements and expected results up to 2020 and beyond, dependant on the sub-sector they are addressing. Overall, NPP-2 interventions are comprehensive and interlinked, with implementation across 34 provinces (including target districts in Counter-Narcotics priority provinces) and all four Cluster ministries taking an active role in this Program. Initially, a 3-year phase approach has been designed for each Component based on Cluster priorities, existing complementary development programs, as well as identified national and local needs. Comprehensive and integrated action plans will be developed upon finalization and approval of this NPP, ensuring a synergistic development approach for both Components. This Program is intended to reach full national coverage within 10 years.

\subsection{Component One: Food for Life}

\subsubsection{Component Goal, Objectives and Expected Results}

The Food For Life (FFL) Component is an innovative, integrated approach to comprehensive and sustainable agricultural development that focuses on production and productivity. The FFL implementation model is based on a bottom-up, participatory planning and implementation approach through a community-based outreach mechanism.

The Goal of FFL is 'to increase agriculture production and productivity of cereals, legumes, oilseeds, horticulture, and livestock in an integrated and targeted approach that will improve rural livelihoods, thus increasing the sustainability of licit agriculture over narcotic crops, and contribute to national and household-level food and nutrition security'.

The Objectives of the FFL Component are:

- Objective 1: Reach farmers through farmers' organizations and cooperatives with effective mechanisms to access quality input supplies and extension services through public and private service providers;

- $\quad$ Objective 2: Strengthen and expand decentralized research and extension for irrigated and dry land agriculture to ensure effective and timely delivery and transfer of knowledge and technology to farmers; 
- $\quad$ Objective 3: Strengthen coordinated agriculture statistics and MIS capacities to efficiently and effectively collect, analyse and disseminate required data for public information, evidencebased planning and decision-making;

- $\quad$ Objective 4: Build and rehabilitate the Strategic Grain Reserves and establish a SGR network and management system for an efficient and effective emergency response; and

- $\quad$ Objective 5: Promote diversification in food production and consumption at household level through education and extension, in cooperation with other stakeholders.

The FFL Component is expected to achieve the following $\underline{\text { Results }}$ over 3 years:

- Increase wheat production to 5.5 million MT;

- Increase rice production to 700,000 MT;

- Increase horticulture production (fruits and vegetables) to 3.7 million MT;

- Increase livestock population to 27 million (excluding poultry);

- Reduce production costs by $10-15 \%$ and increase agriculture value by $20-50 \%$;

- Improve planning, early warning mechanisms and emergency response;

- Increase to $35 \%$ the number of farmers who have access to evidence-based and up-to-date, accurate and relevant market information;

- Improve emergency response, including a 200,000 MT Strategic Grain Reserve capacity; and

- $15 \%$ increase in licit crop production and incomes in target areas.

The above objectives will be achieved through a combination of interventions and adapted packages across 8 Sub-Components, dependant on local needs and carried out at the district level, in partnership with private sector enterprises and institutions, and with oversight from the Centre and the Provinces. Although each Sub-Component is presented separately, reflecting the need to articulate specific challenges, functions and outcomes, the implementation of FFL will follow an integrated model for planning and delivery, leading to the achievement of the Component's overall targets, including counter-narcotics objectives. As such, activities and outcomes under each Sub-Component link in one way or another to the overall FFL Objectives and to other sub-components, although there is not a oneby-one relation between objectives and sub-components. The FFL strategic framework is a living decision-making tool that is designed to ensure that investments in its elements remain demand-driven. As such, expansion to other commodities and markets may also be explored in later years.

\subsubsection{Sub-Component 1: Data and Information Base}

The aim of this sub-component is to foster a system that provides data and information on the agricultural and food situation, resources, production, marketing and development programs in an efficient, timely, reliable, and eventually national-driven manner.

Efforts will focus on strengthening institutional capacity of MAIL in data collection, analysis and dissemination; coordinating complementary efforts of existing government and donor-led projects in agriculture statistics; initiating and sustaining Afghanistan land cover analysis; strengthening and expanding management information systems (MIS) and establishing gateway to geo-information systems (GIS).

This will result in enhanced collection, assembly, and analysis of agriculture statistics data within MAIL. It will improve the timely diffusion of information about domestic, regional, and international weather, crops, production and market opportunities to a broad array of Afghans by capitalizing on the country's network of radio stations, newspapers, television, and emerging access to the Internet. It is also expected to improve evidence-based policy decisions and early warning systems.

\subsubsection{Sub-Component 2: Cereals, Legumes and Oilseeds}

Under the framework of this sub-component, the aim is to increase the yield and total production of cereals (wheat, rice, maize), legumes (lentils, peas, beans) and oilseeds (flax, linseed, sesame, sunflower, cottonseed, olive) at national level with support to subsistence and semi-commercial farmers. Wheat being the main staple crop that accounts for more than $70 \%$ of cereal consumption will be given the highest priority, while other crops (e.g. rice, legumes and oilseeds) will assume a targeted 
approach based on cultivation contexts, crop rotation mechanisms, nutrition targets, market and value chain opportunities. Development of a Wheat Sector Policy by end 2012 is at the forefront of the Government's agenda.

Efforts will focus on improving research and extension capacity at the sub-national level with increased linkages between the two. Adaptive and demand-driven research techniques focusing on famers and farmer group needs will be introduced. New and sustainable varieties of seed, technologies and farming system mechanization at the pre and post-harvest times to increase yield, reduce cost and harvest losses will also be introduced. Linkages to existing input distribution systems (i.e. farm stores, a depots) and encourage demand-driven and market-oriented private sector investments for inputs (e.g. seed, fertilizer), mechanization and value-chain services will be established and strengthened. Synergies with the current projects such as IAIDS will be closely built to ensure a unified policy approach.

The interventions will result in increased wheat yield in irrigated and rain-fed cultivated areas (Sustained production of 5.5 MT wheat by 2015), reduced post-harvest losses, increased farmers' capacity to sustainable farming systems, and an extension system that is accessible to farmers and famer groups throughout the country. The farmers will be enabled to access better inputs, knowledge and awareness about other potential cereal crops, rice cultivation methods and seed varieties, as well as legumes and oilseeds for nutrition and income opportunities.

\subsubsection{Sub-Component 4: Horticulture}

Promoting sustainable increase in horticulture crop production and productivity, including development of high-value crops (e.g. raisins and almonds), and improved rural livelihoods at the community and market level are the aims of this sub-component.

As with the cereals sub-component, interventions will promote technology development for horticultural production through adaptive research and technology transfer through improved and expanded extension services. Efforts will focus on potential export commodities like almonds, raisins, pistachio and pomegranate to boost production, value-chains and market linkages with complementary support from EMD interventions. A streamlined approach with NPP-1 irrigation activities will also be undertaken to address irrigation challenges to the horticulture sector.

Existing market information systems will be enhanced to improve geographic spread, appropriateness, accuracy and timeliness by the end of 2015. The strengthening of public sector institutional capacity and increased social mobilization will result in community and agriculture organizations development. Orchards and vineyards around the country will be rehabilitated and higher standards of production will be achieved to obtain higher market prices by the end of 2015. MAIL will seek to establish partnerships and synergies with all on-going horticultural projects and will build upon best practices to expand the extension to other potential provinces and districts.

\subsubsection{Sub-Component 4: Livestock}

With $80 \%$ of population residing in rural areas, there are two major livestock production systems in Afghanistan i.e. nomadic and semi-nomadic herds-people, and sedentary farmers with variable degree of small ruminants. Under the framework of this sub-component, FFL aims to increase farmers' knowledge and capacity for production and marketing of poultry products, milk and dairy products, sheep and goat, honey, and fisheries.

Efforts will focus on regulating, monitoring and coordinating animal health service delivery; increasing commercial milk production, productivity, processing and marketing schemes; promoting poultry farms development, increased productivity, and the utilization of poultry slaughter by-products \& waste materials; and enhancing marketing of animal products through value addition and exploitation of domestic and international export markets for meat and animal by-products.

Further efforts will be focused on improving honey production, and extension of fisheries with facilitation of a functioning market supply chain for these productions will be undertaken. FFL will promote responsible use of rangeland resources along the migration routes by intensive and extensive producers, and develop early warning systems to identify impending climatic shocks in order to avoid unnecessary losses due to starvation. 
As a result, animal productivity will be raised through improved feeding practices in selected districts for at least 25,000 farmers by the end of 2015, regulations and guidelines for food safety formulated and implemented, and a network of animal disease surveillance and diagnostics centres with oversight from Central Veterinary Diagnostic \& Research Laboratory will be strengthened to deliver effective services to livestock farmers by end 2015 and beyond. Increased number of milk producers' cooperatives will have been developed and strengthened in selected provinces and districts. Kuchi and natural resources management policy will be reviewed and implemented, and dispute and conflict resolution measures will be fully effective by 2015 .

\subsubsection{Sub-Component 5: Food Nutrition}

FFL aspires to raise awareness of food nutrition in collaboration with relevant government entities, and to ensure households around the country have sustainable access to nutrient-rich foods. Levels of under-nutrition and malnutrition remain too high, especially among the poorest families and vulnerable groups that include women and children. Hence the improvement in the nutritional levels of the most vulnerable groups will be targeted through provision of knowledge on key practices to promote good nutrition, and the identification and implementation of health and other goals that supplement good nutrition practices. Given the multi-disciplinary nature of the challenge to enhance food nutrition status, FFL will work with relevant Government entities in this regard, particularly the Ministries of Education, Public Health, Rural Rehabilitation and Development, and Labour and Social Affairs.

The efforts will focus on raising awareness of food nutrition, feeding and caring practices at household level with MoE and MoPH; improving access to more diverse nutrient rich safe foods to vulnerable groups with MoPH and MRRD; and ensuring adequate sustainable supplies of diverse nutrition-rich foods to households with MRRD and MoLSA. MAIL will continue to progressively implement urban and peri-urban agriculture, targeting poor households and women-headed families for better diversifying of income and nutritious food supplements.

\subsubsection{Sub-Component 6: Emergency Preparedness and Response}

The high frequency of natural disasters such as drought, floods, water scarcity, trans-boundary pests, volatility of agriculture commodity prices, and inaccessibility of large parts of the country during winter season are regular threats to food security and agriculture dependent farmers. The aim of this sub-component is to enhance the resilience of livelihoods against threats and emergencies to ensure the food and nutrition security of vulnerable rural households and other at risk groups.

FFL will focus notably on efforts to strengthen good governance and institutions for Disaster Risk Reduction (DRR) in agricultural sectors; establish the Strategic Grain Reserves (SGR) as an integral part of Afghanistan's response mechanism to national and local food emergencies; and increase preparedness for emergencies in the agriculture and livestock sector and responses to disasters are effective. As mentioned in Sub-Component 1 of FFL, measures will be taken to strengthen and harmonize the Food and Nutrition Security (FNS) information and early warning systems across national and international actors.

In the short-term the Government is targeting a SGR of 200,000 MT primarily for emergency relief, including 150,000 MT in the four silos and 50,000 MT in the rehabilitated warehouses. This will be complemented by strengthened capacities at all levels to improve response to, and recovery from, future threats to food and nutrition security and improved coordination amongst MAIL, ANDMA, UN agencies and civil society networks.

\subsubsection{Sub-Component 7: Dry Land Farming}

FFL will develop and promote a nation-wide profile of improved Dry Land Farming (DLF) practices and technologies to assist farmers to double production in DLF. While over $50 \%$ of farming activity in Afghanistan occurs under rain-fed conditions in the dry land areas, at the subsistence level, FFL will focus on the major problems that limit productivity in rain-fed agriculture, namely, inferior cultivation practices, poor soil quality and management, and inferior germ-plasm which compromises the opportunities to improve production and productivity. 
Successful interventions will need to be farmer-centred, and to concentrate on assisting farmers to graduate from 'risk aversion' to 'risk management'. There is an urgent need to undertake research and regionally-based DLF surveys in order to generate greater knowledge and understanding of DLF system potential through, to have access to credible inputs, to be able to support successful demonstration of what is possible, and to identify viable markets for produce, which in turn will help inspire greater crop diversification.

By 2015, there will be improved and more extensive DLF research and extension facilities and programmes; a Northern region DLF research operation will have been formulated and established; demonstration blocks will have been established for farmers and fully operational and available to all farming groups across the country; system for wheat intensification will have been developed and introduced to farmers around the country; and improved practices for horticulture cultivation in dry lands will have been established and disseminated to farmers.

\subsubsection{Sub-Component 8: Integrated Pest Management}

The Government prefers to achieve the goal of increasing production and productivity through introduction environment-friendly, ecosystem-based farming practices to reduce the fecundity and breeding ground of pest population, especially locusts. Instead of focusing on second and other lower level symptom problems of pests and diseases, through integrated pest management (IPM), FFL will focus on the primary problem of conventional production methods that facilitate more pest and disease infestation to the fields.

To this end, FFL focus will be to develop and introduce sustainable strategies for crop protection through establishing the foundation for a national IPM program and an emergency pest control unit within the Plant Protection and Quarantine Directorate (PPQD) of MAIL; provide hands-on training using Farmer Field School (FFS) and other group-based participatory approaches to develop their capacity in successful plant protection and crop management; strengthen the early warning system for epidemic insect pests, especially locust; and increase farmers' awareness and understanding of the causes for locust outbreaks, while paying attention to community-wide collective efforts. There is also a need to provide improved and up-to-date equipment for advanced physical, mechanical, cultural, biological and chemical control for locust pests with safe use of less hazardous chemical insecticides.

\subsubsection{FFL Implementation Framework}

The FFL model is a bottom-up, participatory planning and delivery approach by reaching to farming communities and their organizations, enabling private sector partnerships as well as MAIL's extension and MRRD's social mobilization networks as support mechanisms (see model below). The delivery of services will be carried out through existing government, private sector and civil society organisations, and guided by policy that will be formulated and implemented from the Centre through the provinces to the districts. FFL will utilise existing structures, organisations, resources and activities where possible, through improved coordination mechanisms and management. Since FFL is primarily a MAIL program, in practice the implementation of FFL means MAIL taking ownership through its existing structure and ensuring departments across the Ministry are actively engaged in the processes leading to planning and implementation of activities, in coordination with MRRD and MCN. The structural arrangement for implementing FFL is designed to highlight the Ministry's ownership of the Component by ensuring it is fully embedded within the MAIL organization.

Lessons learnt from other MAIL programs have been incorporated into the design and implementation methodology for FFL. While the implementation of the Component will start with a narrow focus during the first year, notably in key agro-ecological zones and $\mathrm{CN}$-priority provinces, it will eventually link with and absorb related on-going MAIL projects as they phase out and as FFL implementation mechanisms and institutional settings are strengthened. As such, it is anticipated that the roll out of FFL will ensure that implementation is effectively coordinated with functioning MAIL programs to guarantee support from on-going projects across all FFL Sub-Components. FFL will first start establish itself before taking on the responsibilities and coverage of the current projects, thus increasing coordination among them and moving towards greater "integration" within the FFL framework and sector-wide strategy for agriculture and rural development. Geographical adjustments will also be made in line with the overall goals and objectives of the ARD Cluster to ensure that the benefits of coordinating all Components and NPPs are maximized. 
Furthermore, as current competencies of MAIL at the sub-national level are somewhat limited, further assistance may be required from facilitating partners, albeit on a reduced basis at the provincial and district level, while MAIL continues to build its internal capacity through capacity building and change management activities. The FFL implementation model is therefore defined to strengthen planning and implementation capacities at the national and sub-national level so that when the Component scope is enlarged and externally-funded projects phase out, both MAIL and DAILs will be able to facilitate the provision of services aimed and focused at sub-national level with a collaborative and effective approach.

The different Sub-Component activities will be packaged and implemented to address the specific needs of individual farmers' groups using the following decentralized Outreach process:

- DAIL extension workers and with support from DRRD social mobilizers will enter districts and communities via the DDAs and CDCs, identifying farming communities and farmers' groups (cooperatives, associations, etc.) who will be the main beneficiaries for FFL interventions. Leveraging the community mobilization capacity of these structures will assist in consolidating the linkages between development activities and local governance, and ensure effective collaboration among local stakeholders for the implementation of agricultural programs. If there are no suitable farmers' groups yet constituted or effective, but there is a functioning CDC, MAIL will deliver the first level of services/inputs through the CDC while at the same time forming and supporting the farmers' group during the start-up phase. Once ready to assume responsibility, the main activities will transfer across to the farmers' group;

- As the specific needs of beneficiary groups vary across the country (i.e. landless, subsistence, and semi-commercial farmers, herders, Kuchis, women groups) and depend on potential crop production opportunities, FFL will deliver services and inputs to farmers' groups using multiple approaches with a focus on local procurement and delivery. This will include adapted packages, which may or may not be subsidized based on the needs of beneficiary groups, including a voucher system for inputs reclaimable through private sector enterprises. Advanced farmers groups with a view to expansion may qualify for affordable agricultural credit assessed on their viability and level of contribution, as well as other forms of services and assistance under complementary EMD interventions. The private sector, including farm stores, ag depots, veterinary field units, etc. will be encouraged and supported to play an increased role in providing extension services, agriculture inputs, mechanization and other infrastructure services to farmers, based on local needs and opportunities.

- Within the Government procurement framework, responsibility for selecting the best procurement and service delivery option will lie with locally-based implementation teams, including DAIL and DRRD departments supported as needed by external technical assistance, and will be based on discussions with farming communities and farmers' organizations. Field-level monitoring and evaluation of specific interventions may be provided by third-party committees composed of local governance structures and community-based organizations (including DDAs and CDCs), as appropriate. Further details will be articulated by the FFL Secretariat and Technical Committee during the development of FFL's Operations Manual.

\section{Food Zone Implementation Approach}

The Food Zone Program (FZP), a rapid-action initiative of the ARD Cluster under FFL, led by the Ministry of Counter-Narcotics (MCN), is envisaged to intervene in narcotics-plagued provinces on a priority basis with comprehensive $\mathrm{CN}$ measures during the early stage of implementation of NPP-2, and then link with longer-term FFL and EMD interventions to sustain the momentum against resurgence of poppy cultivation. The complete FZP program document is referenced in the annexes of the NPP-2 package, and specific implementation plans for AL interventions under FFL will be developed subsequently.

Consequently, as guided by the Program governance structures, the FFL sequence of implementation will also prioritize target districts in $\mathrm{CN}$-priority provinces such as Helmand, Kandahar, Farah and Uruzgan, and gradually expand to target districts in provinces where low levels of cultivation have persisted (i.e. Dikundi, Nimroz, Zabul, Badghis, Nangarahar, Badakhshan) or where a resurgence of 
poppy cultivation has been observed in recent years (i.e. Baghlan, Kapisa and Balkh). In these areas, a range of alternative livelihood interventions (i.e. provision of locally-adapted agriculture inputs, promotion of high-value horticulture and other licit crops such as saffron and cumin, livestock value addition) will be primarily coordinated and implemented by $\mathrm{MCN}$, effectively leveraging existing extension and community-based networks (i.e. CDCs and farmers' organizations) as well as linking with longer-term activities implemented under the FFL and EMD Components.

Throughout implementation, poppy-free zones will be created, consolidated and expanded each year to cover greater areas. The number of beneficiaries and target districts will be determined based on the population of each province and consideration of vulnerabilities, remoteness of the districts and access to markets, in consultation with IDLG, provincial governors, provincial development councils and line departments. Food Zone interventions are designed to sweep across the narcotics-plagued districts in a rapid manner, thus paving the way for long-term activities under the FFL and EMD Components in order to solidify the gains made.

\subsection{Component Two: Enterprise and Market Development}

\subsubsection{Component Goal, Objectives and Expected Results}

The Enterprise and Market Development (EMD) Component is an integrated approach that targets the most promising areas for support in value addition and market development in the rural economy and then provides focused technical support for rural enterprises and farmers, financial support and access to land, ultimately facilitating job opportunities and employment. Through coordinated delivery of complementary activities at community level, economic growth will be stimulated and the private sector will flourish.

The Goal of EMD is 'to sustain economic growth and poppy reduction through improved employment and income opportunities for rural people by means of enterprise development, credit and access to land'.

The Objectives of the EMD Component are:

- Objective 1: Improve on-farm and off-farm incomes through the development of viable community-based enterprises, small and medium enterprises and larger agri-businesses;

- $\quad$ Objective 2: Support private-sector supply and demand through investable surplus, import substitution and export-led economic growth;

- $\quad$ Objective 3: Improve linkages to domestic and export markets; and

- $\quad$ Objective 4: Improve and secure access to supportive rural credit and inclusive land tenure.

The EMD Component is expected to achieve the following Results over 3 years:

- $\quad$ Reduce unemployment rate by $10 \%$;

- Improve female participation in economic activities by 5\%;

- $\quad$ Reduce imports in basic agricultural products by $20 \%$;

- Improve access to agricultural credit with $\$ 90$ million lent;

- Bring 15,000 hectares of new land into productive use for licit farming activities;

- Improve regulatory and procedural effectiveness of land reform;

- Establishment of new community enterprises increased by $30 \%$;

- $\quad$ Promoted 3,900 new enterprise groups;

- $\quad$ Facilitated and supported 340 SMEs; and

- Contributed to the overall NPP-2 target of $18 \%$ reduction in cultivation of narcotic crops.

Furthermore, by the end of a 10-year time period, EMD is also expected to contribute to a $50 \%$ increase in rural incomes and employment, largely due to increases in production and improvements in productivity coupled with an increase in the number of SMEs, agribusinesses and other rural enterprises. Afghanistan's exports of agricultural products will increase to US $\$ 2.5$ billion due to improved quality and increased quantity and to better processing by a larger number of agri-businesses. The Component will enable Afghanistan to substitute the majority of its imports of basic agricultural 
products, including poultry and dairy products as well as off-season fruits and vegetables. Around 100,000 hectares of land will be leased for promotion of agribusinesses, industrial parks, communication and general services.

There are 4 Sub-Components in the EMD Component. They differ from FFL sub-components in that they are current programs or Executive Agencies within the Cluster Ministries. However, combining these four Sub-Components under one umbrella Component adds value through closer coordination and more integrated planning, thereby identifying and exploiting synergies and eliminating any potential wasteful overlap. Overtime, this coordinated approach to implementation and service delivery will allow a progressive re-alignment of current and future programmatic intervention instruments and supporting initial frameworks, ultimately contributing to the foundation of an integrated sector-wide strategy.

\subsubsection{Sub-Component 1: Integrated Rural Economic Development and Marketing}

Inadequate supply of raw product, a shortage of processing capabilities and facilities, lack of technical and managerial skills, and poorly functioning domestic markets are the main challenges in rural development. Under the framework of this sub-component EMD addresses this by developing Economic Development Packages (EDPs) to stimulate competitive rural communities through strengthening selected agricultural value-chains and inviting either other NPPs or external private sector institutions to support discrete elements.

In the initial phase, activities under this Sub-Component will be primarily supported by the Comprehensive Agriculture and Rural Development Facility (CARD-F). CARD-F focuses on generating economic value through enhancing selected value chains in priority provinces. The SubComponent targets the value chains with the greatest economic potential and then delivers interventions, by means of EDPs, to increase their impact in target economies. Initial activities will include the development of economic development packages (expanded to 12 provinces and 60 districts) and the procurement of economic support packages. The initial estimated economic impact is 43,000 jobs created, 66,000 jobs safeguarded, and \$724 million in net benefit.

\subsubsection{Sub-Component 2: Rural Enterprise Development}

The aim of this sub-component is to improve employment and income of rural men and women, and the sustainability of targeted local enterprises, through nationwide support to community-based enterprise and Small and Medium Enterprise (SME) development. The interventions of this subcomponent will follow up on FFL interventions that work at the grass root levels, while CARD-F targets value chain development at a slightly higher level involving commercial farmers and commercial production.

In the initial phase, activities under this Sub-Component will be primarily supported by the Afghanistan Rural Enterprise Development Program (AREDP). AREDP was designed as a multidonor, Government-led program to improve rural employment and income, and to strengthen the private sector through savings groups and progressively building these into larger, more efficient institutions capable of supporting increasingly complex lending. The Sub-Component also supports a loan guarantee and business skills development. Initial activities will include the promotion of 10,500 Saving Groups, 3,675 Farmer Support Groups, 6,420 Enterprise Groups, 2,247 FEGs, 1,280 Village Savings and Loan Associations, as well as facilitating and supporting 640 SMEs. Efforts will be made to focus on $\mathrm{CN}$-priority provinces during the first 3-years of implementation through enhanced collaboration between MRRD and MCN.

\subsubsection{Sub-Component 3: Sustainable Agriculture Credit}

Under the framework of this sub-component, EMD will facilitate and support the rapid growth of the agriculture sector by providing sustainable credit tailored for all farming and agri-business purposes, and improving employment and income of rural people. 
In the initial phase, activities under this Sub-Component will be primarily supported by the Agricultural Development Fund (ADF). ADF was established to accelerate and increase the volume, value and structure of credit available to rural businesses and financial institutions for on-lending. Among others, initial activities will include lending to farmers' organizations and agribusinesses, innovation grants, and Islamic financial products.

\subsubsection{Sub-Component 4: Afghanistan Land Authority}

The aim of this sub-component is to implement and enforce the Afghanistan Land Management law by making available Government-owned land for industrial use, providing equitable land access for subsistence farmers and the landless, and strengthening land enforcement mechanisms.

This Sub-Component will primarily be implemented by the Afghanistan Land Authority (ARAZI). ARAZI was established to significantly increase the amount, quality and security of Goverment-owned land available for licit economic use and investment; its role includes land titling, zoning, planning and property rights. Initial activities will include land allocation for commercial purposes, mediation and arbitration support, mapping, survey and registration of land, land policy development and legislative reform

\subsubsection{EMD Implementation Framework}

On overview of these sub-components highlights a number of common challenges and opportunity for synergies in grouping them as Sub-Components within an integrated Component. These include improved coordination of interventions, attainment of greater policy coherence, reduced overhead, better value for money and increased direct investments along the entire value chain within the agricultural sector. Combining these four Sub-Components under one umbrella Component adds value through closer coordination and more integrated planning, notably through the Program's governance structures and delivery mechanisms, thereby identifying and exploiting synergies and eliminating any potential wasteful overlap.

However, for mainly legal reasons, key activities under these four sub-components cannot be merged into one program. The Afghanistan Land Authority (ARAZI) and the Agricultural Development Fund (ADF) are Executive Agencies with clear mandates in their sub sectors, land and credit. Both have been established in this manner so that they can function semi-autonomously outside of government bureaucracy. Both have their own board structures, which comprise public and private sector members. CARD-F is a multi-ministry facility soon to extend across all 4 Cluster ministries. AREDP is an established program in MRRD within the ARTF and funded by the World Bank.

Overtime, through increased coordination and re-alignment of activities, this initial project-based approach will help establish the foundations of a comprehensive and integrated sector-wide strategy for agriculture and rural development. This process will also help develop the public sector's role and capacity to foster an enabling environment for agribusiness development and innovation, including through skills development and information dissemination. To this end, MAIL has notably been working on further developing and supporting the concept of Agribusiness Service Centres to support agribusinesses capable of generating employment, local supply chain development, and cooperatives capable of improving rural productivity, value addition and livelihoods.

\section{Program Governance Structure}

NPP-2 is predominately a MAIL program, with the exception of AREDP activities that are governed by MRRD, and CARD-F implemented jointly by MAIL, MRRD and MCN. As well, following the Food Zone approach, AL interventions in narcotics-plagued areas will be implemented primarily by MCN, with coordination support from MAIL and MRRD. The challenge facing implementation of NPP-2 is therefore to ensure effective linkages between initiatives, which will ultimately rest with the efficacy of relevant governance structures.

The Inter-Ministerial Committee (IMC) will constitute the highest level of governance of the Program and will have general oversight for its implementation. The IMC will notably provide 
strategic directions, policy guidance, and oversee budgetary absorption. The IMC will also ensure the integrated operationalization of the Components in order to achieve the desired overall impact, by means of approving Component and Sub-Component budgets and implementation plans. This Committee will include the Ministers of the ARD Cluster, as well as senior management and advisory staff appointed by the relevant Ministries.

There will also be a Management Committee, chaired by MAIL's Deputy Minister for Technical Affairs, whose role will be operational management oversight, most particularly for FFL. The Management Committee will be run by senior staff from MAIL, MRRD and MCN. As well, since NPP-2 contributes directly to the Government's CN objectives, the Management Committee will also report to the $\mathrm{CN}$ Monitoring Mechanism.

The FFL Secretariat will carry out coordination of FFL and will report to the Office of the Deputy Minister for Technical Affairs through the Management Committee. FFL strategies and interventions will be coordinated by the Secretariat for facilitation and implementation through MAIL and DAIL departments at the national, provincial and district levels, as appropriate. Specific AL activities implemented under the Food Zone approach will be coordinated by the FZ Steering Committee of each target province, led by the Governor reporting to MCN and accountable to the IMC, and supported by technical units and the AL working group, in which MAIL and MRRD will also be represented.

Oversight for each Sub-Component will be provided by a single EMD Operational Board, chaired by the relevant lead Minister or Deputy Minister, which will also be accountable to the IMC and comprising appropriate representatives from Cluster ministries. The Operational Board will focus on technical discussions, coordination and oversight to assure integrated delivery of the Sub-Component outputs.

To assist in the implementation of the various parts of NPP-2, there will also be a Technical Committee comprising technical directors, program managers and other observers from relevant Ministries. This Committee will provide technical support and assist with facilitating coordination between functional areas of the Cluster ministries, as well relevant programs and stakeholders.

As with all NPPs, there will be a need to prioritise activities within the Components and SubComponents. Prioritisation decisions will be made via the IMC based on contributions to the overall Program, income and job generation ability, and capacity to execute budget. There will also be a strong focus on the linkages between national, provincial and district planning and service delivery. Policy and legislation coming from the central level will be implemented down to the provincial and district levels, whilst the needs identified at the district and provincial levels will be included at the central level in the development of specific interventions.

The Components will be on-budget, with funds either being channelled through the Afghanistan Rehabilitation Trust Fund (ARTF) or via a Special Account. Fiduciary and procurement responsibilities will be managed through specific, appropriate measures applied to each Component and implementing Ministry. Donors may have the possibility to earmark funding based on specific Components or Sub-Components as well as geographically.

\section{Monitoring \& Evaluation}

Since the introduction of Cluster groupings of ministries and the development of the ANDS Prioritization and Implementation Plan, monitoring and evaluation has been given renewed emphasis. Intended results - in the form of both outcomes and outputs - have been defined for the NPPs. The total number of intended results has been kept manageable, and arewell defined and elaborated in matrices, allowing for the monitoring of different program components that contribute to the achievement of specific program and cluster outcomes and outputs. Moreover, the Government is committed to achieving greater transparency and accountability for its performance, and will regularly review the matrices of intended results through the cluster process. A structured system and procedure will be adopted by the respective ministries' technical teams, at the component level, to verify the FACTS: F- Fund flow and Financial regulations adherence; A-Accessibility to the scheme/program 
and Assets created; C- Clarity on the scheme/program and Control on interventions; T- Transparency and Transfer of benefits; and S- Selection of the site/works and Selection of beneficiaries.These rigorous technical reviews will be undertaken with an aim to identify gaps in implementation and to propose necessary corrective actions in consultation with key government, civil society, private sector and international community partners. Lastly, detailed designs, costing and implementation timelines linked to NPP deliverableswill be undertaken once endorsed. These will be linked to the national budget process and the ANDS Results-Based Management System to inform decision-making.

The monitoring and evaluation arrangements for NPP-2 Components will build upon the Program's Logical Framework. The necessary coordination and oversight of Component activities will require establishing a functional M\&E framework and oversight body as part of a joint, harmonised approach across involved ministries. To this end, MAIL and other ARD Cluster Ministries are currently rationalizing and coordinating their efforts in MIS, M\&E and other information systems. Key parts of such system will be regular joint monitoring visits, a clear reporting formats and schedules, regular presentations to inform management decisions and to update implementation and financing partners. The mapping of existing interventions, projects, programs in an established database, together with the regular and systematic review of on-going activities, extracting lessons learnt for the promotion of best practices will be integral parts of the Program's M\&E System. On-going monitoring will be facilitated by the relevant implementing ministries and agencies, and reported to the IMC.

Results-based management approaches will be also applied across Program Components, specific to their respective design and linked to the overall NPP M\&E framework and high-level indicators. The monitoring frameworks of Program Components will strengthen and drive much of the on-going monitoring functions and systems within ARD Cluster Ministries with a collaborated and harmonized approach both at national and sub-national level. The monitoring framework will also be built on existing MoF's Program Budgeting standards. The establishment of results-based planning and reporting for the program will strengthen the current budgeting process and will further build upon the systems and approaches already introduced to departments in MAIL and other Cluster ministries. The overall NPP will also incorporate a high-level evaluation framework that will enable periodic assessment of interventions' relevance, performance, efficiency and impact in relation to stated objectives. The evaluation framework for NPP-2 will also include gender-segregated indicators to monitor effective and equitable participation of women in the agriculture and rural development sector.

AL interventions implemented under the Food Zone approach will include their own M\&E framework, which will also be linked with other Components and overarching goals. In coordination with MAIL and MRRD, MCN will also conduct joint field monitoring and post-impact assessments at the district level after completion of activities across NPP-2, as indicated in the CN Monitoring Mechanism and the NALP. The intent is to determine the impact of the AL sub-projects on the transformation of rural livelihoods.

\section{Linkages and Synergies among NPPs}

The NPPs together form a set of activities whose purpose is to develop an enabling framework that communities need to build up their productive assets, reduce instability and insecurity, and contribute to improving household food security and incomes across the country. The Cluster ministries, although responsible for significant deliverables to rural areas, do not service the total needs of the communities on their own. Linkages and coordination among and within the ARD NPPs, as well as with activities of other clusters, are essential for reaching the overarching goal of the ARD Cluster and NPP-2.

The complementary aspects of the four ARD NPPs are evidenced in a number of ways. In NPP-2, for example, increases in agricultural productivity and diversification under the Food for Life (FFL) Component support the increase in jobs and incomes under the Enterprise and Market Development (EMD) Component. Similarly, alternative livelihood interventions under the Food Zone approach are envisaged to build synergies with FFL and EMD activities in narcotics-plagued provinces. In turn, FFL and EMD interventions will help sustain the momentum against resurgence of poppy cultivation in the target districts beyond completion of Food Zone activities. Additionally, without the activities of NPP1 (National Water and Natural Resources Development Program) to increase availability of water and improvement of natural resources base, we do not have the foundation and regulations for sustainable 
agriculture development. NPP-2 therefore capitalises on the economic opportunities of natural resource management to maximise the benefits from improved agricultural production achieved through the provision of improved irrigation services. The development and support for SMEs through the EMD Sub-Components adds to this ability to draw on NPP-1 initiatives to create employment and strengthen the rural economy. Furthermore, support for increased access to rural credit and better regulation of land issues under EMD will have positive implication across all ARD Cluster NPPs. As well, improved infrastructure delivered through NPP-3 (National Rural Access Program) promotes access to domestic and regional markets, an improved overall rural economy, and response to emergencies and disasters.

The FFL Component of NPP-2 also contributes to the National Food Security and Nutrition Framework, a national policy and strategic document that identifies the roles of the many ministries and agencies involved (MAIL, MRRD, MoPH, MOLSA, MOWA, ANDMA and MoE). As an overarching policy and strategic framework for food security and nutrition, it identifies linkages and program interventions to availability, access, stability and utilization of food at the national and household level, all of which must be addressed by the relevant stakeholders.

Furthermore, given that Afghanistan's rural economy is largely village-based, the role of communities in identifying development needs, in their ability to respond to them and maintain infrastructure once created, as well as the direct role of households and families in managing and promoting more sustainable use of natural resources, and in the negative effects of their interactions, becomes of paramount importance. NPP-4 (Strengthening Local Institutions), with its use of community-led approaches, its creation of inclusive and sustainable community institutions, and their use as mobilization and implementing agents, or of arbiters of service delivery by Government and other actors, will make over time a vital contribution to the successful delivery of the objectives of other ARD NPPs. The district- and community-level bodies fostered by NPP-4 also link to the communitybased management institutions made use of and strengthened in this NPP-1, such as Irrigation Associations, Water User Associations, Rangelands and Forestry Social Associations, and Protected Areas Committees.

Finally, effective linkages with other NPPs, notably under the Private Sector Development and Infrastructure clusters, will also facilitate synergies with ARD NPPs and create the enabling environment needed for the development of domestic and international markets and for the Afghan agribusinesses to flourish. As an example, the outputs from the EID Regional Integrated Resource Corridor Program and the Afghanistan Energy and Water Futures Program will directly support many of the activities of NPP-1 and NPP-2.

\section{Cross-Cutting Issues}

\section{Counter Narcotics}

One of the key overall objectives of NPP-2 is the transformation of rural livelihoods by strengthening and diversifying licit sources of income in order to reduce dependency of subsistence and marginal farmers and labourers on cultivation of narcotic crops. Both Components of NPP-2 are envisaged to contribute, directly or indirectly, to the overall goal of strengthening and diversification of licit rural incomes. Alternative livelihood (AL) interventions in narcotics-plagued areas, under the combined FFL and FZP frameworks and led by $\mathrm{MCN}$, will provide viable income-generating alternatives by raising the profitability of licit crops and promoting market linkages. Diversification of plant and animal production into high value products is acknowledged as one of the main contributors to successful reduction in opium production and is in line with the NALP. The rapid-action, short-term but targeted $\mathrm{AL}$ interventions under the FZ, followed by long-term interventions under the FFL and EMD components, are expected to sustain the momentum against the risk of resurgence of cultivation and result in poppy-free districts at the end of the 3-year period.

\section{Gender}

Since the participation of women is considerable in some sectors of agriculture production and processing, which also constitute an important source of livelihood for them, gender appropriate extension services and capacity building activities for women will be provided. NPP-2 will ensure effective outreach to, and participation of, women-led cooperatives, agriculture-related associations and households, and promote access to credit, land and income generation for women. A key theme in 
AREDP is attaining gender equity in targeting its interventions, focusing on facilitating economic opportunities for women. Furthermore, livestock, kitchen gardens, food security and nutrition activities will focus most particularly on women in rural and urban areas. NPP-2 will also strive to strengthen policies, legislation and strategies for increased and more inclusive participation of women in the agriculture and rural development sector, and to mainstream gender across decision-making, program implementation and service delivery, notably by increasing the number of women civil servants, extension workers and farmers' organizations.

\section{Anti Corruption}

Programs that focus on development of the private sector strengthen efforts against corruption. As well, the strengthening of common interest groups such as farmers' organizations, which bring like-minded community members together in shared responsibility, in most cases serves towards decreasing corruption levels. Internal ministry corruption is dealt with via the implementation of new processes reducing the opportunity, while at the same time taking steps to ensure fair salaries for fair work.

\section{Capacity Development}

Each ministry is undergoing some form of institutional reform, change management and capacity development process. These programs will contribute to the ability of the relevant ministries to implement their activities. Furthermore, NPP-2 is viewed as a vehicle for the implementation of these changes at the sub-national level.

\section{Environment}

NPP-2 requires close collaboration with the National Environmental Protection Agency (NEPA) for the development of comprehensive and cohesive strategies for maximizing land use and effective and sustainable use of natural resources, including Environmental and Social Impact Assessments in the case of large-scale projects.

\section{Regional Cooperation}

Strong global and regional links have been developed for technical cooperation, particularly in the fields of research and technology transfer adaptable to Afghanistan. Quality control and diagnostic laboratories will be connected to regional and global reference laboratories. Furthermore, a high level of interaction is required regarding current imports and future exports to facilitate an enabling environment for the private sector and the effective transport of goods and services.

\section{Challenges, Constraints and Solutions}

A number of risks are attached to a program of this magnitude and complexity - primarily financial, time, and quality. In their respective situation analysis, each Component outlines specific challenges and constraints as well as possible solutions, relevant to their sub-sectors. The key challenges are noted as follows:

\section{Program Implementation Challenges}

- Cluster ministries need to identify their true public role, including the transition of contracted staff into civil servants positions;

- Ministries require significant internal reforms to improve their efficiency, performance and accountability;

- Government must remove constraints to and facilitate further private sector investment, rather than undertake direct government action.

\section{Organizational Effectiveness and Human Capacity}

- Lack of availability of skilled and educated human resources;

- Management capacity remains relatively weak;

- Implementation capacity, procurement, financial management and ability of timely decisionmaking could lead to delays in program implementation;

- General lack of technical capacity and number of extension experts available in the field.

\section{Adoption of Innovative and Improved Agriculture Practices}


- Insufficient exposure to modern agricultural practices and new crops, due to past negative experiences;

- Insufficient technology development and agricultural education due to sub-optimal agricultural research and extension services.

\section{Regulatory Constraints}

- Regulatory frameworks are insufficient, sometimes inappropriate, often out-dated and nonenforceable.

\section{Supply Constraints}

- There are often insufficient and quality-deficient inputs to meet the demand from farmers;

- The absence of widespread financial services tailored to cultural and seasonal needs is a major obstacle for improvement in production and productivity.

\section{Production and Commercialization Constraints}

- Production and commercialization of agricultural products in Afghanistan are undermined due to small land holdings, low contractual power of the small producers and difficult access to storage facilities and input, low capability of cold chain system and quality packaging, and significant lack of standardized production in large quantities as requested by the international distribution market;

- Inadequate market price information both domestically and internationally.

\section{Budget Summary Table}

\begin{tabular}{|c|c|c|c|c|c|c|}
\hline \multirow{2}{*}{$\begin{array}{c}\text { National Comprehensive } \\
\text { Agriculture Production \& } \\
\text { Market Development } \\
\text { Program }\end{array}$} & \multicolumn{4}{|c|}{ Proposed 3-Year Budget } & \multirow{2}{*}{$\begin{array}{l}\text { Committed } \\
\text { Funds }\end{array}$} & \multirow{2}{*}{$\begin{array}{l}\text { Required } \\
\text { Funds }\end{array}$} \\
\hline & Year 1 & Year 2 & Year 3 & Total & & \\
\hline 1.0 Food for Life & $\$ 74.8 \mathrm{M}$ & $\$ 169.2 \mathrm{M}$ & $\$ 228 \mathrm{M}$ & $\$ 472 \mathrm{M}$ & $\$ 75 \mathrm{M}$ & $\$ 397 \mathrm{M}$ \\
\hline $\begin{array}{l}1.1 \text { Food Zone specific } \\
\text { AL interventions }\end{array}$ & $\$ 25.0 \mathrm{M}$ & $\$ 30.0 \mathrm{M}$ & $\$ 21.5 \mathrm{M}$ & $\$ 76.5 \mathrm{M}$ & $\$ 20 \mathrm{M}$ & $\$ 56.5 \mathrm{M}$ \\
\hline $\begin{array}{l}\text { 2.0 Market and Enterprise } \\
\text { Development }\end{array}$ & $\$ 162.5 \mathrm{M}$ & $\$ 219.25 \mathrm{M}$ & $\$ 198.5 \mathrm{M}$ & $\$ 580.25 \mathrm{M}$ & $\$ 175 \mathrm{M}$ & $\$ 405.25 \mathrm{M}$ \\
\hline TOTAL & $\$ 262.3 \mathrm{M}$ & 418.45 M & $\$ 448.0 \mathrm{M}$ & $\$ 1,128.75 \mathrm{M}$ & $\$ 270 \mathrm{M}$ & $\$ 858.75 \mathrm{M}$ \\
\hline
\end{tabular}

\section{Budget Notes:}

1. Component budgets are detailed in Annex 1.

2. Funding requested for Food Zone interventions are limited to, and will be earmarked specifically for, AL activities. In September 2012, MCN signed a MoU with the US Government to further develop the Food Zone concept in Kandahar Province. The USG will provide \$10M in 2013 through off-budget funding and \$10M on-budget in 2014. USAID will implement the program beginning in May 2013 through another partner, while MCN will be fully engaged in M\&E at the provincial and district level. MCN will be totally in charge of implementation in the second year.

3. Total funding will be reviewed when actual available funds are known to the Cluster. 


\section{PROGRAM COMPONENTS}

\section{Component One: Food For Life}

\subsection{FFL Goal, Objectives and Expected Results}

The Food For Life (FFL) Component is an innovative, integrated approach to comprehensive and sustainable agricultural development that focuses on production and productivity. The FFL implementation model is based on a bottom-up, participatory planning and implementation approach through a community-based outreach mechanism.

The Goal of FFL is 'to increase agriculture production and productivity of cereals, legumes, oilseeds, horticulture, and livestock in an integrated and targeted approach that will improve rural livelihoods, thus increasing the sustainability of licit agriculture over narcotic crops, and contribute to national and household-level food and nutrition security'.

The Objectives of the FFL Component are:

- Objective 1: Reach farmers through farmers' organizations and cooperatives with effective mechanisms to access quality input supplies and extension services through public and private service providers;

- $\quad$ Objective 2: Strengthen and expand decentralized research and extension for irrigated and dry land agriculture to ensure effective and timely delivery and transfer of knowledge and technology to farmers;

- $\quad$ Objective 3: Strengthen coordinated agriculture statistics and MIS capacities to efficiently and effectively collect, analyse and disseminate required data for public information, evidencebased planning and decision-making;

- $\quad$ Objective 4: Build and rehabilitate the Strategic Grain Reserves and establish a SGR network and management system for an efficient and effective emergency response; and

- $\quad$ Objective 5: Promote diversification in food production and consumption at household level through education and extension, in cooperation with other stakeholders.

The FFL Component is expected to achieve the following Results over 3 years:

- Increase wheat production to 5.5 million MT;

- Increase rice production to 700,000 MT;

- Increase horticulture production (fruits and vegetables) to 3.7 million MT;

- Increase livestock population to 27 million (excluding poultry);

- Reduce production costs by $10-15 \%$ and increase agriculture value by $20-50 \%$;

- Improve planning, early warning mechanisms and emergency response;

- Increase to $35 \%$ the number of farmers who have access to evidence-based and up-to-date, accurate and relevant market information;

- Improve emergency response, including a 200,000 MT Strategic Grain Reserve capacity; and

- $15 \%$ increase in licit crop production and incomes in target areas.

The above objectives will be achieved through a combination of interventions and adapted packages across 8 Sub-Components, dependant on local needs and carried out at the district level, in partnership with private sector enterprises and institutions, and with oversight from the Centre and the Provinces. Although each Sub-Component is presented separately, reflecting the need to articulate specific challenges, functions and outcomes, the implementation of FFL will follow an integrated model for planning and delivery, leading to the achievement of the Component's overall targets, including counter-narcotics objectives. As such, activities and outcomes under each Sub-Component link in one 
way or another to the overall FFL Objectives and to other sub-components, although there is not a oneby-one relation between objectives and sub-components. The FFL strategic framework is a living decision-making tool that is designed to ensure that investments in its elements remain demand-driven. As such, expansion to other commodities and markets may also be explored in later years.

\subsubsection{FFL within Food Security and Nutrition Framework}

The National Food Security and Nutrition Framework (NFSNF) is a national overarching policy and strategic framework for food security and nutrition that is related to the mandates and responsibilities of MAIL, MRRD, MoPH, MoLSA, MoWA, ANDMA and MoE. As such, NFSNF identifies linkages and program interventions to Availability, Access, Stability and Utilization of Food at the national and household level that have to be addressed by the relevant institutions as per their mandates. The FFL Program is particularly focused on increasing food production, hence availability (see diagram below). At the same time, it has positive effects on the other major aspects of food security and nutrition, i.e. access, stability and utilization. Through improved productivity and increased production, farmers will gain improved access to food, since more food will be available at farm household level that can be consumed or sold. Increased and diversified food production will, furthermore, also increase the farm households' resilience to disasters (an aspect of stability) as well as enable them to maintain a more diversified and balanced diet over the year (an aspect of utilization). Such favourable multiple effects on different aspects of food security generally apply to agricultural sector interventions. They also benefit rural dwellers who constitute the majority of the vulnerable and food insecure population groups in Afghanistan.

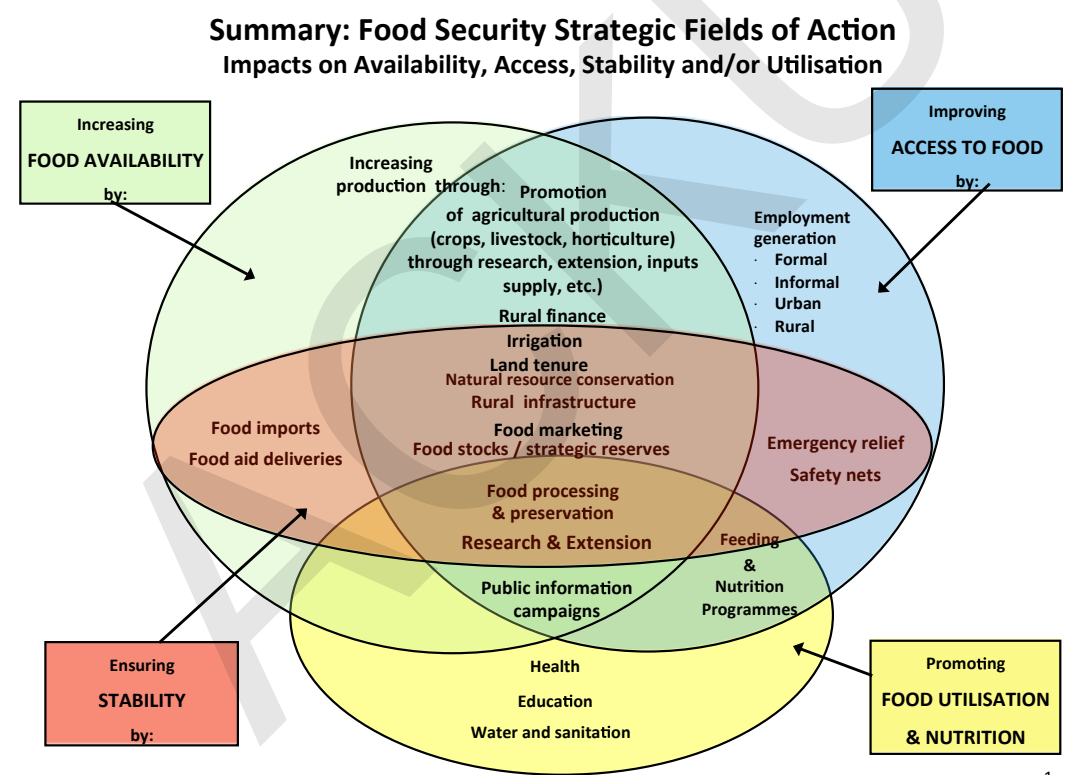

The comprehensive food security policy framework that crosscuts amongst different ministries is shown in Appendix 3 where FFL contribution as part of MAIL mandate is drawn. The Ministry of Agriculture, Irrigation and Livestock ensures that by increasing production and productivity at the subsistence farmer level will contribute to addressing food security and nutrition goals of the Government of Afghanistan. However, the contributions of other line ministries remain equally important to achieve food security and nutrition nationally at the broader level.

\subsubsection{FFL Time Framework}

The emphases that are put on the various goals, objectives, program and activities, as well as accompanying investment of FFL, are expected to shift over time. Hence FFL has been crafted within a time framework that integrates the dual objectives of sustainable and scalable increased food and nutrition security and growth of income. The time framework reflects the belief that improved food and nutrition security is fundamental to growth of income. In turn, and together, both improved food and nutrition security and growth of income are fundamental to sustainability and scalability (see below figure). 


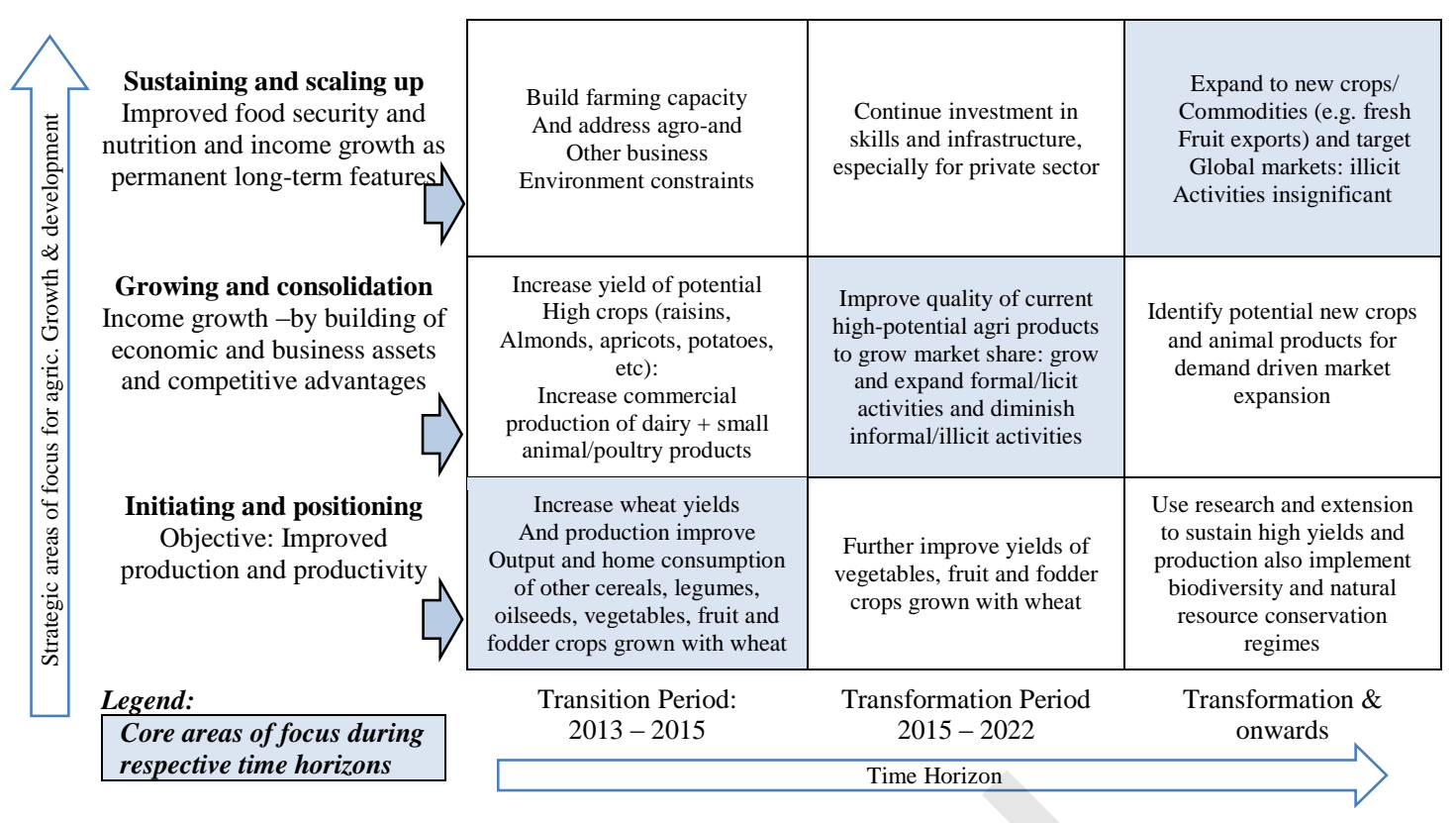

\subsection{Situation Analysis}

\subsubsection{General Background}

Agriculture and rural life play a predominant role in the Afghan economy and society. Despite the increasing number of the urban dwellers in the country, Afghanistan is still dominated by its rural communities and livelihoods. It is estimated that more than $80 \%$ of the people live in rural areas. Women constitute at least $50 \%$ of the rural inhabitants. About $55 \%$ of the Afghan households are engaged in farming around and 6\% have some type of livestock, while 50\% of the labour force is engaged in primary agricultural production. A large burden of the agriculture labour falls on women since in can encompass all of crop production, animal husbandry, traditional crafts as a source of income and also child rearing and providing care for the family. In 2009/2010, agriculture accounted for around $32 \%$ of the GDP.

Agricultural products (including carpets and rugs) represent about $80 \%$ of total licit exports. Major exports are dried fruits and nuts such as raisins, figs, almonds, and pistachios, making up $27 \%$ of total exports in 2010/11, while fresh fruits account for 7.2\%. Raisins are the leading agricultural export, followed by almond, pistachio and walnuts. The carpet and rug industry contributes almost $18 \%$ of the value of total licit exports (but in 2008/09, it was $27.5 \%$ of total exports). Other exports include spices, medicinal plants and leather, linked to the livestock sector. Women are often prominent in these export industries, as carpet makers and also undertaking fruit and nut drying and processing activities at the home and local levels. However, they often excluded or constrained from participation in the more profitable segments of the value chains.

Due to long periods of conflict and recurring droughts, there had been a steady annual decline of $3.5 \%$ in licit production between 1978 and 2004, and a rise in illicit drug crops. Livestock herds also decreased between 1997 and 2004, partly due to the migration of herdsmen to neighbouring countries. Crop production started rebounding by the mid-2000s, and livestock numbers also increased as owners and their animals returned to the country.

The overall performance of the sector is very dependent on cereal crop production, and cereals accounts for over $80 \%$ of the agricultural economy. At the same time, Afghans depend on consumption of cereals, in particular wheat, which is the basic food staple (70\% of total cereal consumption). Food staple production is the basis for income generation for farmers in these areas. However, there are strong annual variations in cereal production, mainly due to fluctuations in seasonal rains and snow precipitation and other weather conditions, as well as uncertain and deteriorated security conditions. All these factors make agriculture growth very volatile. The country has not been self-sufficient for 
many years. Self-sufficiency has significant variations from year to year from a low level of $53 \%$ in 2004 to the highest of $96.6 \%$ in 2009 when the country benefitted from exceptionally good weather. Consequently, national production needs to be supplemented by imports through the private sector or food aid assistance.

Mainly as a result of low level and volatile nature of agriculture and livestock production and productivity, the agriculture sector produces insufficient and highly variable amounts of the nation's primary staple crops, namely wheat, rice, maize, legumes and oilseeds, and the same being true for vegetables and fruits. There is also only a limited level of commercialisation, investment and business entrepreneurship in the licit agriculture sector, leading to limited cash incomes and employment earnings from crop and livestock production and related activities. As such, the licit agriculture sector currently lacks the necessary dynamism in production and productivity and markets to sufficiently address issues of farming and rural poverty, unemployment and underemployment, providing viable alternatives to the cultivation of illicit crops, and alleviating national and household food insecurity.

Agriculture, however, has the potential to further grow, address self-sufficiency issues and contribute to food security, notably by tackling the sector's low production and productivity and creating on and off-farm jobs across value chains. Exploiting this growth potential implies improving the sub-optimal productivity that still affects subsistence and landless farmers, and further promoting the entrepreneurial capacity of semi-commercial farmers. However, to achieve increased production in agriculture and economic growth that makes a significant impact on rural areas, agriculture production needs to grow at a steady average rate of at least 5\% per annum over the next decade. There are significant opportunities for economic growth through improved processing and marketing of this increase in produce, creating employment and income opportunities. Therefore, improving production and on and off-farm income, and ensuring availability of sufficient food supply are major components in strengthening the contribution of the agricultural sector to achieve economic growth and poverty reduction. To ensure agricultural sustainability while exploiting the full potential of licit agricultural production in the rural areas, strong public programs along with the development of the private sector must be considered as the key to capacity building and development efforts.

\subsubsection{Food Insecurity and Poverty ${ }^{1}$}

The 2007-2008 NRVA Survey reported that up to 70\% of Afghans are food insecure, and high food prices, political instability and natural disasters constantly push and hold millions of people into highrisk food insecurity. Food insecurity is not limited to physical availability of food and its domestic production but regards the fundamental right of the Afghan people to have "physical, social and economic access to sufficient, safe, nutritious and culturally accepted food to meet their dietary needs and food preferences for an active and healthy life" (1996 World Food Summit). This right is limited by the prevailing conditions of poverty, lack of economic opportunities, inadequate support to communities and insufficient "safety nets". Uneven distribution of cereal consumption and conditions of poverty are widespread: the richest quintile of the population (20\%) shares $39 \%$ of total consumption, whereas the poorest quintile shares only $9 \%$ of the total consumption.

According to the 2007-2008 NRVA, almost 9 million Afghans (36\% of the country's population), mostly in rural areas, live below the national poverty line, and are unable to meet their basic needs and dietary requirement. Food insecurity is found also in urban areas, accompanied by malnutrition. Recent food price crises affected Afghanistan more severely than other countries because of its high level of poverty. A second group of Afghans, corresponding to $20 \%$ of the population, are only slightly better off, as they still live on the borderline of absolute poverty and food insecurity. Thus over $50 \%$ of the population live in conditions are easily influenced by fluctuations of economic factors such as food prices, income and employment opportunities.

Malnutrition is extremely high due to low levels of dietary intake make malnourishment, especially by women and children. Additional fruit and vegetable consumption is needed as Afghans consume roughly a quarter of the WHO minimum guideline, which is on average met in other Asian developing countries. Maternal, infant, and child mortality rates are high. Most vulnerable groups include

\footnotetext{
${ }^{1}$ This is an overall description of food insecurity and poverty and is not an outline of what the FFL Component will address via its contribution to food and nutrition security and poverty alleviation.
} 
internally displaced people, returning refugees, female-headed households, children, elderly, the nomadic Kuchis, disabled heads of households and the chronically poor.

Women, in particular and not necessarily female-headed households, are found to have a disproportionate inferior access to adequate food, even if the household to which they belong is not considered vulnerable: $21 \%$ of the women in reproductive age group are malnourished, $60.5 \%$ of children under the age of five are stunted (one of the highest levels in the world), and $33.7 \%$ of the latter are underweight. Three most important micronutrient deficiencies are lack of iron and vitamin A and iodine, causing blindness (vitamin A), goitre (iodine) and increasing vulnerability to disease and death. About $4 \%$ of deaths among children under five are caused by zinc deficiency, which causes an increased risk of pneumonia, malaria and diarrhoea. Maternal underweight is a major cause of intergenerational transmission of malnutrition. Micronutrient deficiencies and malnutrition are more likely to occur in women who are illiterate or have not had access to at least primary education.

\subsubsection{Key Agricultural Growth and Development Issues}

\section{Low productivity of land and labour}

Agricultural crop production and productivity in Afghanistan are fractions of their potential. Although $12 \%$ of the land is arable, less than $6 \%$ currently is cultivated. Yields per hectare of various cereal crops are a fraction of levels in surrounding countries. In addition, both the planted areas and the yields are erratic. In some regions, agricultural production has all but ceased due to destruction caused by the war and the migration of Afghans out of those areas. In areas where farming is taking place, production and productivity are constrained by an almost total dependence on erratic winter snows and spring rains for water; irrigation facilities are inadequate to meet demands for increased production for food security and poverty reduction. There is inadequate application and use of recent developments in dry or wetland farming systems, including improved plant nutrients, seed and planting materials, plant protection and disease control, and water harvesting and application techniques.

\section{Inadequate management, use and returns to water}

The availability of snowmelt water appears to be the single most limiting factor to crop production and productivity; it has been estimated that $85 \%$ of output of grains is produced on only $5 \%$ of the irrigated land. (World Bank - 2005) Irrigation systems mainly comprise: traditional systems using informal river diversion structures maintained by the users - about 55 percent of the total irrigated area; traditional systems based on natural springs, kareeez or arhads - about 30 percent of irrigated area; and more modern formal river diversion structures, which were built in the 1960/1970s - about 15 percent of the irrigated area (Rout - 2008).

Many areas of the country are prone to flooding, causing loss of life, farmland, communities and infrastructure. A limited number of reservoirs are available to store water. Eleven percent of the country is without water resources. It is estimated that ground water exists in sufficient quantities for both irrigation and pottage in many parts of the country. However, only one-half of the arable land is cultivated each year, due in a large part to water shortages. Studies undertaken in various parts of Afghanistan over the past fifteen or so years have shown that access to water, especially by poor rural dwellers, is becoming increasingly more threatened.

\section{Shortage of planting materials and other inputs}

Shortage of quality seeds and planting materials remains a major issue in increasing production and productivity. At present, both the private sector and the Government provide only 35 percent of the wheat and paddy seed requirement. Fertilizer use is, for the most part, limited to irrigated wheat and not often used in adequate quantities and combinations. Improved plant protection methods are not widely and systematically applied.

\section{Deterioration of livestock production systems}

During the last three decades, primary production in livestock industry has undergone a significant decline. This is manifested in loss of and reduction in animal numbers, and decreased productivity. Both of these phenomena are strongly influenced by declining feed and overgrazing, and the affects of animal diseases, which have not been adequately dealt with.

Rangelands are overgrazed and nomadic and semi sedentary sheepherders are operating with high livestock mortality rates. Much of the irrigated land, which formerly supported livestock, is now 
without water. Also, many rangelands have been converted into rainfed crop land, leading to soil instability, soil erosion and other problems. Even when rainfall conditions are favourable, improvements in the small ruminant sector (sheep and goats) are hampered by problems with traditional user rights and grazing practices. As ecological conditions become less favourable, herdsmen tend to become even more preoccupied with livestock numbers rather than with productivity. This has the potential to add more fuel to the cycle of decline in the integrity of the rangeland resource base and the productivity of the livestock industry.

\section{Inadequate generation and use of scientific knowledge and methods}

In spite of efforts that have been undertaken to rehabilitate the research and extension system, it appears that there is still limited scientific knowledge coming out of the national research system. Though a large number of rural people are engaged in agriculture, they are not versed in modern scientific agricultural methods. As a result, inputs such as water, fertilizer and chemicals are often either over-used or inappropriately used. The selection of crops is also often done without considering the emerging needs in the market. Thus there is a need for research not just in biological, chemical and physical aspects of agricultural production, but also in economic, marketing and social aspects. Whatever research activities are going on, they need to be better linked to and to address the emerging or actual needs of the communities.

Loss of markets and market shares, and shortage and inconsistent supply of value added products Shortage and inconsistent supply of value added products that meet the high standards of a growing Afghanistan and regional middle class and the even higher global standards act as an impediment to access to the national, regional and global markets. Losses in the tertiary, market-oriented and valueaddition areas of the fruit and nuts and livestock industry during the past three decades have been substantial. Many of Afghanistan's formal niche markets in dried fruits and nuts have been filled by new producers like Iran (pistachios) and Turkey (dried apricots, plums and peaches). In the livestock sub-sector, most commercial and semi-commercial herds and flocks were substantially reduced, and assets such as stocks of breeding animals, hatcheries, feed mills, and poultry and milk processing facilities were lost. Afghanistan has a two-pronged battle on its hands: to claws back the ground lost in the last thirty years and to develop new value-added chains and niches.

\section{Inadequate credit flows from banking institutions}

Inadequate credit flows from formal banking institutions constrain the smooth functioning of the agriculture sector. To-date, it has been impossible to tempt commercial banks to undertake agricultural lending due to the constraints around security and the risk adverse nature of the banks. In answer to this problem the Agricultural Development Fund (ADF) has been established to accelerate and increase the volume, value and structure of credit available to farmers through cooperatives, agri-businesses and financial institutions for on-lending. Without expansion of the ADF this risk will remain.

\section{Shortage of viable alternatives to illicit crops}

In a de facto, but not de jure manner, poppy and cannabis have become a part and parcel of the Afghanistan farming systems. As such, a large part of the solution to the eradication of these illicit crops has to come from within Afghanistan's licit agriculture sector itself. This is one of the major challenges of agricultural growth in Afghanistan - to develop viable alternatives to illicit crops. In 2009 there was a $22 \%$ decrease in poppy area from 2008. In 2010, there was no marked decrease in poppy area or the number of poppy-free Provinces. But there was growing indication that hashish was reaching an all-time high and that most of the new hashish production was occurring in areas, mostly in the south and west, where there had been some decline in poppy production. Thus the challenge of shifting the farming system from the illicit crops dominance to licit crops dominance is crystallized in the fact that two most profitable crops in the country are both illicit.

\section{Inadequate status of women}

Within the households women and girls can face discrimination and exclusion in access to and in sharing out of household resources including land, credit, labour saving technology, etc. They can also face the same constraints and restrictions accessing and using farm products, including food. These phenomena have a tendency to lead to higher malnutrition and mortality indicators for women. Because of their lower social and economic status, as well as their physiological needs, women are often more vulnerable to being overworked and under-paid or under-rewarded. They are hence also more vulnerable to nutritional problems. Poor female education and poor nutrition early in life reduce learning potential, increases reproductive and maternal health risks. This no doubt lowers the overall 
productivity of women, and also lowers production and productivity in the agricultural sector, in which women contribute over $50 \%$ of the labour resources.

\section{Institutional challenges to agriculture development}

Agriculture institutions have also seen a severe deterioration of their service delivery capacity. Years of conflict have destroyed facilities such as offices, research stations, machinery and equipment. Physical reconstruction has started, but the required human resources to effectively and efficiently operate the service system are yet to be fully re-established. The Agriculture and Rural Development Cluster, namely the Ministry of Agriculture, Irrigation and Livestock (MAIL), the Ministry of Energy and Water (MEW), the Ministry of Rural Rehabilitation and Development (MRRD), and the Ministry of Counter Narcotics (MCN), is suffering from these physical, human and financial constraints. In addition, the situation is further aggravated by the access problems due to conflict-induced security concerns.

Essential services are not available or accessible to most farmers. Insufficient outreach of agricultural and veterinary extension services, and poor accessibility of markets for input supplies and product sales, limits the development options in particular for households in remote areas. Even though road conditions continue to improve, the benefits do not yet accrue to most smallholder farmers and communities.

Although rural women are at the forefront of agricultural production and food security in Afghanistan, there are stark gender gaps in accessing agricultural research and extension results, resources and messages. Both research and extension service need to be tailored to addressing the needs of women and empowering women to take advantage of opportunities and to make advantageous decisions both inside and outside households. In addition, there are laws and legal and socio-economic practices that need to be dealt with because they restrict women's access to productive resources and their linkage with agricultural production - and hence compromise both economic growth food and empowerment and nutrition security.

An example of inadequate extension services and accessibility to quality information is seen in the predominant use of poor quality seeds and inappropriate crop varieties, conventional methods of cultivation, and farmer's overall lack of awareness to the negative effect of harmful chemicals, such as pesticides and synthetic fertilizers, affecting crop yields and production while degrading the soil and other natural resource base.

Only about $10 \%$ of farming households receive information on agricultural production, and about $15 \%$ of households with livestock have access to veterinary services. Delivery systems are weak and quality of extension services and inputs are often still inadequate.

MAIL, through the ARD Cluster, seeks to address problems highlighted here with the implementation of the Food for Life Component of NPP2 - National Comprehensive Agriculture Production and Market Development. FFL is an innovative approach to a comprehensive and sustainable agricultural development that focuses on addressing issues of production and productivity, rural livelihoods and food security.

\subsubsection{Potential Options for Agricultural Growth and Enhanced Food Security}

There is tremendous potential for agricultural growth and development and the alleviation of food insecurity and reduction of poverty. What the rather long and varied litany of constraining issues for agricultural growth and development, clearly means that in order to achieve any substantial progress in alleviating the condition of the food insecurity and poverty, there is need for a concerted effort that is multi-disciplinary, multi-sectoral and multi-agency in nature. As such, there needs to be careful selection of priority areas and entry points for involvement by the public sector (that is, Government and development partners). Such an effort also needs to be based on strong collaborative relationships with administrators, technical staff, civil society and the private sector at the Provincial, local and community levels. Care must be taken to ensure that Government interventions never stifle the growth of the private sector.

\section{Intensifying agricultural production for increased output, food self-sufficiency and growth}


A pivotal focus of agricultural growth needs to be on increasing the yield of wheat in irrigated areas by: (a) consistently increasing the yield of wheat in the North and West to current levels in the South and East (i.e. to about 3 tonnes per hectare), and (b) increase the yield in the South and East to about $125 \%$ of the level of surrounding countries (i.e. to about 4-5 tonnes per hectare). To consistently achieve these targets in wheat production, greater investments in irrigation infrastructure and water management techniques is required. Achieving this kind of growth in wheat production will lead Afghanistan to full self-reliance in food, with the possibility of putting surpluses in the National Grain Reserves (NGR). This will provide the leverage for further growth. Investments in irrigation and water management need to be followed-up with investments in high yielding seeds and planting materials, and also in fertilisers, plant protection, credit, research and extension. Measures to make agricultural input and output markets more competitive and efficient will bring considerable benefits to farmers. Improving the availability of other infrastructure and services, technical and market information in rural areas will be essential to explore the full potential of both farmers and entrepreneurs.

\section{Increasing agricultural production to diversify food, and raise livelihood activities and income}

Wheat is currently grown on more than 50 percent of all arable land. Increasing yields of irrigated wheat, will allow more land to be available for other high value crops. Also, use of irrigated wheat land during off seasons in higher value commodities is central to raising agricultural productivity and incomes. In addition, dry land and un-irrigated lands need to be encouraged to cultivate rice, maize, barley, soya beans, cowpea, oilseeds, fodder crops, and a wide range of fruits and nuts (such as almond and raisins) and vegetables. Prospects for import substitution in these areas are immense. Hi-tech green houses, drip irrigation and solar power irrigation methods can help to put under-irrigated and unirrigated lands into better use. With better road, railway and air transport networks, floriculture and salad vegetables from intermediate zones can be supplied to hotels, airlines and groceries in Afghan cities and as far as Dubai, and can be a great source of income to emerging generations. The revival and further development of the livestock industry will be an integral part of this diversification effort. Home gardens, backyard agriculture and poultry and small animal production are the other important sources to meet household daily needs. Value chain development and the replacement of poppy and hashish crops with profitable licit commodities is part of the diversification effort. Support from relevant partner ministries and agencies is essential to ensure that households understand the need for diversification.

\section{Creating market-oriented opportunities for on- and off-farm enterprises and employment}

There is a very real need for a supportive environment for enterprise development which encourages the commercialization and the growth of labour-intensive industry in rural areas. Investments in national and provincial roads, irrigation and storage facilities are measures that will strongly support the development of dynamic rural sector activities, both on the farm and off the farm through wellconnected market network. Creating a supportive climate for agricultural and rural enterprises goes hand-in-hand with requisite policies to promote: integrating into the world economy, encouraging the private sector, strengthening the banking system (including special mechanisms for meeting the credit and other financial needs of farmers and rural entrepreneurs), and ensuring fiscal stability.

\section{Agricultural livelihoods recovery for displaced people and disaster victims}

Emergency mitigation, stabilization and relief programs include the management of national food reserves, the emergency provision of improved seed, quality fertilizers, and animal feed to the most vulnerable farmers as well as the implementation of emergency integrated plant protection. These programs and measures have to be seen and developed as crucial components of ensuring crop and livestock production and safeguarding food security in the areas and communities that are worst affected by conflict, drought, flood, adverse winter conditions, physical isolation, and unfavourable price adjustments. It is important to understand that in these areas and communities, such emergency support is part and parcel of the necessary long-term adjustment process for development. Mainly for this reason, emergency programs' capacity to stabilize food quantities and prices, and to replenish and rehabilitate the means production and livelihoods of severely affected households should be considered to be an integral component of the Government's and development partners' immediate and medium term development priorities.

\section{Enhancing institutional and human capacities in agricultural and rural sectors}

The essence of enhancing institutional and human capacities is the development of a supportive society that is based on the bottom-up development principles. A supportive society recognises the intrinsic value of individual, community, social and commercial enterprises, and facilitates the transformation of 
all good ideas into rewarding work. A supportive society recognises and embraces the need to facilitate the development and maintenance of infrastructures and services that will make it possible for "everyone to have a go". It epitomises the recognition that economic growth is important and is the only way long-term poverty can be reduced, and also that ensuring equitable access to the means and benefits of growth is equally important. An important aspect developing human capacities lies in instituting gender sensitive and women-empowering and enabling measures in all aspects of promoting the growth of agricultural production and productivity.

\subsubsection{Cultivation of Narcotic Crops and the Illicit Economy}

The opium poppy economy is considered the single greatest challenge to the long-term security, development, and effective governance of Afghanistan. Opium cultivation, production and trafficking undermine the rule of law through increased corruption, insecurity and insurgency. The illicit economy has also established traditional and rival power structures and led to instability, which has hampered reconstruction and development efforts, thus affecting long term economic growth. The increasing number of drug users in Afghanistan drains the resources for health care and social services. Despite the efforts of GoA and the international community over the last decade, the narcotics problem remains a serious challenge (131,000 ha in 2011 , corresponding to $63 \%$ of global cultivation, amounting to 5800 MT or $82 \%$ of global production of raw opium) for Afghanistan in achieving its development goals.

Since opiates are central to the macro-economy, contributing 16\% of the GDP (Gross Export Value of \$2.6 billion in 2011 according to UNODC Opium Survey of 2011), and the livelihoods of a quarter million rural households, mostly poor, currently depend on growing opium poppy and to a lesser extent on Cannabis, if the security, governance, development and CN objectives of GoA are to be achieved, sustainable alternative livelihoods must be identified for those who are currently (or have been) engaged in illicit cultivation and production of narcotics, as well for those who are vulnerable to exploitation by narco-entrepreneurs because of poverty, food insecurity (i.e., drought-induced migration of households from Ghor to southern provinces in 2011) and chronic unemployment. Without such support, there would be a substantial increase in poverty, public discontent and insurgency resulting from unbalanced eradication campaigns. Experience from Helmand shows that repeated eradication campaigns without AL interventions create poverty. Eradication alone without provision of AL inputs to subsistence and marginal farmers, in addition to perpetuating poverty, will dis-alienate the rural communities and push them in the arms of the narco-entrepreneurs and insurgents, thus affecting security and governance in negative ways.

The migration of poppy cultivation from the rest of the country to the southern provinces, over the last decade, and its comeback in isolated pockets of the northern and eastern provinces in recent years show that there is a strong link between insecurity and cultivation. Lessons learned from a decade of CN and development interventions by GoA and the international community in Afghanistan demonstrate that a holistic approach is needed to combat narcotics, and efforts under security, governance and development must be coordinated to achieve a significant and sustainable reduction in poppy cultivation.

\subsection{Implementation and Governance}

\subsubsection{Implementation Framework}

The FFL model is a bottom-up, participatory planning and delivery approach by reaching to farming communities and their organizations, enabling private sector partnerships as well as MAIL's extension and MRRD's social mobilization networks as support mechanisms (see model below). The delivery of services will be carried out through existing government, private sector and civil society organisations, and guided by policy that will be formulated and implemented from the Centre through the provinces to the districts. FFL will utilise existing structures, organisations, resources and activities where possible, through improved coordination mechanisms and management. Since FFL is primarily a MAIL program, in practice the implementation of FFL means MAIL taking ownership through its existing structure and ensuring departments across the Ministry are actively engaged in the processes leading to planning and implementation of activities, in coordination with MRRD and MCN. The structural arrangement for implementing FFL is designed to highlight the Ministry's ownership of the Component by ensuring it is fully embedded within the MAIL organization. 


\section{FFL Implementation Model}

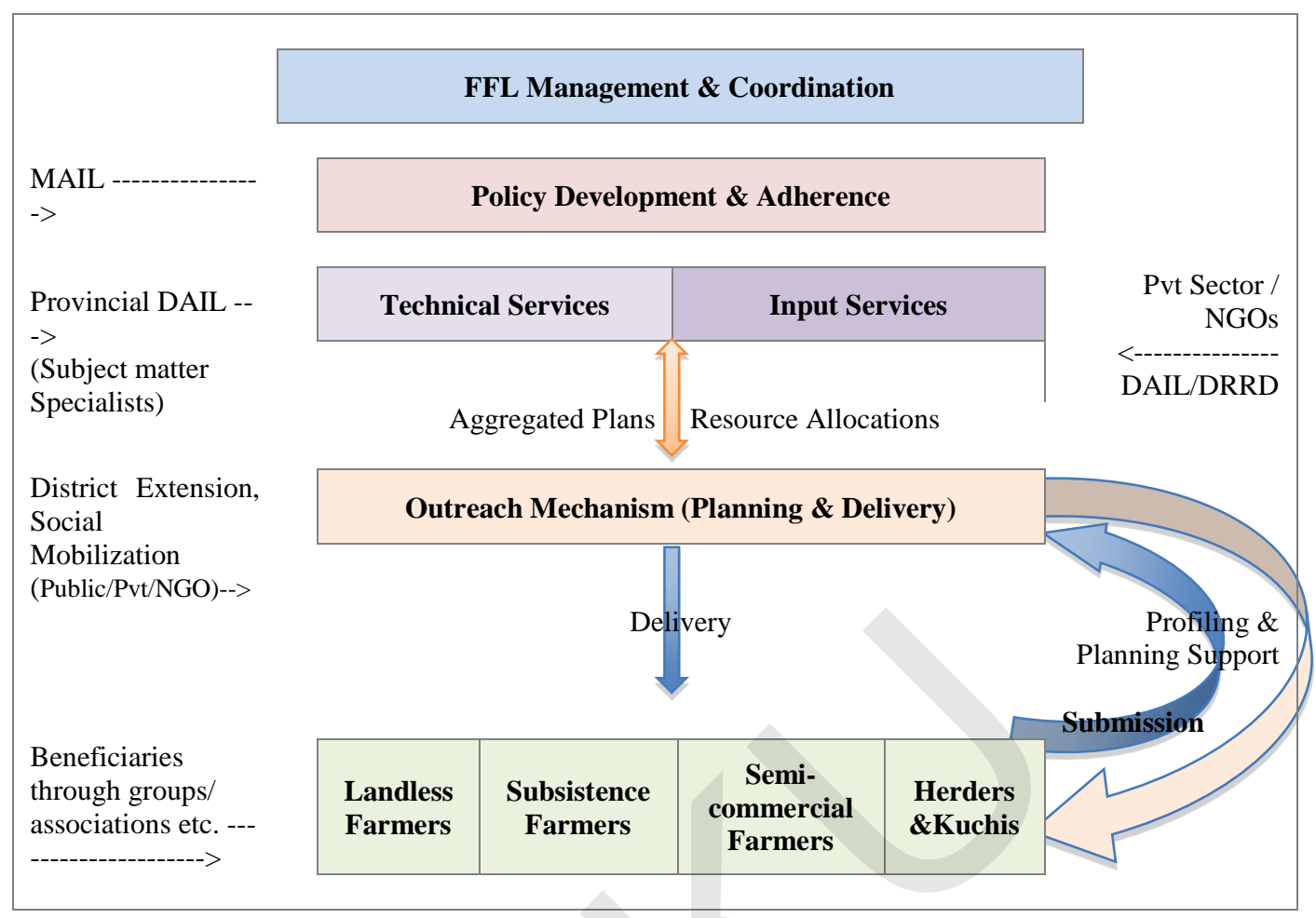

Lessons learnt from other MAIL programs have been incorporated into the design and implementation methodology for FFL. While the implementation of the Component will start with a narrow focus during the first year, notably in key agro-ecological zones and $\mathrm{CN}$-priority provinces, it will eventually link with and absorb related on-going MAIL projects as they phase out and as FFL implementation mechanisms and institutional settings are strengthened. As such, it is anticipated that the roll out of FFL will ensure that implementation is effectively coordinated with functioning MAIL programs to guarantee support from on-going projects across all FFL Sub-Components. FFL will first start establish itself before taking on the responsibilities and coverage of the current projects, thus increasing coordination among them and moving towards greater "integration" within the FFL framework and sector-wide strategy for agriculture and rural development. Geographical adjustments will also be made in line with the overall goals and objectives of the ARD Cluster to ensure that the benefits of coordinating all Components and NPPs are maximized.

Furthermore, as current competencies of MAIL at the sub-national level are somewhat limited, further assistance may be required from facilitating partners, albeit on a reduced basis at the provincial and district level, while MAIL continues to build its internal capacity through capacity building and change management activities. The FFL implementation model is therefore defined to strengthen planning and implementation capacities at the national and sub-national level so that when the Component scope is enlarged and externally-funded projects phase out, both MAIL and DAILs will be able to facilitate the provision of services aimed and focused at sub-national level with a collaborative and effective approach.

\subsubsection{Outreach}

One of the most critical challenges of the Government today is reaching out to small-scale farmers and vulnerable groups in the districts and rural areas. MAIL in particular faces this challenge as its extension network is underperforming and in some cases ineffective. In this model, access to farmers will be achieved through an extensive outreach network consisting of DAIL and DRRD staff (notably extension workers and social mobilizers), local governance structures such as District Development Assemblies (DDAs) and Community Development Councils (CDCs), and established farmers' organizations. The purpose of this approach is to engage farmers at the district level in participatory 
needs assessment and planning, which will determine the type and scope of technical and input service delivery required.

The different Sub-Component activities will be packaged and implemented to address the specific needs of individual farmers' groups using the following decentralized Outreach process:

- DAIL extension workers and with support from DRRD social mobilizers will enter districts and communities via the DDAs and CDCs, identifying farming communities and farmers' groups (cooperatives, associations, etc.) who will be the main beneficiaries for FFL interventions. Leveraging the community mobilization capacity of these structures will assist in consolidating the linkages between development activities and local governance, and ensure effective collaboration among local stakeholders for the implementation of agricultural programs. If there are no suitable farmers' groups yet constituted or effective, but there is a functioning CDC, MAIL will deliver the first level of services/inputs through the CDC while at the same time forming and supporting the farmers' group during the start-up phase. Once ready to assume responsibility, the main activities will transfer across to the farmers' group;

- As the specific needs of beneficiary groups vary across the country (i.e. landless, subsistence, and semi-commercial farmers, herders, Kuchis, women groups) and depend on potential crop production opportunities, FFL will deliver services and inputs to farmers' groups using multiple approaches with a focus on local procurement and delivery. This will include adapted packages, which may or may not be subsidized based on the needs of beneficiary groups, including a voucher system for inputs reclaimable through private sector enterprises. Advanced farmers groups with a view to expansion may qualify for affordable agricultural credit assessed on their viability and level of contribution, as well as other forms of services and assistance under complementary EMD interventions. The private sector, including farm stores, ag depots, veterinary field units, etc. will be encouraged and supported to play an increased role in providing extension services, agriculture inputs, mechanization and other infrastructure services to farmers, based on local needs and opportunities.

- Within the Government procurement framework, responsibility for selecting the best procurement and service delivery option will lie with locally-based implementation teams, including DAIL and DRRD departments supported as needed by external technical assistance, and will be based on discussions with farming communities and farmers' organizations. Field-level monitoring and evaluation of specific interventions may be provided by third-party committees composed of local governance structures and community-based organizations (including DDAs and CDCs), as appropriate. Further details will be articulated by the FFL Secretariat and Technical Committee during the development of FFL's Operations Manual.

\section{$\underline{\text { FFL Outreach Model }}$}

\section{OUTREACH}

Access to farmers \& farming groups

(DAIL/DRRD mobilization teams - Coops / NGO Partners)

Through Delivery Mechanisms to strengthen \& support to:

\begin{tabular}{|ll|}
\hline \multicolumn{1}{|c|}{$\begin{array}{c}\text { Government } \\
\text { Functions }\end{array}$} \\
\hline$\circ$ & Extension services \\
$\circ$ & Input supplies \\
$\circ$ & Research / demo sites \\
$\circ$ & Agriculture and market \\
& Information \\
$\circ$ & Farmers' organization \\
& support \\
$\circ$ & Ag Dev. Activities \\
$\circ$ & Strategic Grain \\
& Reserves \\
\hline
\end{tabular}

\begin{tabular}{|ll} 
& \multicolumn{1}{c}{ Farmer } \\
Groups (PS)
\end{tabular}

\begin{tabular}{ll} 
& $\begin{array}{c}\text { Private } \\
\text { Sector }\end{array}$ \\
\hline & Farm Stores \\
$\circ$ Ag Depots \\
$\circ$ VFU's \\
$\circ$ Credit \\
O Women entrepreneurs \\
O Other Pvt Sector \\
Enterprises \\
\end{tabular}


In complement of the ongoing Horticulture Cooperatives Development Project (HCDP), FFL will also include strong interventions to strengthen agriculture cooperatives into sustainable agro-product enterprises. Such plans will address constraints to the formation, development and sustainability of agricultural cooperatives, and its interventions will focus on the following areas: support the formation of farmers' cooperatives and associations; enabling legal and regulatory frameworks to facilitate better access to services; provision of organizational support and access to Business Development Services (BDS) for cooperatives and their members; and support the construction of processing and storage facilities, particularly cold storage, processing and packaging facilities that add value to agricultural products produced by farmers' cooperatives. These plans and interventions will be closely coordinated, and possibly integrated, with the roll out of FFL to leverage synergies and ensure that the implementation and outreach methodology deployed are consistent and complementary.

\subsubsection{Food Zone Approach}

The Food Zone Program (FZP), a rapid-action initiative of the ARD Cluster to be implemented partly under FFL and led by the Ministry of Counter-Narcotics (MCN), is envisaged to intervene in narcoticsplagued provinces on a priority basis with comprehensive $\mathrm{CN}$ measures during the early stage of implementation of NPP-2, and then link with longer-term FFL and EMD interventions to sustain the momentum against resurgence of poppy cultivation. The complete FZP program document is referenced in the annexes of the NPP-2 package, and specific implementation plans for AL interventions under FFL will be developed subsequently.

Consequently, as guided by the Program governance structures, the FFL sequence of implementation will also prioritize target districts in $\mathrm{CN}$-priority provinces such as Helmand, Kandahar, Farah and Uruzgan, and gradually expand to target districts in provinces where low levels of cultivation have persisted (i.e. Dikundi, Nimroz, Zabul, Badghis, Nangarahar, Badakhshan) or where a resurgence of poppy cultivation has been observed in recent years (i.e. Baghlan, Kapisa and Balkh). In these areas, a range of alternative livelihood interventions (i.e. provision of locally-adapted agriculture inputs, promotion of high-value horticulture and other licit crops such as saffron and cumin, livestock value addition) will be primarily coordinated and implemented by $\mathrm{MCN}$, effectively leveraging existing extension and community-based networks (i.e. CDCs, farmers' organizations) as well as linking with longer-term activities implemented under the FFL and EMD Components.

Throughout implementation, poppy-free zones will be created, consolidated and expanded each year to cover greater areas. The number of beneficiaries and target districts will be determined based on the population of each province and consideration of vulnerabilities, remoteness of the districts and access to markets, in consultation with MAIL, MRRD and IDLG, provincial governors, provincial development councils and line departments. Food Zone interventions are designed to sweep across the narcotics-plagued districts in a rapid manner, thus paving the way for long-term activities under the FFL and EMD Components in order to solidify the gains made.

\subsubsection{Beneficiary Groups}

The overall needs of the various targeted beneficiary groups are reliable access to inputs, services and credit. All beneficiary groups will also need planning and technical support. However, their specific needs differ and the model has to be responsive to those differing needs.

Although landless farmers will most likely never come out of subsistence, they will need support in finding other opportunities for income generation, such as employment through improved agricultural activities that will be generated in the sector. This issue will largely be addresses through Component 2 of this NPP.

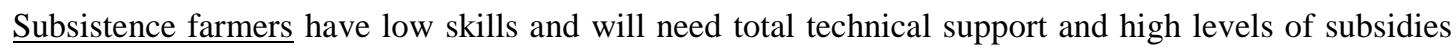
for input supply. This group, like the landless farmers, will be susceptible to food shortages and therefore must be prioritised (together with the landless) in times of emergency and shortage.

The semi-commercial group have higher skill levels and, provided they have access to inputs and credit, will be able to produce food surplus to requirement that in turn will contribute to feeding the poor and landless. However, in order to achieve this they will need an enabling environment (including access to credit, inputs and markets) that must be provided through the model. 
The herders (including Kuchis) have low skill levels and limited access to facilities and services due to their nomadic nature. They have issues with settlement that can often lead to conflict, overgrazing and lost opportunities for by-product marketing.

\section{$\underline{\text { FFL Beneficiary Groups }}$}

\begin{tabular}{|l|}
\hline Landless Farmers \\
\hline Need other income \\
opportunities \\
o Never come out of \\
subsistence (based \\
on farming)
\end{tabular}
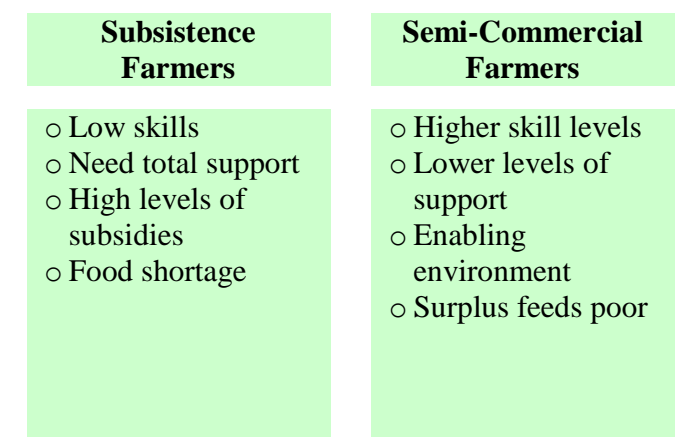

Herders and Kuchi
○ Low skills
o Limited access to
all facilities
o Settlement issues
o Over grazing
o Lost opportunities
for by-product
marketing

Since the participation of women is considerable in some sectors of agriculture production and processing, which also constitute an important source of livelihood for them, gender appropriate extension services and capacity building activities for women will be provided. FFL will also ensure effective outreach to, and participation of, women-led cooperatives, agriculture-related associations and households, and promote access to credit, land and income generation for women. Furthermore, livestock, kitchen gardens, food security and nutrition activities will focus most particularly on women in rural and urban areas. FFL will also strive to mainstream gender across decision-making, program implementation and service delivery notably by increasing the number of women civil servants, extension workers and farmers' organization.

\subsubsection{Governance Structure}

A small, but cost-effective FFL Secretariat will carry out coordination of FFL interventions, and will report to the Office of MAIL's Deputy Minister for Technical Affairs through the Management Committee. FFL strategies will be coordinated by the Secretariat for implementation through MAIL and DAIL departments at the national, provincial and district levels, with coordination support from MRRD and MCN. Some targeted international assistance may be requested to support the Secretariat, while most of the national staff positions will be supported through the Ministry'sTashkeel and contracted positions. The FFL Coordinator will be an employee of MAI 


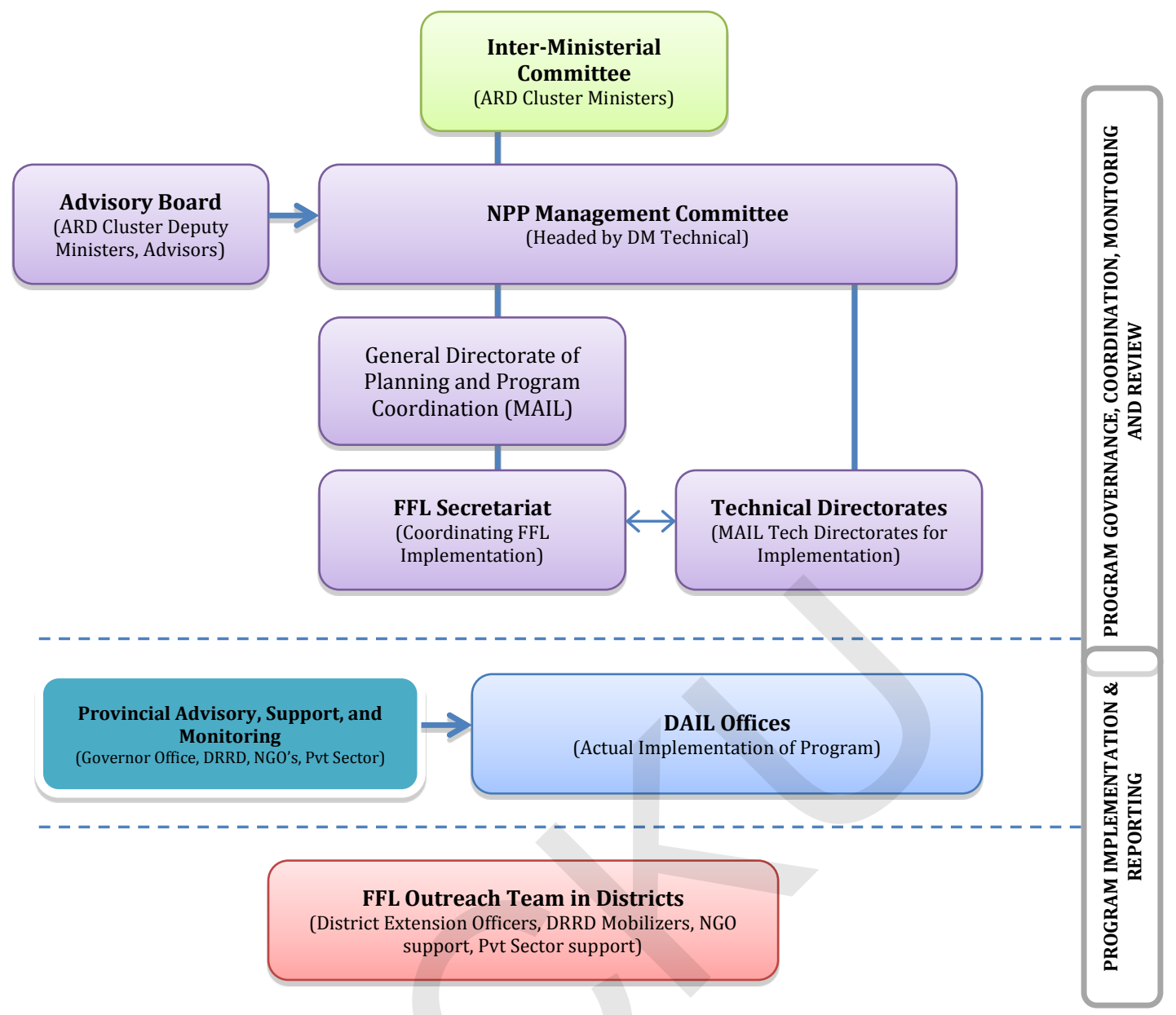

The implementation of FFL will be handled through MAIL technical Directorates with support from technical short-term advisors, Cluster ministries and coordinated by the FFL Secretariat. The Advisory Board will provide technical advice and assist with facilitating coordination and increased integration between the cluster and donor-funded programs.

\subsubsection{Technical Assistance, Change Management and Capacity Building}

MAIL does not want to find itself in a position where there are unsustainable program overheads as donor funding depletes and the Government is required to fund more of the overall program budget. Other national programs have experienced significant success when implemented through international and national facilitating partners, but this is a non-sustainable format, as the skills are not sufficiently transferred to government to ensure continued implementation in the absence of the facilitating partners.

Therefore, the approach to be deployed in this Component will be provision of targeted and limited technical assistance to the DAIL offices through facilitating partners at the provincial and district levels. The majority of the external assistance will be provided to the DAIL staff through training to be held at provincial and district levels. This training of trainers will be consistent and complementary with on-going capacity building and change management activities within MAIL, and will ensure that the changes being driven from the centre based on the needs at the sub-national level will be incorporated into the overall training for the implementation of the Component. The implementation of the FFL Component then becomes a conduit for change management as well as an avenue to build the technical capacities of the DAIL staff. The facilitating partners, when not training at provincial level, will be expected to form mobile teams with the provincial DAIL staff and provide support at district level. 


\subsubsection{Implementation Plan}

The implementation plan briefly links the implementation modality, outreach and governance structure of FFL to portray how the interventions of FFL will be deployed at the national and sub-national level using the Outreach mechanism.

- Policies will be formulated and developed at the national level by the relevant Program governance structures and MAIL departments, in accordance with higher-level national policies derived from the Afghanistan National Development Strategy (ANDS), National Agriculture Development Framework (NADF) and other ARD strategic frameworks. National-level management and decentralized outreach through the provinces to the districts will ensure adherence to policy.

- The coordinated planning process through the outreach mechanism will identify priorities and needs in all farming groups (beneficiaries), undertake district profiling and needs assessment and collecting baseline information. This will be aggregated to plan coordinated delivery of adapted and packaged technical and input services;

- At times entering through DDAs and CDCs on a need basis, existing farmers' groups, associations and cooperatives will be used for initial assessments and baseline information. New farmers' groups will also be created and the existing ones will be strengthened to facilitate the profiling, planning and further implementation of the Program;

- Aggregated plans and assessments will be passed to the provincial DAIL departments (subject matter specialists) from the districts, where aggregated implementation plans will be formulated and prepared;

- The plans will be constructed according to the specific needs of district-level groups, and will be used to identify and procure the resources as well as the type of services and inputs required. Planning at this level will be guided by policy that will be informed by district profiling and other sources of information;

- The services and inputs will include support in: cereals, legumes and oilseeds; horticulture and livestock; food security and nutrition; emergency preparedness; integrated pest management; and dryland farming;

- Delivery mechanisms will include: DAIL offices; information centres; demonstration farms; agriculture depots; VFUs; and Kuchi service centres, and all other relevant private sector enterprises. Many of these will require rehabilitation and capacity development that will be provided through the implementation of the model;

- Field-level implementation teams will comprise specialists across each sub-component area of expertise, including DAIL and DRRD staff, whose responsibility will be to oversee the coordinated implementation and delivery of services;

- These specialists will work closely with their counterpart subject matter specialists, both nationallevel officials and external technical advisors. They will ensure appropriate planning is coordinated across districts and farming groups (this will be an oversight role where the detailed planning will be carried out by the outreach function), to ensure coordinated planning and delivery of services.

- $\quad$ Provision needs to be made for a comprehensive capacity building program that will be integral with all parts of this Component. Capacity building of MAIL/DAIL functions and organizational change will be a cross-cutting approach that runs throughout the implementation of this Component;

- Program monitoring and oversight will be carried out at the sub-national level and at the national level on a continuous basis to identify bottlenecks, provide additional technical support and inform policy options based on results.

More detailed procurement and implementation plans will be developed upon endorsement of the NPP, as per requirements of the ARTF process. 


\subsection{FFL Sub-Components}

Food for Life is based on the coordinated implementation of 8 Sub-Components that are outlined below. The description of each Sub-Component is covered in three sections:

- Background:analysis of the specific situation and the importance of the Sub-Component in meeting the overall objectivesof FFL;

- Scope: brief presentations of the main aims and core areas of focus for each Sub-Component, including expected results and impact of interventions.

- Deliverables: statement and outline of the main interventions envisioned under each SubComponent.

Detailed implementation plans for each Sub-Component will be developed upon NPP endorsement.

\subsubsection{Sub-Component 1: Data and Information Base}

\subsubsection{Background}

Reliable and up-to-date data and information about the agricultural sector is an indispensable basis for the Government to design, plan, implement, monitor and evaluate food security and other development strategies, programs and projects. It is also deemed important for farmers, traders and other stakeholders to make good decisions. MAIL faces considerable challenges in meeting the obligations to facilitate as well as to directly contribute to the collection, compilation, analysis and dissemination of agricultural and related data and information, and also to use the data and information in the planning and management of the developing activities and programs under its purview.

The collection, compilation and dissemination and use of agricultural data and information, even inside MAIL, have largely been driven by a number of disparately implemented externally funded projects. In most cases, donors did not realise the value of seeking MAIL's cooperation in carrying the projects' activities forward and in linking the projects to MAIL's development program framework until the projects were into or approaching their final stage.

At present, MAIL is supported by four main projects in its effort in improving the agricultural data and information base of the country, namely Strengthening Agricultural Economics, Market Information and Statistical Services (SAEMISS) that focuses on national and sub-national production and marketing data and information; Agro-Meteorological Project that focuses on collecting and disseminating information on the main weather and climatic variable like rainfall, snow, temperature, humidity, sunshine, cloud cover, including assessments on crop conditions; Famine Early Warning System Network (FEWSNET Afghanistan), that undertakes regular collection of data and information on agro-climatic conditions, crop conditions, food commodity markets and trade, water availability, extent of vegetation, and livelihood conditions; Management Information Systems (MIS) Project that provides MAIL leadership with decision-making information that include provincial and national level planning, implementation and $\mathrm{M} \& \mathrm{E}$ data, as well as basic data on agricultural conditions, agrometeorology crop production, market, export-import, and other situational observations. The MIS Project/Unit collaborates with the USDA PAYWAND Project, an Internet portal of up-to-date Afghan agricultural information that uses data from MAIL, the Ministry of Finance's Customs House and other sources. Except for the SAEMISS, the other projects have been implemented almost entirely by contracted staff who have been hired and deployed outside of the Civil Service structure.

In order for MAIL to undertake the planning and subsequent implementation of the FFL and other NPPs, it is important to identify the main thrust areas, programmes, activities and institutional arrangements within which to continue to develop and grow the agricultural data and information system of the country to meet the challenges.At the same time, it is necessary to tie up the many loose ends from the project approaches that dominated the agricultural data and information field over the past decade. It is also necessary to ensure that all prioritized thrusts, programs and activities, whether new or continuing from on-going projects, find room in the data and information base of the Ministry.

\subsubsection{Scope}


The aim of this sub-component is to foster a system that provides data and information on the agricultural and food situation, resources, production, marketing and development programs in an efficient, timely, reliable, gender sensitive, and eventually national-driven manner.

Efforts will focus on strengthening the institutional capacity of MAIL in data collection, analysis and dissemination; coordinating complementary efforts of existing government and donor-led projects in agriculture statistics; initiating and sustaining Afghanistan land cover analysis; strengthening and expanding management information systems (MIS) and establishing gateway to geo-information systems (GIS).

This will result in enhanced collection, assembly, and analysis of agriculture statistics data within MAIL. It will improve the timely diffusion of information about domestic, regional, and international weather, crops, production and market opportunities to a broad array of Afghans by capitalizing on the country's network of radio stations, newspapers, television, and emerging access to the Internet. It is also expected to improve evidence-based policy decisions and early warning systems.

\subsubsection{Deliverables}

\section{Strengthened data and information base institutional framework}

- Design and implementation strategy for FFL's Data and Information Base, based on identified the information needs of key groups within the public and private sectors, and identified and most cost-effective ways of meeting those needs on a self-sustaining basis;

- Implement information users' needs surveys covering the private sector (including farmers/ herders, traders, food processors, and consumers), NGOs, government and donor organizations, and identified the types of information products needed/ desired by each as well as complementary outreach/ training activities the various users desire;

- Implement institutional analysis for linkage of policy analysis, planning, implementation and M\&E units with information units, putting emphasis on developing ability to maintain objectivity of information collection, compilation and analysis, access to information and results of analyses by policy makers; and ability to easily coordinate data needs for the analysis with the data collection activities of the decentralized market information system;

- Initiate "Afghanistan Agricultural Outlook Conference" to bring together key data information base stakeholders to share information and tactics useful in developing improved production and marketing and related forecasts. Serves as an important venue for stakeholders to meet, become acquainted, exchange commercial and other information, and transact business.

\section{Afghanistan land cover change analysis}

- Cost effective land cover surveys will be carried out building on the current EU project by end of 2012, to cover all the land classes in Afghanistan. Special attention will be given to analysis of agricultural land, natural vegetation and urban areas paying particular attention to spatial and temporal changes.

\section{Agricultural production, marketing, trade and export data}

- Precision and timeliness of collection and dissemination of data and information will be improved and commodity coverage will be progressively expanded from only cereal crops to horticulture, livestock and other enterprises;

- Data and information will be made more specific to points on the value chain and the characteristics of the clients, including women clients;

- Appropriate training will be provided, and a civil service cadre position for agricultural data and information will be created in the Provincial Planning Unit.

\section{Agro-meteorology and early warning system}

- Understanding and predictive capacity on climatic, weather and other pertinent factors on food security and risk mitigation and management will be improved;

- Data collection for precipitation, temperature and crop stages will be improved;

- Compilation of agri-relevant hydrological data and inventorying of irrigation systems and their status will be undertaken in collaboration with Ministry of Energy and Water (MEW);

- Analytical capacity for tracing long-term climate change as well as detecting early warning signals will be developed; 
- Regional collaboration on climate change and early warning will be promoted;

- Dissemination of monthly and seasonal bulletins on current weather and agricultural operations more efficiently and effectively by the end of 2015 .

\section{Management information systems}

- Analysis, planning, implementation, monitoring and evaluation and decision-making in MAIL as well as in supporting Cluster Ministries will be facilitated through a computerised and online Management Information System (MIS) that is being developed and will fully operational by the end of 2015;

- This will service all operations in MAIL and specifically will conduct performance tracking of MAIL projects and programmes, produce demand driven data and information, and collect and collate early warning data from various sources around the country;

- Improving the rapidity of data collection and analysis through establishment of electronic links between MAIL and DAIL, and developing information management software for routines to automatically generate standard features of information reports.

\section{Information gateway togeo-spatial information system}

- An integrated solution for spatial and non-spatial information management will be developed and managed by MAIL by the end of 2015;

- The system will deliver collection, formatting, storage and publication of relevant information.

\section{System for surveys}

- System for agriculture production and marketing surveys will be improved to enable more accurate assessments on food surpluses at farm level.

- FFL stipulates an increase in production and marketable surplus at farm levels. These need to be assessed for agronomic and economic prospects for various types of farming systems on a regular basis. The Sub-Component will also support commodity-specific value chain analysis and commodity specific marketing studies.

\subsubsection{Sub-Component 2: Cereals, Legumes and Oilseeds}

\subsubsection{Background}

Wheat. Wheat is the main cereal and staple crop in Afghanistan. It accounts for more than $70 \%$ of total cereal consumption and is grown on about $57 \%$ of the cultivated land. The majority of Afghan farmers are small landowners or landless labourers and most arable land is used for growing wheat as the main staple food. Their low productivity, low engagement in post-harvest processing, poor market links and lack of income diversification contributes to their high level of poverty and food insecurity.

This year, the average yield per hectare is $2.65 \mathrm{MT}$ under irrigated conditions and 0.3 MT under rainfed conditions. As water is in short supply, there is a need to improve productivity by best utilizing available water (both irrigated and rain-fed), by demonstrating best practices and supply of modern inputs and machinery to farmers and encouraging their adoption in order to achieve higher crop yields per hectare. The total current requirement for wheat is estimated at 5.2 million MT as human food (about $160 \mathrm{~kg} / \mathrm{capita}$ ) and 328 thousand MT as seed annually. If the average yields could be raised from 2.5 MT/ha to a still modest 4.5 MT/ha, present demand for imported wheat could be significantly reduced for most years.

Support to the wheat sector in Afghanistan has been focused around the subsidized input distribution programs (seed and fertilizer) and concentrated on attempts to increase production in high productivity areas. This one-sided approach will not assist in increasing the availability of home-grown wheat, increasing self-sufficiency and making Afghanistan less dependent on wheat imports.

Integrated crop production and management technology is the simplest way to handle the complex problem of production, productivity, profitability and sustainability. In this integrated approach various components such as inclusion of high yielding varieties in cultivation, adoption of appropriate agronomical approaches, management of soil fertility, weed eradication, adoption of appropriate crop rotation, management of diseases and pests, introduction of post-harvest techniques, and introduction of modern storages techniques etc. shall be implemented by the farming communities. This approach 
may facilitate the farming communities with increase in seed yields, and a sustainable and profitable production system.

Since 2005, the formal seed sector has developed rapidly with the establishment of over 100 private seed enterprises, producing 30,000 MT of wheat seed in the 2011 season. In parallel with this expansion, the technical support services of variety evaluation and seed quality control have also been strengthened. One key element in the seed policy was the formation of a National Seed Committee with overall responsibility for managing the seed sector, in accordance with the policy. Another important milestone was the passing of the Seed Law in 2009, which provides a legal basis to the seed industry. The Law also gave legal status to the National Seed Committee and renamed it as the 'National Seed Board'. The National Seed Policy is currently undergoing revision to take account of the present situation and to chart a course for future development.

Research. The need for adaptive research is apparent in the current, outdated farming practices across Afghanistan. In the wheat sector, the negligence of rainfed farming systems is particularly stark. Afghanistan used to have its agricultural research organized following its agro-ecological zones that has not seen the necessary investment in infrastructure rehabilitation and human resources development for a significant period of time. The design of ongoing and pipeline projects has greatly suffered from a lack of common understanding of Afghan farming systems, their strengths, weaknesses and development potentials.

Although the Research Department of MAIL still continues variety trials, no new variety of rice has been released since 2003. More efforts should therefore be made to release new improved varieties that benefit both rice farmers and consumers.

Extension. MAIL has a total of around 1,000 extension agents working in provinces around the country. Neither number nor quality of the extension agents is considered sufficient. The messages and/or extension packages offered to farmers are often neither relevant nor sustainable. Development of technical content (messages/packages) has to go hand in hand with the right communication techniques and media. For adaptation of new technologies and best farming practices there is a need for close interaction between farmers and extension agents. The institutional changes that are recommended through other programs can be applied with a specific view for the needs of wheat farming systems. Learning and changes will be required all along the wheat value chain.

Inadequacies in post-harvest operations, infrastructure, quality of production, and food insecurity further add to the problems in the agriculture sector. High losses after harvesting (15\% for wheat farmers) are due to: improper handling, threshing and cleaning, poor storage; lack of skills for quality processing; poor quality control, also for food safety; limited transport facilities (road infrastructure); insufficient milling capacity; lack of good packaging or labelling equipment; inadequate hygiene practices; lack of cold chains.

Rice. Rice is the second most important cereal crop of Afghanistan after wheat and also an important summer crop after wheat cultivation for food security and a source of income, especially for small scale farmers in rice cultivated provinces across Afghanistan i.e. Kunduz, Baghlan, Takhar, Balkh, Nangarhar, Kunar, Laghman and Herat. As the survey by one of the rice projects of the Ministry shows, a wide range of rice varieties are grown by farmers. Most of them are scattered across the rice growing regions and only a few varieties are widely grown all over the country. Many paddy varieties of rice have been released in Afghanistan from 1970-75 and 1996 to 2003.

The total cultivated area of rice is 208,000 ha (2010-11) with the total production of 481,000 MT/ha (2010-11) and the average yield of $2.31 \mathrm{MT} / \mathrm{ha}$. This yield is relatively low compared to neighboring countries where yields of up to $8 \mathrm{MT} / \mathrm{ha}$ are achieved. Additionally, the Afghan rice cannot compete with the rice imported from Pakistan in either value or quality. Low productivity and poor quality contribute to the widening gap between the increasing domestic consumption and the amount of Afghan rice consumed, resulting in more reliance on imports.

Rice-based Agriculture Development in Afghanistan (RIPA) supported by JICA has commenced from May 2011 for five years, expanding the target areas to major eight rice growing provinces (Nangarhar, Kunar, Lagman, Kunduz, Takhar, Baghlan, Balkh, Herat), which produce almost $90 \%$ of rice in Afghanistan. This project aims to improve rice cultivation techniques suitable for the target areas and 
to identify varieties that are compatible with the market needs by strengthening the collaboration between research and extension work and to establish the extension model of improved rice cultivation techniques at the national level. MAIL will continue to work with RIPA to build internal skills and ensure that support can be provided to rice farmers in a sustainable manner.

Challenges in rice production: The main problems faced by rice farmers are lack of: proper knowledge both for the cultivation and the processing; agricultural machinery for the rice production; improved varieties and quality seed; irrigation systems; facilities for paddy processing; quality and affordable fertilizer; trained personnel in rice research and extension;

Maize. Maize is the third most important cereal crop of Afghanistan after wheat and rice. It covers about $6.5 \%$ of the total cereal area of the country and accounts for about $6.8 \%$ of total cereal production of Afghanistan (MAIL, 2011). Even though historically maize has been an important crop of Afghanistan, its production in recent years has not increased.

The productivity reached close to 3 MT in 2002, remained between two and two and a half tones during 2006 to 2010 and sank to a low of 1.6 MT in 2011. Similarly, total production has remained less than half a million ton being only 0.3 million MT in 2011. Table A (below) depicts maize production, productivity figures in the region to indicate what should easily be achievable under our agro-climatic conditions with available new technology.

However, even with this low productivity maize production has been sufficient for domestic food grain needs. Maize has more potential than what it has currently been utilized for. Maize is a highly remunerative crop for farmers as well as for industries. It is a crop whose all plant parts have specific domestic and/or industrial use. An increase in maize production will not just meet traditional domestic needs but will fuel growth of several industries.

Challenges in maize production: The major challenges facing maize in the country include nonavailability of quality seed, appropriate extension activities and non-availability of quality and quantity inputs at the right time. Poor mechanization, inadequate storage, infrastructure, market support, credit etc. further stifle crop growing and processing activities.

Soya. Afghanistan is currently a small producer of the world's supply of soybeans. It is expected that the estimated production of soybeans will be 5,000 MT in Afghanistan in 2012. Furthermore, Afghanistan imports more than $90 \%$ (over 180,000 MT) of the vegetable oil it consumes each year. However, the country's farmers cannot take advantage of this huge potential market because they lack access to suitable oilseed crop varieties and good quality seed. Introduction of these varieties, coupled with suitable methods of cultivation, could encourage farmers to adopt soybean as a new cash crop.

Soybean can offer a profitable alternative summer crop with high-yield potentials as well as nutritious and commercial benefits, as a substitute for meat, eggs and milk; has number marketing potentials in farm of oil, animal feed, soy flour, tofu, etc; and soybean is a short duration summer crop that has a very high yield potential, low dependence on chemical fertilizer, irrigation water and other inputs. The climatic conditions, temperature ranges, and moisture regimes are suited for soybean cultivation in most of the provinces in eastern, central, western, northern and southern regions.

After successes in soybean introduction and production during 2004 to 2006 by NIE and MAIL, in 2010, soybean farming was introduced to all 34 provinces. About 10,000 farmers were trained on soybean production jointly by MAIL Extension and NEI and harvested 2,000 tons. This result led soybean to be designated by MAIL as an official "staple crop." In 2009 and 2010, the Japanese Government awarded a special grant to support soybean production among farmers in 15 provinces and train housewives, especially pregnant and lactating mothers, on home use of soybeans. The Korean Government donated 7 new varieties of soybean to be tested along with 5 new US varieties for adaptability by MAIL Research and occurred in 10 research stations from 2009 to 2011, funded by the Japanese Government. The trials developed a few new varieties that are currently under review. Results are scheduled to be released by the National Seed Commission in 2012. The Baston Seed Company also opened the doors of a new soybean processing facility in Bagram in April 2011.

Challenges to soybean production: Major challenges include: farming communities have not understood properly the nature of soybean cultivation, its commercialization and marketing; the 
appropriate and well adapted varieties to Afghanistan's environments are not available; farming communities are not well acquainted with the pattern of cropping system and production technology; processing facilities for Soya products such as extraction of edible oil and its refinement and commercialization are lacking.

Legumes. Food legumes provide an important opportunity to contribute to food security and nutrition in a sustainable manner, through intensification and diversification of agricultural systems. In addition to their role in human nutrition, they are valuable sources of animal feed and an integral part of croplivestock farming systems in the developing world.

Because of their ability to fix atmospheric nitrogen through symbiotic nitrogen fixing, the legumes play a significant role in crop rotation, improving the soil health, diversifying cropping systems and maintaining soil fertility to sustain agricultural production systems.

Food legumes are commonly known as "Poor Man's Meat" because of their high protein content (17$35 \%$ ), low price as compared to meat, and thus have widespread use by the poor. These crops also contain high proportion of macro and micronutrients $(\mathrm{Ca}, \mathrm{P}, \mathrm{K}, \mathrm{Fe}, \mathrm{Zn}$ ), vitamins (niacin, Vitamin $\mathrm{A}$, Ascorbic Acid, Inositol), fibre and carbohydrates for balanced nutrition. Food legumes are rich in lysine, an essential amino acid that is low in cereal protein. On the contrary, sulphur-containing essential amino acids (methionine, cystine and tryptophan) are high in cereals and low in legumes. Therefore intake of cereal and legumes together gives complementarities in amino acid balance in foods. Nutrition from food legumes also lowers cholesterol level and their carbohydrates are good for diabetes.

Currently, only an estimated 40,000 to 50,000 ha are devoted to pulse production in the country, as farmers are not aware of the value of such crops. By undertaking crop rotation it will not be necessary to dedicate additional acreage of farmlands to the growing of pulses and legumes.

To enhance breeding efficiency, biotechnological tools, most particularly molecular-marker technology can be employed to tag key desirable genes, and effective use of marker-assisted selection will be carried out. These efforts can be made cost effective and rapid through close collaboration with international centres.

Oilseeds. Afghanistan imports more than $90 \%$ (over 180,000 tons) of the vegetable oil it consumes each year. The country's farmers can take advantage of this huge potential market if they are facilitated to have access to suitable oilseed crop varieties, good quality seed, and processing and other postharvest handling and marketing amenities. Overcoming these challenges could help farmers abandon poppy farming in favour of oilseed cash crops.

Researchers have evaluated the performance of new oilseed crops as well as new varieties of the oilseed crops that some farmers are already growing. Crops, both on-farm and at research stations, tested include soybean, peanut, sunflower, maize, canola, safflower, linseed, flax, cotton and sesame.

Research will be continued and expanded to assess different varieties of these crops. Among the new oilseed crops, canola grow particularly well in Northern Afghanistan when sown in the fall, and could also grow well even in dry areas if sown in the late winter and early spring. The crops is relatively easy to grow and thresh, and have a high content of good quality oil - up to $40 \%$ in some varieties. Safflower is another promising oilseed crop which is extremely drought-resistant and is well-adapted to dryland cropping. Safflower seed also has high oil content - up to $41 \%$ in some varieties. Early results indicate that safflower can be grown successfully when planted as an early spring crop. However, even better results might be obtained through planting as a fall crop, thus maximizing the use of winter rains in dryland areas.

Among, existing crops sesame has very strong potential for expansion in dryland areas as it is a particularly drought-resistant oilseed. It is also often planted after winter wheat, and thus increasing the potential for increased land productivity and cash income. Sesame is the preferred oil for making pulau, the national rice and meat dish. Afghanistan sesame oil is also on demand in international markets, and is exported in substantial quantities as far as Turkey. Although sesame oil is the most expensive on the market, it tends to be in short supply. This means that sesame could be a profitable crop. 


\subsubsection{Scope}

Under the framework of the Cereals, Legumes and Oilseeds Sub-component, the aim is to increase the yield and total production of cereals (wheat, rice, maize), legumes (lentils, peas, beans) and oilseeds (flax, linseed, sesame, sunflower, cottonseed, olive, etc) at national level with support to subsistence and semi-commercial farmers. Wheat being the main staple crop that accounts for more than $70 \%$ of cereal consumption will be given the highest priority, while other crops (e.g. rice, legumes and oilseeds) will assume a targeted approach based on cultivation contexts, crop rotation mechanisms, nutrition targets, market and value chain opportunities. Development of a Wheat Sector Policy and Programme by end 2012 will be at the forefront of the Government's agenda. The Wheat Sector Policy and Programme Framework be the main vehicle for moving the various facets of FFL that are related to wheat.

Efforts will focus on improving research and extension capacity at the sub-national level with increased linkages between the two. Adaptive and demand-driven research techniques focusing on famers and farmer group, especially women' needs will be introduced. New and sustainable varieties of seed, technologies and farming system mechanization at the pre and post harvest times to increase yield, reduce cost and harvest losses will also be introduced. Linkages to existing input distribution systems (i.e. farm stores, a depots) and encourage demand-driven and market-oriented private sector investments for inputs (e.g. seed, fertilizer), mechanization and value-chain services will be established and strengthened. Synergies with the current projects such as IAIDS will be closely built to ensure a unified policy approach.

The interventions will result in increased wheat yield in irrigated and rain-fed cultivated areas (sustained annual production of 5.5 MT of wheat by 2015), reduced post-harvest losses, increased farmers' capacity to sustainable farming systems, and an extension system that is accessible to farmers and famer groups throughout the country. The farmers will be enabled to access better inputs, knowledge and awareness about other potential cereal crops, rice cultivation methods and seed varieties, as well as legumes and oilseeds for nutrition and income opportunities.

\subsubsection{Deliverables}

\section{Wheat and rice policies and strategies development}

- Guiding policy framework for the wheat sector development activities, its components and all related activities established and implemented at provincial and district level;

- National Rice Development Strategy developed and implemented at provincial and district level;

- Considering the requirements to achieve food security at national, provincial, and household level, the NRDS will play a very important role. Building on the on-going JICA rice project, FFL will further assist in formulating strategies on the development and expansion of improved techniques for rice cultivation at the national level.

\section{Research capacity rehabilitation and development}

- Adaptation of existing research to the Afghan context and development of related packages and extension messages;

- Infrastructure and human research capacity development;

- Establishment of top-class (wheat) research capacity, basic and adaptive research for all agroecological zones and farming systems;

- During last few years, 4 new maize varieties have been developed, which have yielded from 5 to $6 \mathrm{MT} / \mathrm{ha}$ in various national trials conducted for 3 years. The activity to bring in new genotypes should continue. Furthermore, information on package of practices to be adopted for best possible harvest under a given agro-climatic condition and planting date needs to be developed. Package of practices for disease and insect pest management of the crop will be developed. Well-researched and confirmed extension messages covering all aspects of maize production will be developed for all the agro climatic zones. International collaborations in Maize research will also be conducted;

- Support for applied soybean and oilseeds research programs and regional stations (i.e. yield testing, experimental applications, plant breeding and pathology management).

\section{Improved extension services and networks}


- Development of an adapted extension approach to reach un-served and underserved wheat farmers, and introduction of innovative extension approaches adapted to the Afghan context;

- Research and extension services for rice strengthened at provincial level to ensure sustainable increases in rice production, from seed supply to post-harvesting;

- Facilitate knowledge/ technology transfer and access to quality inputs, farm tools and equipment;

- Conduct training and establish demonstration sites at district level;

- Conduct outreach on the utilization of soy products for human consumption and animal feeding.

\section{Establishment of regional rice stations}

- $\quad$ Regional rice stations established and fully operational by the end of 2015;

- It is envisaged that a minimum of 4 regional centres will be required (East, North, North East and West), if not one in each targeted province, where the existing research stations of MAIL could be utilized. In order to strengthen the research capacity of those regional rice stations, human as well as physical capacity (facilities and equipment) will be improved

Improved supply of quality inputs (seeds, fertilizers, agro-chemicals)

- Implement lessons learnt and follow-up on the National Wheat Seed Distribution Program with further dissemination of seeds (from previous distributions);

- When rice extension activities move to the next stage (i.e. from demonstration farms to farmers' fields), critical issues of quality input supply for farmers will be identified and actions coordinated with other initiatives of FFL to ensure quality inputs supply to farmers;

- Training on maize production management and farmer field demonstrations will be organized for extension workers in maize regions. The right quality and quantity of inputs will be made available at planting time through extension workers to ensure a sustained supply of critical inputs needed for maize crop so that gains demonstrated in the plots are achieved by farmers. MAIL also needs to ensure proper legislation and enable a business environment for growth of these markets. Initially, before establishing a national maize seed certification system, maize farmers will be trained on various issues of quality seed production and storage;

- Better established linkages to existing input distribution systems such as Farm Stores and Ag Depots, assessment of these systems and possible integration in activities.

\section{Improved post harvest practices, processing and marketing}

- Reduced post-harvest losses through improved dissemination of advanced processing technologies at local farming level;

- Post-harvest practices for rice improved at farmer level and throughout the distribution chain.

- Further studies will be conducted and strategies to improve post-harvest practices of the country will be developed;

- Support for the establishment and management of soybeans and soy products processing facilities (i.e. oil extraction and refinement, soya milk and flour, soya nutritional feeds);

- Support for the establishment and capacity development of soya growers and processors associations.

\subsubsection{Sub-Component 3: Horticulture}

\subsubsection{Background}

Afghan dried fruits (mainly almonds and apricots) accounted for more than half of the world market in 1982, but declined to $16 \%$ in 1990. Although the share of the world market is much lower now, Afghan Pistachios rank \#7, Almonds \#11 and Apricots \#16 in world production according to FAO-STAT 2010 data. However, the focus on food crops for international export markets at the expense of perennial crops has resulted in a horticulture industry that is becoming unbalanced and underdeveloped particularly for the home market and especially in locations distant from market centres or in places unsuitable for production of exportable fruits and nuts. Today, Afghanistan imports large volumes of vegetables and fruits that could be domestically grown. There are many opportunities for growing more fruit and vegetables locally, which would provide employment and economic development opportunities. Furthermore, traditional as well as modern gene-pool preservation and management systems have been strained and many have collapsed during decades of conflict. 
If well managed, the returns to the farmer on the various fruit and nut crops can easily exceed the returns he receives on the illicit opium crops. The promising opportunities for Afghan horticulture are based on the fact that Afghanistan has outstanding climatic conditions for fruit production, a unique competitive advantage. Fresh grapes, raisins, almonds, pistachios, fresh and dried apricots and pomegranates are among the most promising crops at present, with cherries and citrus fruits offering potential for the future. With appropriate extension support, the private sector is expected to lead the modernisation of the horticulture industry. Direct employment opportunities are increased through activities such as weeding, harvesting, sorting and processing. Peri-urban horticultural crop production, and the associated markets and processing facilities can also help supplement income and employment among the poor and disadvantage in urban areas.

Horticultural crops also have a significant role to play in the rehabilitation, efficiencies in land use and conservation of Afghanistan's network of fragile mountain ecosystems and the establishment of sustainable farming systems. Fruit trees such as pistachio and almond have been a part of the Afghan agro-economic production and conservation systems for centuries, facilitating optimal use of scarce water resources and marginal land, and providing and sustaining incomes and livelihoods even in years of extreme drought or crop loss.

In 2011, the area planted to vegetables and fruits is estimated to be 128,000 ha and 119,000 ha, respectively (MAIL, 2011). Between 2006 and 2009, the country has regained some of the lost ground and become the $7^{\text {th }}$ largest exporter of raisins (US\$150 million and the $11^{\text {th }}$ largest exporter of almonds - US\$110 million). Fruit \& nuts constitute 35\% of Afghanistan's total exports. New production programs like HLP, CHAMP and IDEA-NEW ${ }^{2}$. Current production is consumed locally or shipped to major Afghan markets. A small fraction is exported "bulk", in poor packaging, un-graded and to border markets like Quetta and Peshawar. Without the development of new markets, the increased production capacity will be delivered to these same markets. Prices will drop and farmers will suffer a setback. Moreover, the valuable germplasm collection of Afghan fruit varieties has been collected and is being enriched with the EU support ${ }^{3}$ and the establishment of an extensive extension and farmers support network is in progress with the help of the World Bank. ${ }^{4}$

Challenges in the horticulture sector: The key challenges for the horticulture sector have been summarized as follows: unreliable off-farm water schemes, slow construction of irrigation systems and inefficient catchment and storage of water; limed demand-led research applicable to support the horticulture production sector; insufficient baseline data, reliable data bases and market information for sound policy planning and business decisions; use of inferior varieties and mixtures of varieties that do not allow consistent high-quality products delivered to markets; low knowledge and skills base among producers, service providers and consumers; limited supply of quality inputs and services, especially for diversifying to specialized and higher-value crops; negative effect of low quality sapling and seeds (including from other countries); fragmentation and low capabilities of production, processing and commercialization chains; insufficient availability of credit; and insufficient and outdated legal and regulatory system to strengthen food safety, certification for export, development of grades and standards, and create national marketing entities.

\subsubsection{Scope}

Promoting sustainable increase in horticulture crop production and productivity, including development of high-value crops (like raisins and almonds), and improved rural livelihoods at the community and market level are the aims of this sub-component.

As with the cereals sub-component, interventions will promote technology development for horticultural production through adaptive research and technology transfer through improved and expanded extension services. Efforts will focus on potential export commodities like almonds, raisins, pistachio and pomegranate to boost production, value-chains and market linkages with complementary support from EMD interventions. A streamlined approach with NPP-1 irrigation activities will also be undertaken to address irrigation challenges to the horticulture sector.

\footnotetext{
${ }^{2}$ Horticulture and Livestock Project (HLP), Commercial Horticulture and Agricultural Marketing Program (CHAMP), and Incentives Driving Economic Alternatives - North, East \& West (IDEA-NEW).

${ }^{3}$ Perennial Horticulture Development Project, Phase I and II (2006-2015).

${ }^{4}$ Horticulture \& Livestock Project, Phase I and II (2007-2017).
} 
Existing market information systems will be enhanced to improve geographic spread, appropriateness, accuracy and timeliness by the end of 2015. The strengthening of public sector institutional capacity and increased social mobilization will result in community and agriculture organizations development. Orchards and vineyards around the country will be rehabilitated and higher standards of production will be achieved to obtain higher market prices by the end of 2015. MAIL will seek to establish partnerships and synergies with all on-going horticultural projects and will build upon best practices to expand the extension to other potential provinces and districts.

\subsubsection{Deliverables}

\section{Applied and adaptive research programmes to promote technology development for} horticultural production

- Adaptive varietal research through renovated research systems for the support of commercial farming will be improved by the end of 2015 ;

- The development of technologies is based on adaptive research, which is geared towards finding the right varieties for the different areas and different seasons, and will include varieties for fresh produce markets, for sequential harvesting and for cold storage, for drying and for other methods of preservation and marketing. Some areas for expansion have already been identified and new varieties of fruit have been imported for testing. Other priority areas for research include genetic resources and variety development, integrated production technology, crop improvement and pest control measures, and development and promotion of integrated pest management to safeguard both the crops and the export markets. Systems of research and technology transfer will be developed and put in place to ensure that sufficient technical competences and trained personnel are available in all sectors and levels of the perennial horticulture industry, both public and private;

- Through this Sub-Component, MAIL will support the establishment and renovation of research systems for the support of commercial farming, including capital investments and research activities to support soil testing and amelioration as well as identification of pollinators. Furthermore, MAIL will focus international collaboration on research and extracting lessons learned from other countries for best utilization of resources and developing demand-led adaptive research programs;

- MAIL will also seek to support the development of a sustainable horticulture industry based on international and national phyto-sanitary standards. This includes the introduction and widespread use of improved varieties and building the technical capacity of the public sector for quality control and the private sector for operation of the nurseries and distribution businesses. This will be combined with evaluation trials to ensure yield and quality of new materials;

- This Sub-Component will include activities to preserve the National Collection of fruit germplasm and sustain the ongoing identification, characterization and evaluation of the local genetic resources and the on-going popular cultivars. To date, a number of species and accessions have been maintained, described and evaluated, including as per international standards. Similar activities will be continued and expanded. Furthermore, the most promising varieties and rootstocks will continue to be released to the private nursery industry for multiplication and propagation. MAIL will also oversee the import of some varieties and germplasm lines from international research organizations and countries with similar climatic conditions.

Development, transfer and adoption of improved horticulture production technology, through improved formal extension services

- Demonstration sites, extension services and skills training will be enhanced through the country at provincial and district level by the end of 2015;

- MAIL will seek to establish partnerships and synergies with all horticultural projects that are conducting extension activities. Furthermore, systems for distribution of farm inputs and planting material will be developed in a public-private sector partnership and the farmers trained in proper techniques for production of additional planting material. MAIL agricultural extension agents will also be trained to include vegetable production technology as an integral component to farm activities;

Orchard rehabilitation and comprehensive horticulture planting and re-plantingto increase horticulture production and productivity 
- Orchards and vineyards around the country will have been rehabilitated and higher standards of production will have been achieved to obtain higher market prices by the end of 2015;

- This will support short-term interventions to increase the speed of new orchard planting. This will go hand in hand with interventions (essential inputs) for higher productivity of the orchards with improved orchard systems and applications of soil irrigation, pest and disease control sciences, backed by appropriate regulatory systems. Specific activities will include, but not limited to, rehabilitation and upgrading of poorly-managed and unproductive existing orchards and vineyards; establishment of new horticulture crops, vineyards and commercial orchards (medium and high-density); establishment of trellis system in vineyards and vegetable gardens; accelerated development programs for currently minor crops such as citrus, cherries, and pears; and promotion of new horticulture crops (off-season vegetable production using greenhouse technology).MAIL will also assist in identifying appropriate growing areas defined for major horticulture crops ('zoning'), taking into account climate, soils, water and other factors and it will facilitate that the required technologies and input and service provision are available.

Established post-harvest and commercialization systems, including collection and dissemination of sustainable horticulture production and market information

- Existing market information systems will be enhanced to improve geographic spread, appropriateness, accuracy and timeliness by the end of 2015 ;

- MAIL, in consultation with its partners, will collect and disseminate horticulture production information, including but not limited to, fruit crop production data; price and weather-related information and statistics. It will also conduct specialized horticulture surveys based on administrative report (in the case of area coverage) and representative sampling methodology (for estimation of fruit yield per unit area) to map horticultural production in the country. This would establish the current level of activities in all fields of horticulture including the marketing patterns of the various products. It would also assist in identifying development bottlenecks and input and service provision gaps.Activities undertaken in this area will be implemented through SubComponent 1;

- $\quad$ Post-harvest and commercialization systems: specific activities will include, but not limited to, promoting picking, grading, packing and storing techniques and technology; improving drying techniques and inputs for apricots and raisins; facilitate the establishment of fruit and vegetable processing units, low-cost pre-cooling facilities, private packing houses and cold storage facilities; support for the creation of a refrigerated containers transport service centre; capacity building activities at field level for all stakeholders involved in handling and marketing of horticultural crop products; local marketing of crops to facilitate import substitution and export to regional and international markets; and promotion of agribusiness entrepreneurship;

- MAIL will also facilitate improvements in food safety certification, export documentation, and marketing certifications. MAIL will coordinate with the Ministry of Commerce and Industry, and develop innovative public-private sector partnerships for streamlining export documentation. MAIL will also establish a certification authority (for both seed and planting material), including the setting up of laboratories, training of staff and all other aspects of a regulatory system that meet international standards. Furthermore, MAIL will seek to leverage synergies and programming linkages with the Enterprise and Market Development Component in order to create an enabling environment for the development of marketing linkages among farmers, traders and wholesale markets through growers association and specialized farmers.

Strengthenedpublic sector institutional capacity, and increase social mobilization through community and agricultural organizations development.

- Institutional capacity for operational support in extension, research for the promotion of good practice and mobilisation of horticultural farmer groups will be increased by the end of 2015;

- Institutional Development: Efforts to improve institutional and capacity development across MAIL are underway and there is satisfactory progress to date. The Sub-Component will notably leverage synergies with the Change Management process that is taking place across MAIL in support of institutional reform and capacity development. Specific activities will include, but not limited to, capacity-building and operational support for MAIL horticulture, extension, quarantine and research services; recruitment and retention of horticulture experts in MAIL, and creation of horticulturist positions at the provincial and district levels; promotion of agriculture education and training programs; development of formal and informal training institutions; and development of planting material quality control legislation and services provision; 
- Social mobilization: MAIL will work to create an enabling environment to further structure the professional horticulture sector, notably by facilitating capacity development support for organizing independent agricultural organizations and cooperatives, and promoting the emergence of sustainable farmer, producer and nursery grower associations. There will be synergies and programming linkages with the Cooperatives Support Program for Agricultural Development in order to build the capacity of producer cooperatives to develop into sustainable agribusinesses.

\subsubsection{Sub-Component 4: Livestock}

\subsubsection{Background}

Currently, $80 \%$ of Afghanistan's population resides in rural areas and of these, $8 \%$ are considered to be extensive livestock producers (about $5.5 \%$ of total population). There are two major livestock production systems in Afghanistan: a) The nomadic or semi-nomadic system involving Kuchi pastoralists; and b) sedentary farmers with variable numbers of small ruminants.

What is apparent is that if this traditional form of pastoralism is to survive, the Kuchi will need to invest in supplementing the diets of their animals, during the winter months, in order to avoid losses of up to $10-15 \%$ in the bodyweight of their animals at this time of the year. Such investments in feeding will have to be linked to marketing animals during the winter in order to maintain sufficient income to offset the cost of winter-feeding. In effect, this means that the traditional all year round extensive management system formerly practiced by the Kuchi will become semi-intensive during the winter, whilst remaining extensive during the summer months.

The sedentary farming system, which is practiced by the vast majority of settled farmers, is a simple mixed farming enterprise which is characterized by the maintenance of small numbers of animals which provide small, but nevertheless important quantities of high protein content foods, milk, eggs and to a lesser extent, meat which are important components of the household diet. Being subsistence in nature, the incentives for investing in health interventions such as preventive vaccination or strategic treatment for control of internal parasites are not usually appreciated by the vast majority of sedentary farmers. The Kuchis, on the other hand, being more dependent on their livestock as a source of income are therefore more knowledgeable and more willing to invest in animal health interventions. These differences in demand for services at the various different levels of the livestock production systems need to be taken into consideration when designing and coordination the establishment of an effective animal health service delivery system.

Already Afghanistan is in a position to export large volumes of hides and skins, wool, cashmere fibres, and intestinal casings for sausage manufacture. In the future value addition can enhance farmers' incomes through processing some of these raw products into higher value commodities, such as leather, carpets, cloth and other products.

In peri-urban areas there is a gradual trend towards specialization in dairying, in order to satisfy the rapid growth in demand for milk and milk products on the urban markets. The FAO has been engaged in a series of Dairy development projects, which have been implemented more or less continuously over the past 15 years. Similarly, semi-commercial and commercial poultry production is also expanding rapidly to meet the same demand for eggs and poultry meat.

In some areas winter fattening of sheep and goats is beginning to take off and will increasingly become a specialized form of semi-commercial production which will not only complement the extensive production of sheep and goats on the upland rangelands, it will also help to satisfy the growing demand for meat in urban markets and eventually will provide an exportable surplus to regional markets. A feasibility study will be undertaken in order to explore the potential economic and financial returns derived from intensive fodder production and winter-feeding of sheep and goats.

Survey estimates (Schloeder\& Jacobs 2009) suggest that 1,668,800 animals are brought for trade to Afghanistan's six major livestock markets annually. With the exception of cattle, the markets are predominately supplied by livestock originating from the extensive livestock production system under Kuchi management (72.2\% of sheep and $63.7 \%$ of goats). The karakul pelt industry experienced resurgence in 2005, with an estimated 536,000 karakul hides exported from Afghanistan. 
Estimates of the percentage of the small ruminant population owned by Afghanistan's pastoralists, range from $40-50 \%$, based upon the 2003 FAO census and up to $50 \%$ to $60 \%$, according to more recent studies (Schloeder\& Jacobs 2009). Key to the resilience of the Afghan pastoralists, as they have often proved over time, is their mobility and their capacity to adapt to changing circumstances. With $70 \%$ of Afghanistan's landmass qualifying as rangeland (including mountainous and barren land), this use of the landscape and lifestyle easily makes sense. Rangelands suitable for utilization as a grazing resource cover an estimated 45\% Afghanistan's land surface area; they are essential for the socioeconomic development of the country, providing the main feed supply for an estimated 22 million small ruminants (see Livestock population estimates 1967 - 2012), the by-products of which (meat, dairy, wool, dairy and leather) account for more than 50\% of Afghanistan's export revenue. In addition, they provide vital ecosystem support services as water catchment areas, including natural control mechanisms for soil erosion and flooding. They are a unique habitat for wildlife and a globally significant 'carbon sink'. On a subsistence level, they provide a range of products for local people including fire-fuel, fruit, nuts and medicinal plants.

Beekeeping is a farm activity that can be carried out in combination with large-scale commercial horticultural, agricultural and forestry projects as well as on very small-scale enterprises. Honeybees are an important resource essential to agriculture as well as for the well being of the environment. Beekeeping results in the production of honey, bees-wax, and other products that provides a valuable, non-perishable nutritional component to the household diet. In Afghanistan, beekeeping is an important income generating activity with very high potential. Currently, there are 100,000 bee colonies in Afghanistan, yet there is the potential to expand this figure to at least one million bee colonies.

The French Cooperation Office for MAIL (FCOMAIL) has been and will continue to be involved in developing the beekeeping sub-sector in Afghanistan since 2007.

Additionally, there is a good potential in development of fisheries in the country. With the increased number of water reservoirs built within the Component 1 of NPP1, it will bring new and inexpensive opportunities to extend inputs to households and communities in development of fish farms as the project is being implemented.

\subsubsection{Scope}

With $80 \%$ of population residing in rural areas, there are two major livestock production systems in Afghanistan i.e. nomadic and semi-nomadic herds-people, and sedentary farmers with variable degree of small ruminants. Under the framework of this sub-component, FFL aims to increase farmers' knowledge and capacity for production and marketing of poultry products, milk and dairy products, sheep and goat, honey, and fisheries.

Efforts will focus on regulating, monitoring and coordinating animal health service delivery; increasing commercial milk production, productivity, processing and marketing schemes; promoting poultry farms development, increased productivity, and the utilization of poultry slaughter by-products \& waste materials; and enhancing marketing of animal products through value addition and exploitation of domestic and international export markets for meat and animal by-products.

Further efforts will be focused on improving honey production, and extension of fisheries with facilitation of a functioning market supply chain for these productions will be undertaken. FFL will promote responsible use of rangeland resources along the migration routes by intensive and extensive producers, and develop early warning systems to identify impending climatic shocks in order to avoid unnecessary losses due to starvation.

As a result, animal productivity will be raised through improved feeding practices in selected districts for at least 25,000 farmers by the end of 2015, regulations and guidelines for food safety formulated and implemented, and a network of animal disease surveillance and diagnostics centres with oversight from Central Veterinary Diagnostic \& Research Laboratory will be strengthened to deliver effective services to livestock farmers by end 2015 and beyond. Increased number of milk producers' cooperatives will have been developed and strengthened in selected provinces and districts. Kuchi and natural resources management policy will be reviewed and implemented, and dispute and conflict resolution measures will be fully effective by 2015 . 


\subsubsection{Deliverables}

\section{Animal health:}

\section{Animal health service delivery}

- Sustainable, and cost effective "private good" services accessed by the majority of livestock keepers by the end of 2015;

- This includes regulation of animal health service delivery, veterinary education and training, and practice of veterinary medicine by veterinarians and veterinary para-professionals according to international standards. MAIL will also focus on regulation of importation, manufacture, distribution, sale and use of veterinary medicinal products including animal vaccines, according to international standards. Other areas addressed in this deliverable include monitoring and coordination of the expansion of animal health services to reach marginalized farming communities and facilitation of SMEs and service and input supply business through horizontal linkages with other NPPs.

\section{Animal health - disease prevention and control}

- Network of animal disease surveillance and diagnostics centres with oversight from Central Veterinary Diagnostic \& Research Laboratory in Dar-ul-Aman strengthened to deliver effective services to livestock farmers by end 2015 and beyond;

- Disease surveillance, laboratory diagnostic services and the planning and implementation of disease prevention and control programs for selected diseases which have a "public good" benefit - for instance those diseases which can be transmitted from animals to humans (zoonotic diseases), such as Brucellosis, Highly Pathogenic Avian Influenza, Rabies, Glanders or diseases which have an important economic impact on livestock production, such as Foot and Mouth disease. Such prevention and control programs are expensive and should not be attempted unless there is a long-term commitment from government and donors to provide the necessary financial support. Small gains in reduced disease prevalence can be lost overnight when there are gaps in funding or shortfalls in financial resources. Short-term interventions will have little or no benefit and will only be a waste of valuable resources. Import and export regulation of animals and animal products in order to protect national and international markets from the introduction of animal diseases or chemical hazards. This involves Border Inspection, and when necessary quarantine, sampling and testing for certification for safety for animal or human health and the environment.

\section{Veterinary public health}

- $\quad$ Regulation for food safety formulated and implemented by the end of 2015;

- Regulation of food safety for imported and domestically produced products of animal origin. This involves the creation of an inspectorate for ante and post-mortem meat inspection of animals being slaughtered for human consumption, and establishment of laboratory facilities for testing for biological, chemical or physical hazards present in food products derived from animals, both domestically produced and imported. A second inspectorate is in the process of being established at Border Inspection Posts. In the medium to long term it will be necessary to establish Veterinary Inspectorate at all major international border crossing points.

\section{Animal health extension}

- Public/private partnership established to deliver animal health extension services to livestock farmers around the country by the end of 2013;

- Facilitating extension through a public/private partnership enhancing the outreach of existing private animal health service providers to encourage farmers to invest in disease prevention interventions as well as creating public awareness in relation to the prevention of the spread of animal diseases, especially those which are transmitted from animals to humans - this can be achieved through developing innovative mass media message delivery systems utilizing radio, $\mathrm{TV}$, static and mobile exhibitions, demonstration units and road-shows. 
Dairy:

\section{Artificial insemination services}

- Animal health, Artificial Insemination (AI) services and animal husbandry practices for increasing milk production strengthened and made accessible to dairy farmers around the country by end 2015;

- The project will initiate a community-based process in which 25,000 farmers (the same 25,000 who will receive improved fodder seed) are directly involved in animal disease surveillance under the Animal Health element. Communities of farmers will be assisted to improve the status of their livestock by raising their knowledge of the impacts of animal parasites and diseases and on the actions required to combat them. Fattening practices will be demonstrated. The program will also facilitate provision of veterinary services and organize vaccination campaigns through the selection of community members who will be trained as animal health workers and will work within their farmers groups on a cost recovery basis;

- Animal breeding services and artificial insemination (AI) will be facilitated by linking up farmers with the province AI centres in order to upgrade the milk production potential. Local AI technicians will also be trained and equipped and will support the service to the dairy producers community. They will report cases, which need assistance from the animal health staff of the VFUs and thus also contribute to the development of better relationships between farmers and the technical staff as a whole. To cover the cost of the service a financial contribution from the beneficiaries will be included from the very beginning. Over the period of time this contribution will be increased to the full cost, however, it is not expected to reach this level within one year.

\section{Feed resources development}

- Animal productivity raised through improved feeding practices in selected districts for at least 25,000 farmers by the end of 2015;

- The project will select and introduce through 50 demonstrations of improved varieties of fodder (Berseem, Lucerne, sorghum, oats and vetch), and will encourage farmers to raise animal productivity through adopting better feeding practices. Fodder production will be stimulated in selected districts for at least 150 farmers, and eventually expanded in other districts. Selected farmers organized into local community-based cooperatives and will be contracted to produce fodder seeds under strictly monitored conditions. 25,000 livestock owners will receive improved fodder seeds distributed through the cooperative networks being created. Feed processing units and small storage facilities will be established in partnership with private sector entities in order to produce mixed feed on a commercial basis. Assistance in improving winter animal feeding (hay) and housing will also be provided. Timely and affordable delivery of concentrate feed to the dairy farmers will be facilitated either through the establishment of a farmer-owned feed mill or through access to already established private feed mills.

\section{Milk collection and processing}

- Small-scale milk for cash scheme formulated and implemented comprising milk processing units and marketing support in selected districts by end 2015;

- This will assist participating households, in particular women, to sell milk for cash on a regular basis by organizing some 150 milk collection points. New milk processing units with three up to five metric tones capacity will be established in Kandahar, Helmand and Khost for processing of milk into pasteurized milk, yoghurt, butter and butter milk. Also cheese-making machinery will be provided in Baldachin, Saripul, Kunnar and other suitable places depending on identified market demand. This will assist householders, particularly women, to sell milk for cash on a regular basis by providing milk collection and processing services. Members of the public will have access to milk and dairy products at higher standards of hygiene. Technical support services to the farmers, as well as the accumulation of capital for future investment will come from the marketing of the products. The collection of milk and marketing facilities of the existing five dairy unions will upscale and develop to supply dairy products as per demand of the provinces cities of the project targeted area.

\section{Institutional support to community-based dairy cooperatives}

- Legal village level milk producers' cooperatives developed and strengthened in selected provinces and districts by end of 2015 ;

- The project will be closely linked to the Cooperatives Support Program under NPP2 which falls within the Enterprise and Market Development Sub-Component and will assist in the 
establishment of village-level milk producers' cooperatives legally registered under Government regulation, and in the establishment of a dairy union at the provincial level. Cooperatives' leaders will be trained in management, organization, accounting and participatory techniques. All farmers in the targeted villages will be given an opportunity to join the cooperatives. Decisions regarding purchase price for milk and selling prices for cooperative members will make dairy products. Regular meetings will be held in order to inform members on cooperative activities and economic situation. This Component will support and assist farmers to become gathering and as per Government regulations/ law establish cooperatives societies, dairy unions, private sectors and national dairy federation. Technical support services to the farmers, as well as the accumulation of capital for future investment will come from the processing and marketing of the products. Also support dairy unions to form national dairy federation.

\section{Poultry:}

\section{Commercialise backyard poultry farming}

- Small-scale commercial poultry businesses emerged from subsistence production in selected districts around the country by end 2015;

- Create an environment to improve communication and build capacity of women in poultry production who have difficulty in interacting with potential colleagues and customers due to cultural constraints;

- Bring conceptual changes to farmers so as to encourage small-scale commercial poultry farming and to assist poor families to earn cashto fulfil their daily requirement.

\section{Small-scale commercial poultry farming}

- $\quad$ More self-help community development groups formed and supported to achieve independence in selected districts by end 2015;

- Formation of self-help groups to foster community development, gender empowerment and promote the concept of saving money among the poor to build self-confidence and social security in the long term through small scale poultry farm development and to turning the attention of families toward commercialization to able beneficiaries to stand on their own feet.

\section{Sheep \& Goat:}

\section{Public sector reform - institutional development}

- Kuchi and natural resources management policy reviewed and implemented, dispute and conflict resolution fully effective by 2015 ;

- Focus will be on analysis and review of previously identified and agreed roles and responsibilities of the public and private sectors. Review the existing policies, legal and regulatory frameworks associated with natural resource management and livestock to ensure that issues associated with Kuchis and their lifestyle are properly addressed. Establish and staff the Kuchi Policy Unit and develop modalities for coordination with the Natural Resources Management Directorate and the Animal Health and Production Directorate and more specifically with the project concerning "Kuchi Targeted Interventions". Ensure that modalities to address disputes and conflicts are functional, integrated and coordinated for rapid resolution of contentious issues. Carry out training needs assessment and conduct necessary special training programs to enable appointed personnel to perform their functions for migratory nomads more effectively.

\section{Natural resource management - improving access to summer pastures}

- Community-base rangeland management process and planning established to strengthen rangeland management to preserve rights of Kuchi groups by end of 2015;

- This is closely linked to the activities to be undertaken within the Environmental Conservation component of the National Water and Natural Resource Development program. For this reason, it is important to note that the activities listed below will be undertaken in close collaboration with the Directorate of Natural Resource Management in order to avoid duplication of effort and to ensure a harmonized and coordinated approach towards NRM;

- Much of the work will concentrate on conducting inventories of rangelands to inform the process of developing appropriate community-based land use plans; review and update the mapping of the possible migratory routes for Kuchis and their livestock as per the three different categories of Kuchis; identification of flash-points for Kuchi/community conflicts and disputes. This 
deliverable will also focus on establishment of community based rangeland management committees with both sedentary farmer and Kuchi representatives; development of joint rangeland improvement strategies to agree user rights; develop and agree on mechanisms for complaints management. There will also be estimates undertaken along migration corridors to determine diet quality for sheep and goat; diet quality estimates will, in turn, assist producers to select supplemental feeds necessary to keep herds healthy.

\section{Evolution of semi-intensive production system}

- Fully extensive pastoral production system, formerly enjoyed by nomadic Kuchis replaced with semi-intensive production systems by end of 2015 .

- This will involve undertaking a feasibility study to develop models for intensification of sheep and goat management and feeding during winter months. On the basis of the abovementioned study, develop financially viable sheep and goat fattening demonstration units employing settled Kuchis on MAIL demonstration farms. Organize group visits for (Kuchi and sedentary) farmers living within range of urban markets.

\section{Animal health interventions to improve production and productivity}

- Veterinary field units will be identified and mapped along all Kuchi migratory routes and additional service providers enabled at strategic locations by the end of 2015 .

- Identify and map all Veterinary Field Units along the migratory routes for the Kuchis and their livestock; As and where necessary in consideration of economic returns establish additional service providers at strategic locations and train more Kuchis as paravets and in very remote areas; Basic Veterinary Workers; Inform the Kuchis about the location and develop modalities for needs based services and input provision; Development of specific compulsory epidemiological surveillance and disease prevention programs for monitoring of trans-boundary and contagious diseases to prevent disease transfer during migration will also be carried out; Promote and facilitate local and domestic chicken and turkey production (experienced in Turkey and Iran among nomads); Explore honeybee production for Kuchi who only have limited migrations.

\section{Drought/other climatic shock mitigation through emergency destocking}

- Shock mitigation measures formulated and implemented for migratory livestock management by end 2015;

- During times of crisis and when there are no other alternatives, extensive producers will sell livestock they are no longer able to feed. When the market is inundated with animals, traders offer lower prices that are typically not sufficient to provide forage to support the remaining herd. Three destocking activities based on research sponsored by the Global Livestock collaborative research support program (GL-CRSP) are proposed for Afghanistan.

\section{Alternative livelihoods for settled Kuchis}

- Alternative livelihood options for Kuchis identified promoted and implemented in selected provinces and districts by end of 2015 ;

- Facilitate formation of women's producer associations for the distribution of improved but appropriate breeds of poultry to enhance backyard poultry production for sedentary Kuchi households, not just semi-sedentary; Provide the opportunity to all Kuchis, those who can use it will, and this will facilitate their adaptation to changing circumstances; Train and mobilize female extension agents operating local small hatcheries and link to services and inputs as well as cooperative marketing of eggs and broilers; Promotion of market linkages and access to higher value chain with specific attention to local capacity for wool, cashmere and meat processing and value adding to natural resource products in general and medical plants in particular; Facilitate access to credit, business support services (such as simple profitability analysis tools for businesses) and develop loan packages specific for Kuchis. This should be conducted in collaboration with ADF. Examples of where credit can be useful include credit for supplementary feed, veterinary service packages for lamb fattening, poultry keeping, turkey keeping etc., for small-scale livestock trade (a major coping strategy of the Kuchis), and other petty trade.

\section{Beekeeping:}

\section{Selection of beekeeping beneficiaries}

- $\quad$ Beekeeping beneficiaries identified, selected and engaged in selected districts by the end of 2015; 
- The beneficiary should be interested in beekeeping and should have enough time for beekeeping activities. They should provide at least a $10 \%$ contribution towards the total cost and be more than 18 years and physically capable of work. They should be committed to the term of contract and the rules of engagement.

\section{Establishment of beekeeping groups}

- Groups of beekeepers established, resource and trained in selected districts by end of 2015 .

- To facilitate capacity building and follow up activities considering time and resources it is necessary to organize the selected beneficiaries in small groups and each group should be headed by a group leader. The group leaders will be trained as a local extension agent of beekeeping in the local area. The criteria for selection of group leaders include: literacy, acceptance of responsibility, honesty, have enough time to serve the group members, commitment to the term of contract.

\section{Establishment of beekeeping cooperatives/unions}

- Beekeeping cooperatives and unions established and fully functional in selected districts by the end of 2015.

- Beekeeping cooperatives and unions will be established through building linkages back to the smaller community-based beekeeping groups, with assistance from the Cooperatives Support Program. The processes of establishing a cooperative/union includes: facilitation of group discussions, identification of cooperative with a specific names and address and coverage areas of activity for the cooperative, preparation of constitution, rules and regulation, selection of management committees and registration of cooperatives with MAIL related department.

\section{Capacity building of animal production personnel in provinces}

- Animal production directorates at provincial level capable of carrying out their roles and responsibilities in all provinces by the end of 2015.

- The training program for provincial MAIL officers will involve the theoretical and practical capacity building of field staff and will focus on all the different activities based on the seasonal production cycles.

\subsubsection{Sub-Component 5: Food Nutrition}

\subsubsection{Background}

It is often assumed that investments in agriculture and food security will "automatically" lead to improvements in household food security and nutrition. However, evidence from around the world shows that unless agricultural programs are specifically designed to address nutrition problems, their impact on nutrition is limited, inexistent or even negative. Monotonous diets based mainly on energy dense, but micronutrient poor starchy staples are common in food insecure areas and contribute to the burden of malnutrition, particularly inadequate micronutrient intake. Food-based strategies have been recommended as the first priority to meet micronutrient needs. An essential element to food-based approaches involves dietary diversification or consumption of a wide variety of foods across nutritionally distinct food groups. Increasing dietary diversity is associated with increased household food access as well as individual probability of adequate micronutrient intake.

Addressing malnutrition in a sustainable way requires understanding the causes of malnutrition and how these can be addressed. These include poor food availability, limited and irregular household access to nutritious, diverse and safe foods, but also inadequate feeding and caring practices especially for women and young children, and exposure to disease, including food and waterborne disease. The nutrition impact of agriculture and food security investments will therefore be maximized if they are part of a comprehensive approach, which tackles food and nutrition security together.

Adopting a "nutrition-sensitive" approach will enable professionals working in the food and agriculture sector to have a more people-centred approach, integrating the different agriculture sub-sectors (staples, fruits and vegetables, livestock, natural resource management) and strengthening linkages with other sectors, in particular health, education, social affairs and women's affairs. 
While awareness about food and nutrition security has grown in recent years, food security is sometimes still confused with staple crop security, self-sufficiency and/or increased production and productivity, with no or limited attention to the quality, diversity of foods, and access. And other aspects of nutrition (intra-household food distribution and preparation; caring practices and health) are commonly overlooked. Understanding the multi-layered and complex causes of malnutrition and the need of an integrated approach among MAIL partners and all involved stakeholders is key for ensuring synergies.

Dietary diversity, i.e. the number of foods consumed across and within food groups over a reference period, is widely recognized as a key indicator of nutrient adequacy. The overall nutritional quality of the diet improves with increasing number of food groups consuming diverse diets offers protection against chronic diseases. Recent nutrition investments were limited, and often focused on treatment of acute malnutrition. Furthermore, in recent years, investments in nutrition have tended to give predominance to health-based treatment interventions, usually relying on imported "ready-to-use foods" or micronutrient supplements, with limited attention to more sustainable interventions based on locally-available foods with a stronger prevention role.

Several policy frameworks calling for integrated action for nutrition have been developed (e.g. Multisectoral Plan of Action for Nutrition, MoPH Public Nutrition Policy). Involved institutions now have to ensure and facilitate their implementation, and in particular to foster for multi-sectoral action at central, district and community levels.

A strong extension system, as well as program rather than project-based planning, are important requisites in order to integrate and scale up nutrition activities as part of comprehensive agricultural programs.

There is a national awareness about the interest and relevance of urban and peri-urban horticulture as a means to improve the food and nutrition security of the urban poor. In view of its multiple implications, integrating urban and peri-urban horticulture into a broader multi-stakeholder "Growing Greener Cities" (GGC) program would not only address home gardens but also public parks, street trees, peri-urban greenbelt and forestry as well as short cycle livestock and poultry according to the opportunities.

In urban slum areas there is a high prevalence of malnutrition as a result of unbalanced diet, with very low intake of fruits and vegetables. However a significant number of the dwellings have access to a small piece of surrounding land area ranging from 20 to 100 square meters, which could be usefully transformed into a productive home garden with vegetables and fruits and could also accommodate short cycle livestock and/or poultry according to the opportunities. Similarly, the peri-urban smallholder-farming sector has a double key role of being a source of employment but also the "proximity supply zone" for the urban population. This sector should therefore be protected as green buffer area against the urbanization process.

Food Safety is not just related to meat inspection and plant health, but has a wider gambit of, including food contaminants such as mycotoxins, chemical residues, microbial and viral pathogens, food-borne disease investigation and control, food control infrastructure and resources, public education and participation, etc. Assuring the quality of foods and prevention of economic fraud is also required to protect the consumer. Essential elements of the national food control systems to improve the safety and quality of food include: food law and regulations, food control management, inspection services, supporting laboratories, and adequate information dissemination and training. The challenges facing the Government of Afghanistan require a multi-disciplinary approach to overcome them. There is a keen interest from government Ministries to work together to build a modern, and effective food control system.

\subsubsection{Scope}

FFL aspires to raise awareness of food nutrition in collaboration with relevant government entities, and to ensure households around the country have sustainable access to nutrient-rich foods. Levels of under-nutrition and malnutrition remain too high, especially among the poorest families and vulnerable groups that include women and children. 
Hence the improvement in the nutritional levels of the most vulnerable groups will be targeted through provision of knowledge on key practices to promote good nutrition, and the identification and implementation of health and other goals that supplement good nutrition practices. Given the multidisciplinary nature of the challenge to enhance food nutrition status, FFL will work with relevant Government entities in this regard, particularly the Ministries of Education, Public Health, Rural Rehabilitation and Development, and Labour and Social Affairs.

The efforts will focus on raising awareness of food nutrition, feeding and caring practices at household level with MoE and MoPH; improving access to more diverse nutrient rich safe foods to vulnerable groups with MoPH and MRRD; and ensuring adequate sustainable supplies of diverse nutrition-rich foods to households with MRRD and MoLSA. MAIL will continue to progressively implement urban and peri-urban agriculture, targeting poor households and women-headed families for better diversifying of income and nutritious food supplements. 


\subsubsection{Deliverables}

\section{Enabling environment for linking food security with nutrition objectives}

- Enabling environment for food security and nutrition objectives created and implemented in selected provinces by end 2015;

- $\quad$ Short-term approaches for nutrition-sensitive policy frameworks and strategies clearly focus on the most vulnerable groups, namely young children and women, and on the most vulnerable areas in the country. They will include increasing the capacity and coverage of MAIL, geographically as well as technically. Food security and nutrition-relevant activities that have been successfully implemented in the past in selected provinces or districts will be identified and included into newly designed projects and programs in order to be up-scaled for nationwide coverage in some cases or based on an agro-system approach. In addition, cooperation possibilities and synergies with other (short-term) technical interventions and projects need to be identified and exploited. In parallel to the suggested improvements in the FNS data and information, the richness of Agriculture Statistics and other information and data systems should be used to improve the planning capacity of all relevant stakeholders and for better targeting;

- In the medium-term timeframe of 3 to 7 years from today, the prevalence of malnutrition in Afghanistan should have decreased significantly and the focus for food security and nutrition implementations will eventually be shifted to new target groups. In order to do so, the nutrition situation in Afghanistan will have to be re-analyzed to identify new or validate persisting target groups for food and nutrition security related activities. New target groups could for example include people living in cities rather than remote rural areas;

- In the long-term, Afghanistan will have to acknowledge and address all forms of malnutrition, including obesity and the nutrition-related non-communicable diseases that are associated with it. Policies and strategies will have to take people's changing dietary habits into account and be adjusted or redesigned accordingly.

\section{Capacity development for nutrition education}

- Capacity for effective nutrition education providing lasting benefit to households at district level achieved in selected districts by end of 2015 ;

- As a quickly implementable short-term action technical training on nutrition will be provided to professionals working on food and nutrition, and nutrition education for households and communities. Nutrition education strategies will be tailored to address the needs of the most vulnerable;

- In the medium-term, nutrition education strategies will increasingly be designed to address the general public, increasing use of public media, reaching out to the broader population beyond the rural and agricultural sector;

- The long-term approach will be to ensure the sustainable availability of human resources trained in agriculture, nutrition and/or rural development by promoting respective careers in universities and allocate budgets to positions requiring training in these fields of expertise.

\section{Enhanced availability and access to diverse (micro-nutrient rich) foods}

- Availability and access to nutrient-rich foods will be promoted and improved to enable households and vulnerable groups to have healthier lives in selected districts by end 2015;

- In the short-term, it will be possible to upscale existing and successful household food security and livelihoods support to vulnerable households and communities, with a focus on diet diversification and improved year-round access to diversified food items.

\section{Urban and peri-urban agriculture}

- Food nutrition and security in all urban areas improved and accessible through strengthened agriculture practices by end 2015 ;

- With appropriate measures taken, the living environment, the food and nutrition security and the livelihood of a significant share of the urban population of the city of Kabul and in other cities in Afghanistan can be significantly improved;

- As a short-term approach to start a "Growing Greener Cities (GGC)" initiative the institutional environment for such initiative will be created and strengthened. Existing policies and Kabul city planning documents will be reviewed and amended to allow for and promote urban and periurban agriculture; 
- In the medium-term, the specific activities to strengthen and expand the GGC will include, the creation of a legal framework to protect farmers against unjustified increases of land rent and protect them against eviction, planning new housing schemes with small spaces for gardening and trees, implementation of "Good Agriculture Practices" as a means to ensure sustainable intensification of the production systems, ensure food safety and quality regulation take into account the needs of urban and peri-urban production, processing and marketing systems;

- As a long-term approach the coverage of the GGC strategy will be expanded to include all smaller cities and towns around Afghanistan through incentive schemes and support measures adapted to their specific needs.

\section{Improved Food safety}

- National food safety quality system developed, institutionalized and implemented across all provinces by end of 2015;

- An integrated approach will be facilitated to developing a national food safety quality system by focusing on policy and institutional framework in addition to enhancing operational aspects by strengthening the capacity of the food inspectorate and analytical services. This will provide a mechanism for discussion and decision-making among the interested Ministries with input from relevant stakeholders, in particular food producers and processor and academia. Food safety considerations will influence also the planning and implementation of other components of the FFL Component, e.g. as regards horticulture and livestock components taking account of the current needs, under the FFL Component the capacity of relevant institutions at the central and provincial level;

- Particular attention will be given to strengthening legal/policy institutional arrangements (including food standards on main foods), an assessment of the current system for food safety and quality - using tools to enable a cross-Ministerial evaluation, and multi-stakeholder analysis an $3 \mathrm{~d}$ identification of priorities, gaps, and strengths.

\subsubsection{Sub-Component 6: Emergency Preparedness and Response}

\subsubsection{Background}

The high frequency of natural and man-made disasters in Afghanistan causes widespread damage and hampers the development process. Beside the natural events, disasters also result from adverse human actions. Primary threats to food and nutrition security in Afghanistan include: natural hazards; climate change, particularly the expected increase in the frequency and intensity of weather-related hazards; and water scarcity; trans-boundary plant pests and diseases (e.g. locusts, wheat rust); trans-boundary and endemic animal diseases; volatility in agricultural commodity markets and soaring food prices; security threats with consequent loss of assets, disruption of livelihoods and displacement.

Large parts of Afghanistan become inaccessible during the winter season, making advance placement of wheat a necessary food security strategy. While Afghanistan has relied on varying levels of cereal imports in recent decades as determined by highly fluctuating levels of domestic wheat production over time, existing public storage facilities after more than three decades of conflict are poorly maintained and are no longer suitable to function as the back-bone of a strategic grain reserve of the country. Private storage facilities are also extremely limited.

The current institutional structure for dealing with disaster management comprises of the National Disaster Management Committee (NDMC), consisting of relevant ministries tasked to intervene by utilizing their existing structures and resources, and the Afghan National Disaster Management Authority (ANDMA) that supports the NDMC in fulfilling its responsibilities mobilizing and coordinating government resources. A wide range of international and national organizations, in coordination with the UN Office for Coordination of Humanitarian Affairs (OCHA), ensures preparedness and early response for natural and human-induced disasters.

The combined capacity of the SGR's intended size of 200,000 MT will be sufficient to feed 2.5 million people for 6 months. MAIL and Government are aware that the proposed size of the SGR would not nearly be sufficient to serve a national price stabilization objective - a reserve of at least 3-4 times the 200,000 MT targeted now would be required for national price stabilization purposes. A reserve of that size would greatly exceed Afghanistan's fiscal and managerial capacity and likely lead to problems that 
are all too well known in other countries like India, Pakistan etc (corruption, leakages, waste etc). However, while mainly for emergency purposes, the proposed SGR in Afghanistan when well managed, can in the medium- and long-term be expected to contribute to limited regional (as opposed to national) price stabilization. This is because poor market integration throughout Afghanistan caused by natural barriers (physical, geographical) as well as man-made barriers (mainly insecurity) would mean that emergency shipments of wheat to isolated regions that face an emergency would likely have a stabilizing effect on local prices in those regions.

The average annual domestic wheat price in Afghanistan for the period 2005-2011 is $\$ 350 /$ metric ton (t) but with significant inter-year variation - fluctuating between \$224/t in 2005 and \$609/t in 2008 .

Table: Supply-Demand Balance of Wheat in Afghanistan (thousand MT) and average price and price variation of wheat (US\$/MT)

\begin{tabular}{|c|c|c|c|c|c|c|c|c|c|}
\hline & 2003 & 2004 & 2005 & 2006 & 2007 & 2008 & 2009 & 2010 & $\begin{array}{r}2011 \\
\text { (est) }\end{array}$ \\
\hline Irrigated wheat & 3,017 & 1,867 & 2,728 & 2,604 & 2,878 & - & 3,387 & 3,082 & 3,117 \\
\hline Rain-fed wheat & 1,345 & 426 & 1,538 & 759 & 1,465 & - & 1,677 & 1,450 & 339 \\
\hline Total wheat production & 4,362 & 2,293 & 4,266 & 3,363 & 4,343 & 2,767 & 5,064 & 4,532 & 3,456 \\
\hline $\begin{array}{l}\text { Estimated wheat } \\
\text { demand }\end{array}$ & 4,000 & 4,080 & 4,162 & 4,255 & 4,330 & 4,416 & 4,505 & 4,595 & 4,687 \\
\hline Seed demand and losses & 736 & 630 & 727 & 636 & 734 & 677 & 806 & 753 & 626 \\
\hline Surplus/shortfall & -374 & $-2,417$ & -623 & $-1,52$ & -721 & $-2,32$ & -247 & -816 & $-1,857$ \\
\hline $\begin{array}{l}\text { Average annual } \\
\text { domestic price }\end{array}$ & & & 224 & 237 & 271 & 609 & 371 & 325 & 389 \\
\hline
\end{tabular}

Source: calculations based on data from Ministry of Agriculture, Irrigation and Livestock (MAIL)

\subsubsection{Scope}

The high frequency of natural disasters such as drought, floods, water scarcity, trans-boundary pests, volatility of agriculture commodity prices, and inaccessibility of large parts of the country during winter season are regular threats to food security and agriculture dependent farmers. The aim of this sub-component is to enhance the resilience of livelihoods against threats and emergencies to ensure the food and nutrition security of vulnerable rural households and other at risk groups.

FFL will focus notably on efforts to strengthen good governance and institutions for Disaster Risk Reduction (DRR) in agricultural sectors; establish the Strategic Grain Reserves (SGR) as an integral part of Afghanistan's response mechanism to national and local food emergencies; and increase preparedness for emergencies in the agriculture and livestock sector and responses to disasters are effective. As mentioned in Sub-Component 1 of FFL, measures will be taken to strengthen and harmonize the Food and Nutrition Security (FNS) information and early warning systems across national and international actors.

In the short-term the Government is targeting a SGR of 200,000 MT primarily for emergency relief, including 150,000 MT in the four silos and 50,000 MT in the rehabilitated warehouses. This will be complemented by strengthened capacities at all levels to improve response to, and recovery from, future threats to food and nutrition security and improved coordination amongst MAIL, ANDMA, UN agencies and civil society networks.

\subsubsection{Deliverables}

\section{Institutional strengthening and good governance for DRR in agricultural sectors}

- A disaster risk reduction approach is mainstreamed across the agriculture and livestock sectors and MAIL has the capacity to guide agriculture-related preparedness, response and mitigation measures by the end of 2015 ;

- As a short-term measure, a dedicated unit within the Ministry will ensure that MAIL will support the NDMC by providing timely and accurate reports on current and potential disasters affecting the agricultural sector. The unit's technical expertise supported by the strong sub-national 
network and delivery capacities will be instrumental in ensuring that appropriate assistance will reach affected communities. The already existing co-ordination with ANDMA will continue and will be further strengthened through more active collaboration on ANDMA's DRR initiatives. Closer co-ordination and collaboration with relevant line ministries and their emergency department will be pursued. Closer interaction is required not only at inter-ministerial level, but also with UN agencies and civil society organizations in supporting government efforts. Close cooperation with Humanitarian Clusters, Task Forces and Networks, will increase MAIL capacities to reach affected rural communities. The Disaster Risk Reduction and Management Unit will also support provincial DAIL to ensure that co-ordination of disaster management is carried out at sub-national level with relevant government and non-government partners and with provincial Disaster Management Committees;

- In the medium-term, MAIL will propose and introduce appropriate legislation, policies, strategies and institutional frameworks for disaster risk reduction in agricultural sectors, and strengthen its institutional capacities to implement these initiatives. The proposed institutional structures and coordination mechanisms will include: Strengthened DRR/DRM Unit inside MAIL. The unit will be composed of core staff (4-5 officers and support admin staff) to be supplemented by designated officers of the different relevant Directorates in case of declaration of emergency status; Strengthened representation of MAIL in the national and local ANDMA structures. MAIL should be represented at all levels in national platforms for DRR; Supporting coordination mechanisms, ensuring linkages among relevant line ministries and agencies (e.g. MRRD, Energy and Water, environment and natural resources);Formalized partnerships between national institutions, international organizations (UN and NGO), National NGO and other community based and civil society organizations, research centres and extension services (one platform already available is the Food security and Agriculture Cluster);Support linkages and communication between traditional community institutions and formal government structures, and enhanced clear and transparent accountability between government and communities;

- In the medium-term, a Legal and Policy Frameworks on Disaster Risk Reduction for Food Security and Nutrition will be established, guiding the work at all institutional levels. The framework will: Ensure national legislation on DRR addresses livelihoods and food security (agriculture, livestock, forestry and natural resource management); Include FNS in national DRR/M strategy and action plans; Integrate DRR into agricultural and rural development policies; Integrate DRR into poverty reduction strategies linked to agriculture, fisheries/aquaculture, forestry and natural resource management; Ensure that environmental and natural resource management laws and disaster reduction strategies are mutually supportive; Mainstream pastoral risk management into national agricultural and development policies and strategies; Regulatory frameworks for national emergency preparedness and response to animal/plant disease outbreaks. The institutionalization of a DRR/DRM Unit in MAIL will be accompanied by capacity development for the implementation of risk reduction in and across Agricultural Sector and the different involved stakeholders. It will include support to strengthen the capacity of MAIL to deliver national legislation, policies and strategies on DRR for FNS through technical advice, human resources and expertise, training, practical tools and services. Decentralized DRR/DRM structures capacities will be strengthened at sub-national level (DAIL, local authorities, extension services and community-based organizations) to deliver DRR for FNS will be built.

\section{Strengthening and harmonizing FNS information and early warning systems}

- Effective hazard early warning systems established at national level and at decentralized level in rural communities across the country, data and information on potential emergencies is available and brought to the attention of all stakeholders in a timely manner by 2015 ;

- To better monitor the different threats and inform decision-making in preparedness and response, policy, advocacy and programming will be a short- to medium-term approach undertaken in close cooperation will other stakeholders in the sphere of agriculture and FNS data and information as under FFL Component 1;

- Activities will include strengthening the monitoring capacity in the following key areas: Weather monitoring and forecasting (rainfall, vegetation index, yield forecast, etc.); Support and streamlining of Meteorological and Hydrological stations network, reinforce coordination and exchange of data and information. Support to remote sensing capacities; Complementing and improving efforts that are already under way for seasonal agriculture forecasting and livestock production monitoring; Ensuring that information on animal diseases, plant pests and diseases, and threats to food safety is acquired and used; Complementing efforts for food price monitoring and liaise with initiatives to expand national coverage (all information will be inserted in GIS 
database that will allow for spatial and time series analysis), adding more food items (such as livestock and livestock products) and improving and harmonizing methodologies for data collection;

- Better Analytical capacities and methods will improve the analysis of impact of shocks on the poor in rural and urban areas and for differentiated groups (women and men, female and male headed households, etc.) facilitating better targeted responses. Better classification of province and districts in crisis and requiring external assistance will improve the timely design of adequate responses (food, cash, agricultural support, etc.). In important role will be played by improving and expanding the geographic coverage for simulation and modelling exercises for the impact of shocks on household food and nutrition security;

- Improved communication products will inform actions, ensuring the right messages reach the right people at the right time to initiate the right responses. Well-designed and targeted policy briefs, monitoring updates, and early warnings will support timely and correct decision-making at all levels.

Better preparedness for emergencies in the agriculture and livestock sector and responses to disasters

- Government, civil society and partners of the agriculture sector at the national, provincial, district and community levels are prepared and able to respond effectively to emergency situations in the agriculture and livestock sectors by end 2015;

- In the medium- and long-term, Afghanistan will benefit from strengthened capacities at all levels to improve response to, and recovery from, future threats to food and nutrition security, and to reduce their potential negative impact on livelihoods;

- The actions taken to achieve this will include: National and Local Preparedness Planning; Formulating local and national preparedness and contingency plans for agriculture, fisheries/aquaculture, forestry and livestock; Inclusion of agricultural sectors also in inter-agency preparedness and contingency plans; Conducting simulation exercises (both real-time and tabletop) to strengthen in-country capacities; Providing guidance on viable operational and financial components of national preparedness plans; Supporting specific crisis and/or sector preparedness planning for identified high-threat diseases; Building and maintaining of emergency seed and animal feed reserves, livestock shelters; vaccine banks to ensure the rapid supply of emergency stock from safe and strategically located facilities; Strengthening management and expanding capacity of the Strategic Grain Reserve (see below); Establishment of a quick and easily accessible Emergency / Contingency Fund;

- Better coordination and implementation of agriculture disaster needs assessments will ensure that all stakeholders prepare a collaborative and harmonized response. With specific reference to nutrition issues, coordinated approaches will facilitate and have to ensure that emergency nutrition interventions (in particular CMAM) are complemented with adequate support to complementary feeding and linked to household food security interventions. This will be a continuation of work done through the nutrition cluster on integrated CMAM approach. Better coordination and harmonization will also facilitate mobilising and managing resources for agriculture emergency relief interventions more easily and more effective and efficiently;

- In case of disaster the unit will be responsible for the provision of emergency services and public assistance during or immediately after a disaster in order to save lives, sustain livelihoods, reduce health impacts, ensure public safety and meet the basic subsistence needs of the people affected.

Strategic Grain Reserves integral part of Afghanistan's response mechanism to national and local food emergencies

- The GIRoA is able to provide food assistance for a period of six months to 2.5 million people affected by natural and man induced disaster by 2015 ;

- The short-term approach includes rehabilitation of four large government-owned grain silo structures with a combined storage capacity of 150,000 metric tons (MT) of wheat, and the renovation of several large Warehouses on the silo compounds. Currently all four silos are seriously dilapidated and unable to serve as the backbone of a national SGR. Two of the four silos (in respectively Kabul and Pul-i-Khumri) are fully non-operational - whereas the silos in Herat and Mazar-i-Sharif are barely functioning - at less than 25\% efficiency causing significant human health hazards and resulting in extremely slow offloading. The silos are in use but in their current shape all four silos are unfit for storing wheat for emergency purposes. Renovation of existing warehouses at the silo compounds will provide safe storage for an addition 50,000MT of bagged wheat. The Government is targeting in the short-term a SGR of 200,000 MT primarily for 
emergency relief - including 150,000 MT in the four silos and 50,000 MT in the rehabilitated warehouses;

- As a medium-term approach, MAIL also plans to design and build smaller warehouses with capacities of 500MT or lower at District Levels to be handed over to farmer's cooperatives. The purpose of this expansion is to support communities and farmers and to ensure improved quality of grain handling and storage immediately post-harvest;

- The primary beneficiaries of the expanded and improved storage capacity at local and strategic locations will be poor households that are mostly net wheat buyers and whose access to sufficient quantities of wheat is seriously compromised on a regular basis because of insufficient supply and high prices. Wheat prices (domestic and international) have shown an increasing trend since 2009 and are expected to remain at relatively elevated levels in the foreseeable future. The SGR will therefore contribute significantly to food security in Afghanistan in general and that of poor households in particular.

\subsubsection{Sub-Component 7: Dry Land Farming}

\subsubsection{Background}

Globally agriculture can be divided into two categories, rain-fed and irrigated. Agro-geographically there are additional categories or definitions, which establish 'dry land' as including agriculture, which occurs under a limited rainfall $(<800 \mathrm{~mm})$. Under such a definition a near all Afghanistan agriculture practice can be considered as being practiced on 'dry land'. Over $50 \%$ of farming activity in Afghanistan occurs under rain-fed situations and unfortunately there has been limited focus historically on neither specific research nor extension work completed on problems confronting rain-fed agriculture.

There are three major problems that limit productivity in rain-fed agriculture: 1) inferior cultivation practices; 2) poor soil quality and management; 3) inferior germplasm which compromises the opportunities to improve.

Achieving change. Dry Land Farming (DLF) at the subsistence level is the most difficult farming practice there is; farmer's major objective is to prevent food insecurity, so simply as a survival mechanism they naturally steer away from any decision which involve or increase risk. Successful interventions need to be farmer centred, assisting them to graduate from 'risk aversion' to 'risk management'. For any change to occur at the farm level, any interventions need to be established upon building trust and confidence with farmers. So there is an urgent need to have access to credible inputs, to be able to support successful demonstration of what is possible, and then for intermediate timeframe, identify viable markets for produce, which in turn will help inspire greater crop diversification.

In 2010, MAIL formed a DLF Unit within the Research Department. This unit has been charged with gaining the trust of the farmers, DAIL and MAIL colleagues, by delivering results on dry land farms. This will be done through regional demonstrations, extension from these models across farming communities and institutional development with MAIL/DAIL and supporting educations organizations including scholarships for vocational, tertiary and post-grad students on DLF.

\subsubsection{Scope}

FFL will develop and promote a nation-wide profile of improved Dry Land Farming (DLF) practices and technologies to assist farmers to double production in DLF. Since over $50 \%$ of farming activity in Afghanistan occurs under rain-fed conditions in the dry land areas, at the subsistence level, FFL will focus on the major problems that limit productivity in rain-fed agriculture, namely, inferior cultivation practices, poor soil quality and management, and inferior germ-plasm which compromise the opportunities to improve production and productivity.

Successful interventions will need to be farmer-centred, and to concentrate on assisting farmers to graduate from 'risk aversion' to 'risk management'. There is an urgent need to undertake research and regionally-based DLF surveys in order to generate greater knowledge and understanding of DLF system potential through, to have access to credible inputs, to be able to support successful 
demonstration of what is possible, and to identify viable markets for produce, which in turn will help inspire greater crop diversification.

By 2015, there will be improved and more extensive DLF research and extension facilities and programmes; a Northern region DLF research operation will have been formulated and established; demonstration blocks will have been established for farmers and fully operational and available to all farming groups across the country; system for wheat intensification will have been developed and introduced to farmers around the country; and improved practices for horticulture cultivation in dry lands will have been established and disseminated to farmers.

\subsubsection{Deliverables}

Accelerating DLF Germplasm collection - with domestic as well as regional and international materials

- Accessing high quality and certified germplasm from neighbouring countries for use in demonstration work;

- Conducting a summer-school wheat seed census to generate baseline information regarding status of existing germplasm;

- Developing in tandem with other countries a crossbreeding program that can be strengthened and expanded on what is being done;

- Exploring the rich genetic heritage of local Afghan varieties can benefit the development of improved strains and varieties of wheat. Cross breeding of Afghan germplasm with DLF released varieties in partner countries can help us to provide farmers with adequate good quality seeds, which can in turn lead them to improved production. Afghan experts will also gain the skills to continue cross breeding processes within Afghanistan. The best samples of germplasm from across Afghanistan should be included in crossbreeding programs with other countries to ensure enough availability of improved seeds in a short time.

\section{Farmer-led sustainable production model of dry land farming}

- Demonstration blocks established for farmers and fully operational available to all farming groups across the country by the end of 2015 ;

- This activity includes the establishment of demonstration plots for farmers in conjunction with the DAIL extension workers. The activities will work in a collaborative way to apply farm planning, improved soil management techniques, use of strategic follow crops including legumes, promote adoption of perennials and intercropping systems, supplementary irrigation, and support access to improved varieties of annual, perennial and forage crops.

\section{Developed system for wheat intensification in dry land areas}

- System for wheat intensification developed and introduced to farmers around the country by 2015;

- The System for wheat Intensification (SWI) assembles a series of sensible common-sense practices which when combined can achieve dramatic improvements in productivity. Initially, the SWI practices will be a component of the overall Wheat Sub-Component activities within FFL and will therefore not command a budget under the DLF Sub-Component.

\section{Dry land farming horticulture program}

- Improved practices for horticulture cultivation in dry lands established and disseminated to farmers in dry land areas by the end of 2015;

- This activity combines the use of improved planting stock with cultivation practices that maximize use of water, and aims to minimize loss of moisture from evaporation. Intercropping practices with both annuals and perennials can then be introduced between plantings. Therefore the activity has a number of gradual stages in implementation, where the biomass/ intensity and dynamics of the demonstration evolve over time.

\section{Dry land farming conservation agriculture program}

- The practice of dry land farming conservation fully developed and widely disseminated among farming groups in dry land areas by the end of 2015;

- The focus of Conservation Agriculture (CA) is to improve soil structure and fertility, which in turn delivers a more sustainable agricultural practice. The activity brings together a number of 
technologies which effect the full planting cycle, land preparation, sowing, cultivation harvest and follow cropping. On slope land, contour ploughing is promoted as critical and terracing where possible is implemented to minimize soil profile disturbance, enabling a build up of organic matter and therefore moisture and nutrient holding capacity. Zero tillage using chisel ploughs, weeding between planting lines, maintaining plant residue after harvest and promoting legume follow crops are all important steps. Overtime, soil structure, fertility, productivity and sustainability will increase.

\section{Improved dry land fodder production}

- Fodder production techniques improved and widely disseminated among dryland farmers by 2015;

- The general health and condition of livestock is correlated with their diet. During winter months it is accepted that the weight of the animal will drop due to inferior calorie and nutrient intake. A more highly productive agricultural model should generate fodder for livestock. Through the integration of perennials and promotion of annual follow crops suitable for fodder, the risks associated with the current available free-range grazing will reduce, control of inputs will enhance meat production, fodder plants will contribute to improved soil fertility and structure, and will better cope with changing climatic conditions in dry areas.

\section{Dry land farming systems survey}

- Dry land systems survey completed by the end of 2015;

- DLF systems in the country are strongly different at regional and even provincial level. The current information and database of agro-systems, soils' condition and opportunities is barely more than a collection of maps. There is a need to know what can be done and where in relation to not only DLF but also all aspects of farming. DLF survey activities will be carried out under the activities of the information and data sub-sector.

\section{Dry land farming education program}

- Dry land farming education program formulated and delivered in relevant districts by the end of 2015 ;

- The activity will include the systematic survey and documentation of the core agriculture curriculum needs for all levels. During the first stage, the fast tracking of intensive, practically orientated technician courses will occur and be delivered through relevant educational facilities targeted at high schools and universities.

\section{Northern region dry land farming research program}

- $\quad$ Northern region DLF research operation formulated and established by end of 2015;

- This activity will further progress the establishment of a DLF team covering the northern region. The team will be responsible for mainstreaming of DLF demonstration activities across other subsectors of the FFL component and other ministry activities. The technical team will assist those provinces that have demonstration areas to adopt and incorporate dedicated areas to demonstrate DLF technologies with province specific attributes considered.

\subsubsection{Sub-Component 8: Integrated Pest Management}

\subsubsection{Background}

Wheat and rice are the important cereal crops in Afghanistan. The average yields of both of these crops are much lower than the national average of most of the neighbouring countries as already stated. A number of pest insects and diseases, such as sunn pest and rust in wheat, and stem borer and bacterial leaf blight in rice along with some fungal diseases have been reported to be one of the most important reasons for these low yields. But when we look at the problem from an analytical view, we see the pest problem is actually the secondary problem. The main problem is the conventional production methods that facilitate more pest and disease infestation to the fields.

For example in wheat, in the entire country, both in irrigated and in dry land areas, crop establishment is mainly done through a broadcasting method of wheat cultivation, which then promotes huge weed populations. From a close observation, in most of the wheat fields it has been found that $50 \%$ of plant populations are actually weeds. This highly affects the plant growth, while making the plants more 
vulnerable to pest infestations such as sunn pest. Instead of applying chemical pesticides, by simply introducing an effective weed-controlling mechanism, the pest problems can be successfully solved while at the same time doubling the crop yields and the profit margin to large extent, as it has already been tested and is now being promoted by the FAO IPM project in 11 Northern provinces of Afghanistan through conducting FFS. Similarly, rust is a seed borne disease in wheat. Using quality seeds and resistant varieties are successfully addressing the problem addressed by the same project.

In rice, the main problem is the traditional planting method. The random transplanting of very old, 4045 days old seedlings is the major impediment in rice for both pest infestation and low yields. By introducing two production methods known as IPM method and the System of Rice Intensification (SRI) method pest problems in rice is being successfully addressed while increasing the rice yields to two to three folds. Similar technologies have been promoted for potato, vegetables and melon. In the case of melon by introducing bagging, covering the melon with plastic or cloth bags, melon fly problem is being successfully addressed.

Locust is another serious problem as in the neighbouring countries of Afghanistan, especially the Central Caucasian Countries (CCS). The main cause of locust problem is the direct result of climate change and recent environmental phenomenon, especially the drought. For successful locust control farmers need appropriate education and new technologies on climate change adaptation and mitigation instead of solely relying chemical spray.

Therefore, instead of just considering only a pest control strategy, IPM needs to be introduced and promoted as a standard approach to crop husbandry in Afghanistan, dealing with all issues of crop production starting from seed to crop variety, soil, water, weed, ecology, post harvest and even marketing issues. This needs to be done through providing farmers with appropriate education using Farmer Field School (FFS) as the effective approach to farmer's education. This will however, require extensive capacity building of the extension staff of all the directorates concerned, especially the directorates of Plant Protection and Quarantine (PPQD) and directorates of General Extension and Research including other national and international partners involved in delivering extension service to farmers. The FAO IPM project is already doing this but this needs to be extended both horizontally to cover more provinces and vertically to include many more crops.

\subsubsection{Scope}

The Government would like to achieve the goal of increasing production and productivity through introduction environment-friendly, ecosystem-based farming practices to reduce the fecundity and breeding ground of pest population, especially locusts. Instead of focusing on second and other lower level symptom problems of pests and diseases, through integrated pest management (IPM), FFL will focus on the primary problem of conventional production methods that facilitate more pest and disease infestation to the fields.

To this end, FFL focus will be to develop and introduce sustainable strategies for crop protection through establishing the foundation for a national IPM program and an emergency pest control unit within the Plant Protection and Quarantine Directorate (PPQD) of MAIL; provide hands-on training using Farmer Field School (FFS) and other group-based participatory approaches to develop their capacity in successful plant protection and crop management; strengthen the early warning system for epidemic insect pests, especially locust; and increase farmers' awareness and understanding of the causes for locust outbreaks, while paying attention to community-wide collective efforts. There is also a need to provide improved and up-to-date equipment for advanced physical, mechanical, cultural, biological and chemical control for locust pests with safe use of less hazardous chemical insecticides.

Community-wide collective efforts to promote IPM will increase the awareness and understanding by farmers and other stakeholders on the real causes for locust outbreak, while at the same time, the introduction of environment friendly, ecosystem based farming practices there will reduce the fecundity and breeding ground of locust population. Through the provision of improved and up-todate equipment for advanced physical, mechanical, cultural, biological and chemical control for locust pests, farmers and the environment will be protected from the use hazardous chemical herbicides and pesticides. 


\subsubsection{Deliverables}

\section{Use of quality seeds and planting materials}

- Farmers in selected districts are trained in the use of best practice for quality seed selection and seed production, as seed is the foundation for a healthy crop by the end of 2015 .

- Emphasis will be given to provide appropriate training to famers on identification and sorting of quality seeds from their own seeds using very simple techniques and methods. Farmers should be also given training on how to produce quality seeds at the farm level using the simple selection process, which has been a traditional but also the most scientific method of seed selection used by the plant breeders. In the case of horticultural crops where non-seed planting materials are used, there are less chances of transmitting seed borne diseases but quality could still be a problem. Therefore, farmers should be given appropriate training on how to identify quality scion, rootstock and mother stock.

\section{Use of quality seedlings}

- Farmers trained to produce high quality seedlings with simple easy to use techniques in selected districts by the end of 2015;

- Crop establishment for most of the vegetables and rice and in the case of fruit crops where seedlings are used are highly related to the quality of seedlings. A strong seedling establishes quickly, leading to vigorous plant growth, while a weaker seedling takes a longer time for establishment and is more vulnerable to pest and disease infestations. Weaker seedlings are also an impediment to higher production. Farmers should be given appropriate training on how to produce quality seedlings using very simple techniques such as preparation of standard seedbeds (i.e. soil and composts for seedling production, timely management of seedbeds and use of other media for seedling production such as plastic bags, raised beds, etc.)

\section{Disease resistant variety selection}

- Selected local variety seeds exploited to maximum potential and made easily accessible to farmers in selected districts by the end of 2015;

- Plant diseases are mainly controlled by varietal resistance. The local varieties have higher degree of resistance to disease than do the high yielding, exotic varieties. Generally, the local varieties are considered as low yielding compared to the high yielding or hybrid varieties. But in many instances, it has been proved that among the local varieties there are many high yielding varieties. This potential for local varieties should be explored and promoted to the farmers as an important strategy for plant protection. Even though there are yield ceilings, average yields of many local varieties of rice, wheat, vegetables and fruits in Afghanistan like elsewhere have not yet reached that level. So, there is still large opportunity for using the local varieties, and thus they should be strongly promoted. In cases for local and new varieties, farmers should be given appropriate training on how to select a particular variety through a ranking process. This should be applicable to all crops such as cereals, vegetables and horticultural crops.

\section{Soil fertility management}

- Farmers educated and trained to ensure maximum productivity of soil through the use of appropriate soil fertility techniques in selected districts by the end of 2015.

- It is well established that due to the prolonged use of chemical fertilizers, soil health has been tremendously deteriorated which is currently a critical impediment to growing a healthy crop and should be considered as the main reason for pest and disease infestation. Therefore, the key to soil fertility management should be to improve the soil health. The concept of "feeding the soil, the soil will feed the plant" needs to be established as the overall strategy for soil fertility management. For this, the following practices should be highly considered: use of adequate animal manure to the soil, use of compost, recycling of crop straw back to the soil, incorporation of growing green manure (legume crop) in the cropping system, reducing or limiting the use of chemical fertilizers, use of organic manure like green manure, animal and human manure, compost and bio fertilizer.

\section{Capacity building of extension/plant protection staff}

- Extension and plant protection staff fully trained and capable of supporting farmers and vulnerable groups in integrated pest management in all provinces by the end of 2015; 
- IPM or Farmer Field School (FFS) is a process-based approach. The success is highly dependent on the skills of the facilitators. Generally, most of the extension workers who are assigned to facilitate FFS do not have direct experience in farming. Without direct experience in farming, their service is mostly limited to delivering crafted messages or recommendations to the farmers as developed by the centralized government extension/plant protection or research systems. Farmers have a hard time in believing these young professionals, as they do not have direct experience in farming. For implementation of a successful IPM program, there is need to develop the capacity of the extension and Plant Protection and Quarantine directorates of MAIL as well other organizations/projects that will be involved in implementation of the cereal and horticulture components of FFL component. Capacity building will be considered at least at two levels; the first level is for the field-level extension workers who will be conducting FFS and other group based training for farmers, and the second level is for senior level provincial and central level staff for planning, monitoring, coordinating of the entire IPM/extension activities across the country. The training will cover both technical and extension process. There will be season-long Training of Trainers course on IPM in wheat, rice, fruits and vegetables. There will be short and customized courses based on the needs of the staff. In addition, there will be review and refresher courses.

\section{Capacity building of farmers and communities using Farmer Field Schools}

- Trained government facilitators will conduct Farmer Field School (FFS) in the communities to develop the skills and capacity of farmers in sustainable crop and pest management;

- 25 farmers will participate in each FFS for the entire duration of a crop, such as wheat, rice, vegetables and fruits depending on the interest of the communities. These farmers will form the core group of farmers in the communities. They will regularly participate in FFS and apply the learning on their own fields. The experience of these farmers will influence the other farmers in the community to create a communitywide roll-on effect to apply the FFS learning in mass-scale. Moreover, an informal sharing system will be established in each FFS through organizing field days and cross visits among the farmers in the same communities or between the neighbouring communities to increase the sharing process and dissemination of new technologies in shortest possible time.

Capacity building of farmers and communities using farmer-to-farmer extension process for non-FFS areas

- FFS is an intensive process. It will take several years to expand FFS activities across the country. Therefore, to cover those communities where FFS will be started later other forms of participatory extension strategies will be introduced to develop the capacity of farmers to address the pest problems. This will include establishment of demonstration plots, conducting research trials and facilitation of farmer-to-farmer extension process using farmers as trainers. Lead farmers in the targeted communities will be trained and assigned to the communities to work with other farmers on an informal basis. There will be also provision to provide need-based support to the communities by the field level plant protection and extension staff depending on the type of need of the communities.

\section{Better anticipation and mitigation of locust issues and disasters}

- A significant amount of crop loss occurs every year due to locust infestation in Afghanistan. However, the exact amount of loss is still unknown. Strengthening human capacities is needed to carry out timely survey to assess the exact amount of crop loss. Survey techniques are still outdated and need to be improved. Establishment of an early warning system is also essential to carryout needed control activities in timely manner;

- The following activities are proposed for better anticipation and mitigation of locust problems: Improve survey operations through a) strengthening human capacities in survey techniques and operational mechanisms, and b) through provision of upgraded equipment/tools and materials; Organize regular joint cross-border surveys across the neighbouring countries because borders are the breeding points and habitats of locusts; Develop monitoring and analyzing systems through a) the newly developed tools and b) extended use of GIS, remote sensing data; Enhance preparedness for risk reduction through harmonized national contingency plans.

\section{Improve response mechanisms to locust outbreaks}


- Allow early reaction and appropriate control operations through strengthening human capacities, policy advice and technical assistance on spraying operations and control campaign;

- Strengthen operational capacities through provision of up-to-date control equipment;

- Enhance public-private partnership for early reaction, implementation of adequate control operations in the respect of good agricultural practices, and appropriate reporting with the assistance of FAO;

- Promote less harmful pesticides and alternatives to conventional pesticides through encouraging the use of Ultra Low Volume (ULV) formulations and related techniques;

- Use alternatives to conventional pesticides;

- Encourage more registration of less harmful pesticides.

Better monitoring and mitigation of the impact of locust control on human health and the environment

- Mitigate impact of locust control operations on human health and the environment through a) appropriate training and b) technical assistance from appropriate institutes and organizations within the region;

- Monitor impact of locust control operations on human health and the environment through a) impact assessments and b) analysis of collected material. 


\section{Component Two: Enterprise and Market Development}

\subsection{EMD Goal, Objectives and Expected Results}

The Enterprise and Market Development (EMD) Component is an integrated approach that targets the most promising areas for support in value addition and market development in the rural economy and then provides focused technical support for rural enterprises and farmers, financial support and access to land, ultimately facilitating job opportunities and employment. Through coordinated delivery of complementary activities at community level, economic growth will be stimulated and the private sector will flourish.

The Goal of EMD is 'to sustain economic growth and poppy reduction through improved employment and income opportunities for rural people by means of enterprise development, credit and access to land'.

The Objectives of the EMD Component are:

- $\quad$ Objective 1: Improve on-farm and off-farm incomes through the development of viable community-based enterprises, small and medium enterprises and larger agri-businesses;

- $\quad$ Objective 2: Support private-sector supply and demand through investable surplus, import substitution and export-led economic growth;

- $\quad$ Objective 3: Improve linkages to domestic and export markets; and

- $\quad$ Objective 4: Improve and secure access to supportive rural credit and inclusive land tenure.

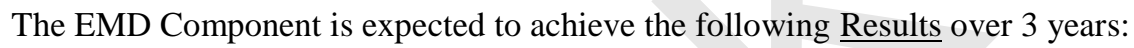

- $\quad$ Reduce unemployment rate by $10 \%$;

- Improve female participation in economic activities by $5 \%$;

- $\quad$ Reduce imports in basic agricultural products by $20 \%$;

- Improve access to agricultural credit with $\$ 90$ million lent;

- Bring 15,000 hectares of new land into productive use for licit farming activities;

- Improve regulatory and procedural effectiveness of land reform;

- Establishment of new community enterprises increased by $30 \%$;

- $\quad$ Promoted 3,900 new enterprise groups;

- $\quad$ Facilitated and supported 340 SMEs; and

- Contributed to the overall NPP-2 target of $18 \%$ reduction in cultivation of narcotic crops.

Furthermore, by the end of a 10-year time period, EMD is also expected to contribute to a $50 \%$ increase in rural incomes and employment, largely due to increases in production and improvements in productivity coupled with an increase in the number of SMEs, agribusinesses and other rural enterprises. Afghanistan's exports of agricultural products will increase to US $\$ 2.5$ billion due to improved quality and increased quantity and to better processing by a larger number of agri-businesses. The Component will enable Afghanistan to substitute the majority of its imports of basic agricultural products, including poultry and dairy products as well as off-season fruits and vegetables. Around 100,000 hectares of land will be leased for promotion of agribusinesses, industrial parks, communication and general services.

There are 4 Sub-Components in the EMD Component. They differ from FFL sub-components in that they are current programs or Executive Agencies within the Cluster Ministries. However, combining these four Sub-Components under one umbrella Component adds value through closer coordination and more integrated planning, thereby identifying and exploiting synergies and eliminating any potential wasteful overlap. Overtime, this coordinated approach to implementation and service delivery will allow a progressive re-alignment of current and future programmatic intervention instruments and supporting initial frameworks, ultimately contributing to the foundation of an integrated sector-wide strategy. 


\subsubsection{EMD within the ANDS Framework}

Individually and collectively, the EMD Sub-Components support the goals and objectives of the ANDS, as well as the National Alternative Livelihood Policy (NALP) under the Alternative Livelihood Pillar of the National Drug Control Strategy (NDCS). ANDS provides the overall framework for developing policy interventions to reduce poverty in Afghanistan. At a broad level, ANDS defines an agriculture and rural development strategy that recognises the need to transform agriculture into a source of growth and means of livelihood for the rural poor. It also presages the EMD with a wider Comprehensive Agriculture and Rural Development initiative that encompasses MAIL and MRRD programmes.

Moreover, at an implementation level within these ministries, a more specific response to rural sector challenges is articulated in the National Agriculture Development Framework (NADF), administered by MAIL, which considers that:

- "Economic growth and food security depend upon natural resource management, increasing agricultural production and productivity, improved physical infrastructure and market development. This is the path to poverty reduction, licit crops and national security".

- Implementation principles identified by MAIL to attain growth and food security include a focus on local consumer and market demand, improved access to credit, land reform and area-based implementation of interventions in an integrated manner at central, provincial and district levels.

- Similarly, MRRD's goal of "helping individuals, households and communities to better manage risks by supporting sustainable rural livelihoods strategies" is reflected in its intervention approach.

The EMD Sub-Components have been identified in the ARD Cluster. GIRoA seeks to organise its ministry-level coordination and implementation efforts around such clusters to meet its development partnership commitments made in the 2010 Kabul Conference. In particular, the scope of interventions to be implemented by the EMD is consistent with donors' bilateral commitments to attain an "effective mix of investment in critical infrastructure and the development of a skilled labour force and of a strong, value-adding agricultural sector", 5 .

\subsubsection{Policy Development for the ARD Sector}

The Sub-Components of the EMD Component together provide an opportunity to generate substantive information to support policy formulation in the agriculture and rural development sector. In particular, all undertake significant quantitative and qualitative appraisals to inform the interventions they deliver, including as they impact specifically women. With some aspects - particularly in the case of ADF with its focus on financial innovation - there is applied research that specifically seeks to generate new thinking.

As such, the EMD Component will seek to aggregate and analyse evidence through its Monitoring and Evaluation Support Office with the aim of developing policy recommendations for IMC. The constitution of the IMC also reflects the need for appropriate wider stakeholder representation among Ministries and agencies that have policy and regulatory-related impacts on this sector.

\subsection{Situation Analysis}

Agriculture is the backbone of the Afghan economy: the sector employs about 79 percent of the population and contributes to 32 percent of the GDP; approximately 79 percent of Afghans live and work in rural areas and are dependent on agriculture-related activities. The national GDP is directly dependent on the success of agriculture with almost a third of official GDP derived from agricultural output. However, seasonal and chronic unemployment are common and food security is weak. These factors contribute to instability, an illicit economy and extreme poverty.

\footnotetext{
${ }^{5}$ Communiqué of the Kabul International Conference on Afghanistan, 20 $0^{\text {th }}$ July 2010.
} 
Among the critical problems that underpin the challenges to rural development are those that relate to poor rural infrastructure that inhibits production, distribution and access to markets, and stifles the growth of the licit economy, including:

- A lack of cold storage, processing, packaging and marketing infrastructure assets;

- Little electricity with which to power irrigation pumps and support cold storage or agri-processing industry;

- Degraded irrigation systems that undermine crop yields;

- Poor road infrastructure that inhibits fast and cost-effective distribution to markets;

- Little or no access to cost effective credit to fund these improvements;

- Social and economic distortions associated with illicit poppy cultivation.

The constraints raise costs of production and often make Afghan cash crops uncompetitive vis-à-vis imports from neighbouring countries. Analysis of the inhibitors of economic growth in Afghanistan over the last few years have mostly reached similar conclusions: these include an inadequate supply of raw product, a shortage of processing capabilities/facilities, lack of technical and managerial skills, and poorly functioning domestic markets.

Farmers are continuously improving their technical capacity, which is evident through increases in productivity and crop quality. Rural households are progressively transitioning from practicing subsistence agriculture to engaging in commercial crop production, in response to market signals. However, the rural economies are still growing at a slow rate due to a lack of access to capital. The Afghanistan private sector, particularly in rural areas cannot jumpstart itself due to a distinct lack of services such as business development assistance, strengthening of marketing systems, and insufficient support for infant industries.

Improving farmers', traders' and agribusinesses' access to credit is essential to accelerate growth in the agriculture sector. Lack of capital and access to finance through mainstream banking or micro-credit schemes is recognised as a constraint to economic development. This derives from several factors:

- Lack of incentives for commercial banks to engage in agricultural lending, evidenced by less than $1 \%$ of loans provided by the banking system being directed to agriculture-related activities in 2010

- $\quad$ Lack of Islamic Lending Products and providers thereof;

- Risks inherent in costly enforcement of contracts and the pervasiveness of unregistered land, limiting farmers from pledging their farms as collateral and financial institutions from having recourse on them;

- Security risks preventing financial institutions from expanding their operations in the rural areas;

- Although there are a few microfinance institutions providing credit for agriculture and nonagricultural activities, in the majority of cases the scale of loans, as well as, the terms and conditions offered are unsuitable for agricultural operations.

Land is recognised as an essential commodity in any country. However, in Afghanistan, a mountainous country with 30 percent flat land from which only 13 percent is arable, land becomes a rare commodity. Nearly 40 percent of this land belongs to the Government, most of which is neither identified, nor claimed by the Government. The lack of identification, the dire need for land, the increasing economic interest of the people, in addition to weak and in some parts non-existence of police and judicial system, create opportunities for land grabbing and increasing conflict over land.

Obtaining land to use for commercial purposes remains one of the most significant constraints to economic growth in Afghanistan. Potential investors face considerable uncertainty concerning the availability of suitable land, its cost and the time required to secure the land after it is identified. Surveys in recent years have consistently shown that access to land and electricity are the two most frequently cited obstacles for investors. Moreover, secure access of small-scale farmers, marginalised groups, women, and young people to land (and water) for agricultural use is a key prerequisite for ensuring their food security and improving their livelihoods.

The Government of the Islamic Republic of Afghanistan (GIRoA) has identified industrial estate development as an important platform in its private sector development strategy. It plans to develop 
industrial parks in various parts of Afghanistan in an effort to produce regional balance in industrial growth. Other categories of land that are being leased support the EMD Component via, non-farming commercial usage, manufacturing, public service, and for agriculture, livestock and agri-business. Furthermore, the lack of equitable access to land is one of the drivers for subsistence farmers to enter into opium poppy cultivation. By making land available to the landless and the subsistence farmers we reduce the risk of additional people entering into the narco-world.

There are only a few economic sectors, which have the potential to generate and support the long-term economic growth of which mining and agricultural industries are highly significant contributors. However, significant gains and development in these sectors will not come to pass until some important regulatory land reforms are undertaken to unleash this potential.

During the last 10 years the donor community has been actively supporting the agriculture sector: investments have focused on upgrading production systems through the introduction of advanced crop production technologies, supporting the development of the agricultural markets and building agriculture related infrastructure. As a result of these interventions, productivity of staple crops has doubled in the last 10 years, area planted to fruit and nuts have increased by 600 percent; farmers are increasingly making investment decisions based on market prospects as information asymmetry has been substantially reduced. However these interventions have been mostly disjointed and targeted at specific geographic areas, thus not available to the entire country. In response to these identified constraints and opportunities, a number of complementary initiatives have been developed and will be coordinated under the ARD Cluster framework for enterprise and market development. Together, these will create an enabling environment and set the foundation of a sector-wide strategy for economic growth in the rural sector within Afghanistan.

\subsection{Implementation and Governance}

\subsubsection{Implementation Framework}

On overview of these sub-components highlights a number of common challenges and opportunity for synergies in grouping them as Sub-Components within an integrated Component. These include improved coordination of interventions, attainment of greater policy coherence, reduced overhead, better value for money and increased direct investments along the entire value chain within the agricultural sector. Combining these four Sub-Components under one umbrella Component adds value through closer coordination and more integrated planning, notably through the Program's governance structures and delivery mechanisms, thereby identifying and exploiting synergies and eliminating any potential wasteful overlap.

However, for mainly legal reasons, key activities under these four sub-components cannot be merged into one program. The Afghanistan Land Authority (ARAZI) and the Agricultural Development Fund (ADF) are Executive Agencies with clear mandates in their sub sectors, land and credit. Both have been established in this manner so that they can function semi-autonomously outside of government bureaucracy. Both have their own board structures, which comprise public and private sector members. CARD-F is a multi-ministry facility soon to extend across all 4 Cluster ministries. AREDP is an established program in MRRD within the ARTF and funded by the World Bank.

The Component will initially operate over a three-year timeframe between 2012 and December 2014, however it is expected to continue through to 2024. Overtime, through increased coordination and realignment of activities, this initial project-based approach will help establish the foundations of a comprehensive and integrated sector-wide strategy for agriculture and rural development. This process will also help develop the public sector's role and capacity to foster an enabling environment for agribusiness development and innovation, including through skills development and information dissemination. To this end, MAIL has notably been working on further developing and supporting the concept of Agribusiness Service Centres to support agribusinesses capable of generating employment, local supply chain development, and cooperatives capable of improving rural productivity, value addition and livelihoods.

In accordance with discussions between GIRoA and its international partners, the Component will be funded on-budget. Implementation delivery mechanisms for all outputs of all Sub-Components will be through either public entities or third-party contracting, and further detailed in subsequent integrated 
plans once the NPP is endorsed. Fiduciary risks will be managed and appropriate measures applied to all four Components.

\subsubsection{Governance and Management}

\subsubsection{EMD Governance}

Oversight for each Sub-Component will be provided by a single EMD Operational Board, chaired by the relevant lead Minister or Deputy Minister, which will also be accountable to the IMC and comprising appropriate representatives from Cluster ministries. The Operational Board will focus on technical discussions, coordination and oversight to assure integrated delivery of the Sub-Component outputs.

Three Management Units for the Sub-Components will produce annual business plans and work plans, with operating budgets demonstrating contribution to Component and NPP outcomes. Given the potential for duplication between CARD-F and AREDP, a single Management Unit will provide oversight for interventions under these Sub-Components.

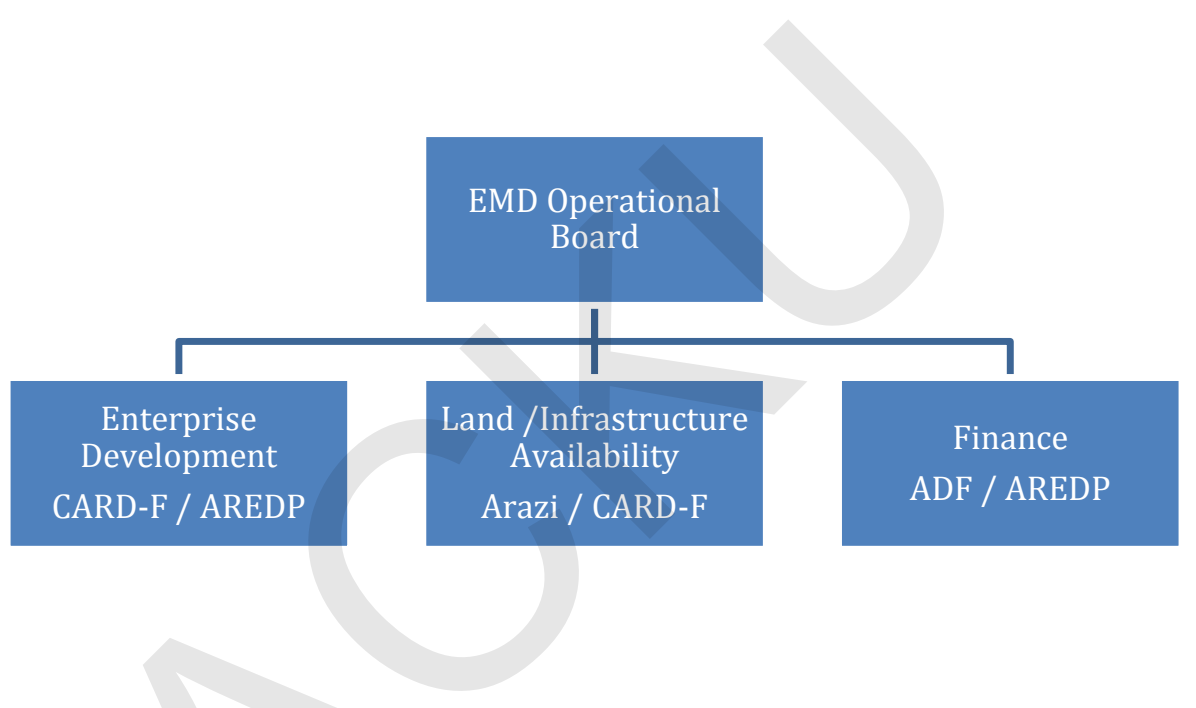

\subsubsection{Sub-Component Management Arrangements}

CARD-F (under Sub-Component 1: Integrated Rural Economic Development and Marketing)

Currently a single lead contractor has been contracted by DFID to act as a Managing Agent and is responsible for procurements and for the provision of technical support to the national Management Unit. However it is anticipated that this role will evolve to an advisory role once the programme is onbudget. EDPs are contracted through the relevant GIRoA line ministries using national procurement systems and policies. Once on budget, the Management Agent will assume an advisory role to the CARD-F team. A subcontract has been placed with a Monitoring Agent for services to assess and limit fiduciary risks to donors.

DFID has budgeted \$45 million as its commitment to CARD-F over the period 2009 to 2013. This funding will cover expenditure up to approximately five EDPs and also the EDP design, implementation as well as monitoring and evaluation costs arising through the CARD-F Management Unit, technical assistance to the Management Unit, and Managing Agent costs. By fully funding the early EDPs and by funding a share of the design, implementation and monitoring costs (initially 100 per cent then declining over time as other donors join the programme), DFID will seek to complete its expenditure on CARD-F during 2015 as the implementation of each of the five EDPs it supports is spread over 3 to 4 years.

The staff requirements of CARD-F are spread across senior management, operations, administration, $\mathrm{M} \& \mathrm{E}$ and procurement. As additional provinces are added, there will be a requirement to add further 
offices. The Kabul based staff are unlikely to increase as operational work transfers to the provincial staffing. The Sub-Component budget of CARD-F over the period $2012-2014$ is in the region of $\$ 301 \mathrm{~m}$, comprising $\$ 10.75$ million in management and $\$ 290 \mathrm{~m}$ in programme costs.

$\underline{\text { CARD-F Budget (2012-2014) }}$

\begin{tabular}{|l|l|l|l|l|}
\hline & $\mathbf{2 0 1 2}$ & $\mathbf{2 0 1 3}$ & $\mathbf{2 0 1 4}$ & Totals \\
\hline Management Costs & $\$ 2.50 \mathrm{~m}$ & $\$ 3.25 \mathrm{~m}$ & $\$ 5.00 \mathrm{~m}$ & $\mathbf{\$ 1 0 . 7 5 m}$ \\
\hline Programme Costs & $\$ 50.00 \mathrm{~m}$ & $\$ 120.00 \mathrm{~m}$ & $\$ 120.00 \mathrm{~m}$ & $\mathbf{\$ 2 9 0 . 0 0 m}$ \\
\hline Total & $\mathbf{\$ 5 2 . 5 0 m}$ & $\mathbf{\$ 1 2 3 . 2 5 m}$ & $\mathbf{\$ 1 2 5 . 0 0 m}$ & $\mathbf{\$ 3 0 0 . 7 5 m}$ \\
\hline
\end{tabular}

\section{AREDP (Under Sub-Component 2: Rural Enterprise Development)}

AREDP will establish a project steering board (PSB), chaired by the Minister of Rural Rehabilitation and Development and including representatives from various ministries, donors, private sector institutions, which will be responsible for overall policy, strategic planning and project oversight. Funding is provided to AREDP Project Management Office, headed by an Executive Director and staffed with technical and financial management staff. AREDP issues contracts directly with international and national contractors to provide specific services in support of the AREDP objectives. AREDP has secured full funding commitments for the three-year NPP period.

Arrangements for delivery of business development services and increased access to financial services will be allocated to specialist suppliers who bring their business networks, specialist technical skills and management systems to the project. AREDP will contract an experienced financial service supplier to administer a partial guarantee facility that intends to cover default risk facing partner banks who lend to target SMEs.

The programme management component of AREDP was designed to plan, manage, supervise and monitor the implementation of all programme activities. AREDP is implemented by a specialized unit created within the MRRD. The unit, operating at central and provincial levels, acts as an independent entity within the MRRD. AREDP finances salaries of contracted staff and various operational expenses of the central and provincial offices. Professional staff are selected from the market through a competitive process.

The Component budget of AREDP over the period 2012 - 2014 is \$50 million, comprising \$15 million in management and $\$ 35$ million in programme costs. The total required budget for the programme activity for 5 years is $\$ 87$ million, out of which $\$ 71.9$ million is secured, an additional $\$ 15.1$ million will still require donor funding to complete the Sub-Component as stated in the AREDP proposal document.

AREDP Budget (2012-2014)

\begin{tabular}{|l|l|l|l|l|}
\hline & $\mathbf{2 0 1 2}$ & $\mathbf{2 0 1 3}$ & $\mathbf{2 0 1 4}$ & Totals \\
\hline Management Cost & $\$ 5.2$ & $\$ 5.0$ & 4.8 & $\mathbf{\$ 1 5 m}$ \\
\hline Programme Costs & $\$ 16.0$ & $\$ 12.0$ & 7.0 & $\mathbf{\$ 3 5 m}$ \\
\hline Totals & $\mathbf{\$ 2 1 . 2}$ & $\mathbf{\$ 1 7 . 5}$ & $\mathbf{\$ 1 1 . 8}$ & $\mathbf{\$ 5 0 m}$ \\
\hline
\end{tabular}

\section{ADF(under Sub-Component 3: Sustainable Agricultural Credit)}

A single lead contractor is contracted to USAID to act as a Managing Agent and is responsible to the Executive Agency responsible for ADF. All national staff recruited within the managing agent are expected to transition to the ADF. ADF is an executive agency with a significant degree of independence, with guarantees of its integrity bound by the Articles of Association and its Credit

\footnotetext{
${ }^{6}$ This CARD-F budget figure would be contracted in 3 years and implemented in 7 years.
} 
Policies and Procedures. ADF will progressively grow the lending capital up to $\$ 100$ million. The ACE programme will progressively reduce its investments in technical assistance and eliminate its expatriate positions between 2012 and 2015.

ADF currently relies on a number of key international staff, which it is looking to reduce over time, supported by a body of local national staff. The Sub-Component budget of ADF is presently $\$ 100$ million. Over the period 2012 - 2014 the budget is \$171 million, comprising \$16 million in management and $\$ 155$ million in programme costs. The current management costs are paid directly to the implementing agency and not reflected in this budget.

$\underline{\text { ADF Budget (2012-2014) }}$

\begin{tabular}{|l|l|l|l|l|}
\hline & $\mathbf{2 0 1 2}$ & $\mathbf{2 0 1 3}$ & $\mathbf{2 0 1 4}$ & Totals \\
\hline Management Costs & $\$ 6 \mathrm{~m}$ & $\$ 6 \mathrm{~m}$ & $\$ 4 \mathrm{~m}$ & $\mathbf{\$ 1 6 m}$ \\
\hline Programme Costs & $\$ 70 \mathrm{~m}$ & $\$ 50 \mathrm{~m}$ & $\$ 35 \mathrm{~m}$ & $\mathbf{\$ 1 5 5 m}$ \\
\hline Totals & $\mathbf{\$ 7 6 m}$ & $\mathbf{\$ 5 6 m}$ & $\mathbf{\$ 3 9 m}$ & $\mathbf{\$ 1 7 \mathbf { m } ^ { \mathbf { 7 } }}$ \\
\hline
\end{tabular}

\section{Arazi(Under Sub-Component 4: Afghanistan Land Authority)}

Arazi was established as a directorate with limited ad-hoc support from specialist contractors. Having an increasingly complex set of deliverables, technical support will be required. It is intended that Arazi appoints a single lead contractor to support it in the delivery of its outputs. An assessment of the fiduciary risks is needed and appropriate measures put in place to mitigate any concerns.

Arazi operates with a core team of key staff supported by a body of specialist consultants. Staff are based in Kabul and in selected provinces. The Sub-Component budget of Arazi over the period $2012-$ 2014 is $\$ 58.5 \mathrm{~m}$, comprising \$22.5 million in management and \$36 million in programme costs.

Arazi Budget (2012-2014)

\begin{tabular}{|l|l|l|l|l|}
\hline & $\mathbf{2 0 1 2}$ & $\mathbf{2 0 1 3}$ & $\mathbf{2 0 1 4}$ & Totals \\
\hline Management Cost & $\$ 7.5 \mathrm{~m}$ & $\$ 7.5 \mathrm{~m}$ & $\$ 7.5 \mathrm{~m}$ & $\mathbf{\$ 2 2 . 5 m}$ \\
\hline Programme Costs & $\$ 12.0 \mathrm{~m}$ & $\$ 12.0 \mathrm{~m}$ & $\$ 12.0 \mathrm{~m}$ & $\mathbf{\$ 3 6 . 0 m}$ \\
\hline Totals & $\mathbf{\$ 1 9 . 5 m}$ & $\mathbf{1 9 . 5 m}$ & $\mathbf{\$ 1 9 . 5 m}$ & $\mathbf{\$ 5 8 . 5 m}$ \\
\hline
\end{tabular}

\subsubsection{Technical Assistance}

Each Sub-Component will be supported by external facilitating partners, as necessary, with reduced involvement toward the Component's end. National counterpart staff within Sub-Components will transition to MAIL and MRRD, as appropriate.

CARD-F (under Sub-Component 1: Integrated Rural Economic Development and Marketing)

The technical assistance component of the CARD-F Program runs until March 2013 and is based on building capacity to deliver and procure EDPs and provide contract management support and M\&E during EDP implementation. If CARD-F is to expand under this Sub-Component to provide national coverage, then additional support will be reviewed and required to 2016 and beyond.

\section{AREDP (Under Sub-Component 2: Rural Enterprise Development)}

\footnotetext{
${ }^{7}$ These funds carry through to 2015 , increased funding of $\$ 71 \mathrm{~m}$ will be required prior to the end of 2014 to ensure the program is self-sustainable by end of 2015 .
} 
The technical assistance requirements for the AREDP are designed to meet the program objectives:

\begin{tabular}{|c|c|}
\hline ELEMENTS & TECHNICAL ASSISTANCE \\
\hline $\begin{array}{l}\text { Objective 1: Improve } \\
\text { employment opportunities } \\
\text { for rural men and women; } \\
\text { Objective 2: Increase } \\
\text { income of rural men and } \\
\text { women; } \\
\text { Objective 3: Provide } \\
\text { business know-how for } \\
\text { sustainability of targeted } \\
\text { local enterprises. }\end{array}$ & $\begin{array}{l}\text { - Consultancy assignments for Provincial Situation Analysis in the } \\
\text { provinces } \\
\text { Consultancy assignments for development of community enterprise } \\
\text { action plans in the provinces } \\
\text { Consultancy assignments for specific training to Enterprise Groups } \\
\text { in the provinces, \& for value chain development \& access to } \\
\text { markets } \\
\text { - Consultancy assignments for training of Village Savings \& Loan } \\
\text { Associations } \\
\text { Consultancy assignment for administration of Partial Risk } \\
\text { Guarantee Facility \& development of lending/financing products by } \\
\text { Financial Institutions } \\
\text { Consultancy assignments for: MIS, Office building design, Impact } \\
\text { analysis, Process monitoring, Technical audit, Program Technical } \\
\text { studies } \\
\text { International consultants for providing support in: Program } \\
\text { Operations and Management, Access to Finance, Business } \\
\text { Development Services, Training, Procurement, Finance, Human } \\
\text { Resources }\end{array}$ \\
\hline
\end{tabular}

The actual number of consultants in each category can only be determined as the interventions in provinces/districts occur. Overtime and expansion of the Sub-Component, the level of assistance required will be reviewed.

ADF(under Sub-Component 3: Sustainable Agricultural Credit)

The technical assistance component of the ADF-Support Program is fundamentally based on maintaining the same level of effort currently provided by the ACE program, with a one-year extension over the current implementation horizon, until December 2015. This will allow ADF to benefit from the expertise of the professional team that structured the ADF. Overtime and expansion of the SubComponent, the level of assistance required will be reviewed.

Arazi(Under Sub-Component 4: Afghanistan Land Authority)

Arazi will require the following expertise to ensure ASC-XP success:

\begin{tabular}{|l|l|}
\hline Function & $\begin{array}{l}\text { No. Of } \\
\text { consultants }\end{array}$ \\
\hline CEO Office & 3 \\
\hline Land Clearance Directorate & 2 \\
\hline Land Inventory Directorate & 2 \\
\hline Land Lease Directorate & 1 \\
\hline Land Conflict Resolution Directorate & 2 \\
\hline Monitoring and Evaluation & 1 \\
\hline Total & 11 \\
\hline
\end{tabular}

Overtime and expansion of the Sub-Component, the level of assistance required will be reviewed.

\subsection{EMD Sub-Components}

Initially implemented through existing programmatic instruments and institutional entities, all four of the Sub-Components are envisaged as running for an initial three-year period between 2012 and 2014, 
with an extended lifecycle of approximately 10 years. The table below shows the primary activities undertaken by the four EMD Sub-Components.

\begin{tabular}{|l|c|c|c|c|}
\hline \multicolumn{1}{|c|}{$\begin{array}{c}\text { Sub-Components } \\
\text { Activities }\end{array}$} & $\begin{array}{c}\text { Integrated Rural } \\
\text { Economic } \\
\text { Development \& } \\
\text { Marketing } \\
(\text { CARD-F })\end{array}$ & $\begin{array}{c}\text { Rural Enterprise } \\
\text { Development } \\
(\text { ARDEP })\end{array}$ & $\begin{array}{c}\text { Sustainable } \\
\text { Agricultural } \\
\text { Credit } \\
(\text { ADF })\end{array}$ & $\begin{array}{c}\text { Afghanistan } \\
\text { Land Authority } \\
(\text { ARAZI) }\end{array}$ \\
\hline Value-chains & $\bullet$ & $\bullet$ & $\bullet$ & $\bullet$ \\
\hline Demand side & $\bullet$ & $\bullet$ & $\bullet$ & $\bullet$ \\
\hline Supply side & $\bullet$ & $\bullet$ & $\bullet$ & $\bullet$ \\
\hline Finance provision & $\bullet$ & $\bullet$ & $\bullet$ & $\bullet$ \\
\hline $\begin{array}{l}\text { Government } \\
\text { capacity building }\end{array}$ & $\bullet$ & $\bullet$ & & $\bullet$ \\
\hline Infrastructure & $\bullet$ & & & $\bullet$ \\
\hline $\begin{array}{l}\text { Community } \\
\text { Development }\end{array}$ & & & & $\bullet$ \\
\hline
\end{tabular}

Detailed project documents and implementation plans for each of the main activities under EMD SubComponents have been developed and are referenced in Annexes. Revised implementation plans will be developed following the initial phase, towards a more coordinated and integrated approach to Component implementation and expansion.

\subsubsection{Sub-Component 1: Integrated Rural Economic Development and Marketing}

\subsubsection{Background}

The Comprehensive Agriculture \& Rural Development Facility (CARD-F), established in late 2009, tackles identified constraints through a holistic approach to maximising economic growth by building rural and agricultural value-chains, as well as investing in the infrastructure that supports them.

Farm production and distribution are evolving from the simple isolated transactional relationships that characterised traditional rural economies, to the rapid and widespread emergence of integrated linkages and close commercial alignments between business partners. Value chains are widely seen as the normative business development framework in the agri-food sector, embracing co-ordination and cooperation between farmers and enterprises at the different stages of the chain, for mutual commercial advantage.

CARD-F has the goal of facilitating sustainable growth in legal rural incomes and employment in target districts.

CARD-F specifically seeks to provide a means of designing, coordinating and funding high-impact interventions through integrated Economic Development Packages (EDPs) for targeted value chains that build on and utilise, as far as possible, existing programmes and projects. The jobs created through CARD-F provide rural men and women with regular sources of income, preventing them from reengaging in the poppy industry. Such programmes and projects are predominantly those of the Ministry of Agriculture, Irrigation \& Livestock (MAIL) and the Ministry of Rural Rehabilitation \& Development (MRRD) and in the near future the Ministry of Energy and Water (MEW).

CARD-F directly addresses the objective of the Agriculture and Rural Development (ARD) Cluster, to build prosperous rural and pastoral communities. It does this by developing the above-mentioned EDPs designed to stimulate competitive rural communities through delivering missing components of identified Value Chains and procuring Implementation Consultants (ICs) to support development of discrete elements of the identified value chains.

EDPs are developed following a consultation period during which farmers, entrepreneurs and other stakeholders express their preferences and priorities for local programmes. CARD-F staff, working with counterparts from the ARD Cluster ministries, undertake surveys, diagnostic studies and 
economic impact assessments to determine the feasibility and relative impact of suggested schemes. Then following further local, provincial and national consultations a final recommendation is made. The EDP is then presented to the Inter-Ministerial Committee (IMC) for approval.

EDPs are implemented by contracted Implementation Partners (government ministries, government programmes, private sector enterprises and NGOs) working under direct contract to one of the three Government Ministries supported by CARD-F.

A total of 9 EDPs in four Provinces have now been designed, and \$17 million of EDP works have been contracted, using Afghan Government procurement systems. A further $\$ 10$ million of EDP procurement work is currently in the pipeline at the moment.

An initial fund of US $\$ 45 \mathrm{~m}$ was made available through the United Kingdom's Department for International Development (DFID) to assist in the development and implementation of the first EDPs, although approximately $\$ 301$ million will be required if all EDPs across 12 provinces are to be developed.

\subsubsection{Scope}

Inadequate supply of raw product, a shortage of processing capabilities and facilities, lack of technical and managerial skills, and poorly functioning domestic markets are the main challenges in rural development. Under the framework of this sub-component EMD addresses this by developing Economic Development Packages (EDPs) to stimulate competitive rural communities through strengthening selected agricultural value-chains and inviting either other NPPs or external private sector institutions to support discrete elements.

In the initial phase, activities under this Sub-Component will be primarily supported by the Comprehensive Agriculture and Rural Development Facility (CARD-F). CARD-F focuses on generating economic value through enhancing selected value chains in priority provinces. The SubComponent targets the value chains with the greatest economic potential and then delivers interventions, by means of EDPs, to increase their impact in target economies. Initial activities will include the development of economic development packages (expanded to 12 provinces and 60 districts) and the procurement of economic support packages. The initial estimated economic impact is 43,000 jobs created, 66,000 jobs safeguarded, and $\$ 724$ million in net benefit.

\subsubsection{Deliverables}

CARD-F results and activities 2012-2014:

\begin{tabular}{|c|c|}
\hline Results & Activities \\
\hline $\begin{array}{l}\text { Preparation of Economic Development } \\
\text { Packages }\end{array}$ & $\begin{array}{l}\text { Currently } 9 \text { EDPs are completed } \\
\text { representing funding requirement of } \sim \$ 45 \\
\text { million } \\
5 \text { further EDPs will be prepared in } 2012 \\
\text { By the end of } 2014, \text { EDPs will be expanded } \\
\text { to cover } 12 \text { provinces and } 60 \text { districts }\end{array}$ \\
\hline Procurement of economic support & $\begin{array}{l}\text { Currently } 3 \text { packages have been procured } \\
\text { with } \$ 17 \text { million commitment; and } 2 \text { other } \\
\text { packages are in the procurement stage } \\
\text { By the end of } 2014 \text { EDPs for } 12 \text { provinces } \\
\text { and } 60 \text { districts could be procured. }\end{array}$ \\
\hline Estimated economic impact & $\begin{array}{l}43,000 \text { jobs created } \\
66,000 \text { jobs safeguarded } \\
\$ 724 \text { million in net benefit }\end{array}$ \\
\hline
\end{tabular}

\subsubsection{Sub-Component 2: Rural Enterprise Development}

\subsubsection{Background}


The Afghanistan Rural Enterprise Development Programme (AREDP) was designed as a national multi-donor funded, Government-led programme to jump start private sector growth in rural Afghanistan. AREDP strengthens the private sector through integrated, value chain, knowledge based interventions from top to bottom and community enterprise development from bottom to top. AREDP is one of MRRD's six national programmes.

The overall objectives of AREDP are to: improve employment opportunities for rural men and women; Increase income of rural men and women; and provide business know-how for sustainability of targeted local enterprises. These objectives will be achieved by enhancing participation of the rural poor in economic activities, supporting them through business development services and access to finance, and improving market linkages and value chains.

The AREDP component will address failures in the markets for business development services and financial services for rural enterprises through a government-led initiative that targets rural areas for specific purpose of providing easy access to credit and business advisory services, while partnering and coordinating with other government entities as well as the private sector through integrated, value chain, knowledge based interventions from top to bottom, community enterprise from bottom to top and by addressing credit and capital needs of rural entrepreneurs.

AREDP has been designed as a two pronged approach with Sub-Component 1: Community-led Enterprise Development; support to village-based enterprise activities, including access to finance; and Sub-Component 2: SME Development; support to rural and semi-urban SMEs, especially those that have backward linkages to rural areas.

Significant investment has been made in the creation of self-help groups (created mainly by NGOs), and these groups have become the basis for further entrepreneurial activities within AREDP. Rural entrepreneurs are often unable to effectively market their products due to uneven quality, lack of knowledge of market demand and limited market access, particularly outside of their immediate surroundings. AREDP aims to improve and 'marry' two critical players of the value chain, i.e. the producers on the one hand, and the buyers on the other, and allow production to be further refined to match market demand.

Afghanistan Rural Enterprise Development Program officially started its activities in June 2010, after the completion of a pilot phase in Parwan and Bamiyan. Since then, AREDP has consistently expanded its operations. The program has now transitions from the pilot to main phase and has significant achievements to date.

AREDP focuses the bulk of their attention at the community level and can raise the incomes of the poorer members of these communities. Once involved in business opportunities the link to CARD at a slightly higher economic level can be achieved.

\subsubsection{Scope}

The aim of this sub-component is to improve employment and income of rural men and women, and the sustainability of targeted local enterprises, through nationwide support to community-based enterprise and Small and Medium Enterprise (SME) development. The interventions of this subcomponent will follow up on FFL interventions that work at the grass root levels, while CARD-F targets value chain development at a slightly higher level involving commercial farmers and commercial production.

In the initial phase, activities under this Sub-Component will be primarily supported by the Afghanistan Rural Enterprise Development Program (AREDP). AREDP was designed as a multidonor, GIRoA-led program to improve rural employment and income, and to strengthen the private sector through savings groups and progressively building these into larger, more efficient institutions capable of supporting increasingly complex lending. The Sub-Component also supports business skills development. Initial activities will include the promotion of 10,500 Saving Groups, 3,675 Farmer Support Groups, 6,420 Enterprise Groups, 2,247 FEGs, 1,280 Village Savings and Loan Associations, as well as facilitating and supporting 640 SMEs. Efforts will be made to focus on CN-priority provinces during the first 3-years of implementation through enhanced collaboration between MRRD and $\mathrm{MCN}$. 


\subsubsection{Deliverables}

AREDP results and activities 2012-2014:

\begin{tabular}{|c|c|}
\hline Results & Activities \\
\hline Promotion of Savings Groups & $\begin{array}{l}\text { Year } 1=4000 \\
\text { Year } 2=4000 \\
\text { Year } 3=2500 \\
\text { Total }=10,500\end{array}$ \\
\hline Promotion of FSGs & $\begin{array}{l}\text { Year } 1=1400 \\
\text { Year } 2=1400 \\
\text { Year } 3=875 \\
\text { Total }=3,675\end{array}$ \\
\hline Promotion of Enterprise Groups & $\begin{array}{l}\text { Year } 1=2500 \\
\text { Year } 2=3000 \\
\text { Year } 3=920 \\
\text { Total }=6,420\end{array}$ \\
\hline Promotion of FEGs & $\begin{array}{l}\text { Year } 1=875 \\
\text { Year } 2=1050 \\
\text { Year } 3=322 \\
\text { Total }=2,247\end{array}$ \\
\hline Promotion of VSLAs & $\begin{array}{l}\text { Year } 1=450 \\
\text { Year } 2=450 \\
\text { Year } 3=380 \\
\text { Total }=1,280\end{array}$ \\
\hline Facilitating and Supporting SMEs & $\begin{array}{l}\text { Year } 1=300 \\
\text { Year } 2=200 \\
\text { Year } 3=140 \\
\text { Total }=640\end{array}$ \\
\hline
\end{tabular}

\subsubsection{Sub-Component 3: Sustainable Agriculture Credit}

\subsubsection{Background}

The Agricultural Development Fund (ADF) is designed as a wholesale lending entity that lends the majority of funds through financial institutions and a smaller portion to non-financial institutions, while making a limited number of loans to agribusinesses. This is to be achieved through the provision of grants to cover some of the additional risks brought about by lending to farmers and farmers cooperatives.

The ADF was established with a $\$ 100$ million grant to GIRoA for an initial period of four years. During this first four years the US Government is also providing technical assistance for the management of the fund through the Agricultural Credit Enhancement (ACE) Programme. The ADF focuses its efforts in support of strategic value chains, i.e. those that by being competitive have the highest probability of promoting economic growth. This strategic focus constitutes an additional safeguard against market risk, which previous rural finance development programmes overlooked.

The level of effort under the current technical assistance contract is expected to progressively diminish until its end in December 2014. Under the ADF Expansion, additional lending capital will require the extension of the technical assistance to the ADF to guide the expansion of its portfolio and ensure the optimal allocation of resources. The proposed expansion will have an implementation horizon of 3 years, beginning in 2013, thereby allowing for the overlap with the on-going technical assistance programme.

This will be an activity led and managed by MAIL. However, it is crucial to note that the ADF is an executive agency with a significant degree of independence, which guarantees its integrity.

Recent analyses suggest that the minimum efficiency scale of the ADF, at which it would be able to sustain its operations while progressively growing the lending capital, is approximately $\$ 180$ million. 
To date, several financial institutions and projects are providing specific credit services such as: micro finance, support to small and medium enterprises (SMEs), construction, working capital, equipment, trade, equity, loan guarantees, equity and market information. However, access to credit for the agriculture sector remains limited and not sufficiently tailored to the direct needs of agriculture.

It is essential to develop a range of financial services adapted to the needs of farmers, from small to large-scale, as well as investors, processors and traders. MAIL is committed to ensuring that women producer groups and entrepreneurs can access the credit they require as easily as men. Credit facilities should also be developed to suit the needs of the Kuchi people. It is also important to ensure that Sharia compliant mechanisms are available within this range of financial services, and the ADF is committing resources and effort to develop suitable products.

IFAD (the International Fund for Agricultural Development) estimates that around 3.5 million clients are still un-served by the micro-finance sector. According to IFAD's Rural Microfinance and Livestock Support Programme (RMLSP) Appraisal Report, "The microfinance sector does not currently provide a broad range of financial services, such as loans designed specially for agriculture or livestock; there is lack of savings services; there are limited insurance products; and little has been done to develop Islamic modes of financing. The IFAD appraisal team and senior staff of MAIL, are concerned about the effect of current high rates of interest in the microfinance sector, now about $18 \%$ flat rate. There seems to be little prospect of reducing these rates until the sector achieves maturity, higher volumes, and more efficient MFIs [Micro Finance Institutions], thus reducing lending costs."

In brief, the ADF constitutes an unprecedented initiative, which has the potential to enable farm investment, capitalising on growing technical knowledge and access to markets provided by an array of agricultural development programmes, and thereby promoting the rapid growth of the agriculture sector. The congruency between MAIL policies and ADF priorities has the potential to maximize the effectiveness and the impact of agricultural credit.

\subsubsection{Scope}

Under the framework of this sub-component, EMD will facilitate and support the rapid growth of the agriculture sector by providing sustainable credit tailored for all farming and agri-business purposes, and improving employment and income of rural people.

In the initial phase, activities under this Sub-Component will be primarily supported by the Agricultural Development Fund (ADF). ADF was established to accelerate and increase the volume, value and structure of credit available to rural businesses and financial institutions for on-lending. Among others, initial activities will include lending to farmers' organizations and agribusinesses, innovation grants, and Islamic financial products.

\subsubsection{Deliverables}

ADF results and activities 2012-2014:

\begin{tabular}{|c|c|}
\hline Results & Activities \\
\hline $\begin{array}{l}20 \text { financial intermediaries and } 100 \text { non- } \\
\text { financial intermediaries participating }\end{array}$ & $\begin{array}{l}\text { Provision of wholesale lending } \\
\text { Lending to Associations and Cooperatives } \\
\text { Direct lending to agri-businesses } \\
\text { Direct lending to CARD-F, Arazi and } \\
\text { AREDP clients }\end{array}$ \\
\hline $\begin{array}{l}10 \text { financial intermediaries and } 50 \text { non- } \\
\text { financial intermediaries with strengthened } \\
\text { capacity for on-lending }\end{array}$ & $\begin{array}{l}\text { Award of innovation grants to off-set the } \\
\text { higher risks / transaction costs associated } \\
\text { with rural and agricultural lending }\end{array}$ \\
\hline $\begin{array}{l}3 \text { new innovative lending products } \\
\text { established either through Centre of } \\
\text { Excellence for Islamic Lending and/or } \\
\text { participating intermediates. }\end{array}$ & $\begin{array}{l}\text { Establish a finance innovation team } \\
\text { Design and test financial products } \\
\text { Design and test lending products }\end{array}$ \\
\hline $\begin{array}{l}6 \text { policies supporting Islamic Finance } \\
\text { Regulations and } 6 \text { Islamic lending products }\end{array}$ & $\begin{array}{l}\text { Establish an Islamic Finance Institute } \\
\text { Design, launch and supervision of Islamic }\end{array}$ \\
\hline
\end{tabular}




\begin{tabular}{|l|l|}
\hline developed & $\begin{array}{l}\text { financial products } \\
\text { Mentorship and formal training to ADF staff } \\
\text { Design and guidance in policy dialogue in } \\
\text { Islamic finance }\end{array}$ \\
\hline $\begin{array}{l}\$ 185 \text { million disbursed (Note these figures cover 2015) } \\
214,000 \text { farmers supported } \\
\text { Household income for ADF borrowers increases by } 10 \text { percent per year }\end{array}$ \\
\hline
\end{tabular}

\subsubsection{Sub-Component 4: Afghanistan Land Authority}

\subsubsection{Background}

Established in September 2009, Arazi (the Afghanistan Land Authority) was set-up as a project within MAIL, becoming an Executive Agency a year later in September 2010. Arazi's mission is to eliminate economic constraints, by improving access to governmental lands for economic and commercial activities. Arazi now operates as a single reference point for both domestic and international investors interested in using government land for investment purposes. Arazi is teamed with the previous named AMLAK departments of MAIL for the delivery of services at sub-national level.

Arazi focuses on regulatory reforms and operations that support the infrastructure needed for long-term economic growth. It seeks to achieve this by directly increasing access to public land for lease, and indirectly through activities supporting private sector and industry development. It also supports the development of the mineral sector and the associated infrastructure investments for the planned Resource Corridors, which will require large-scale land acquisition in coming years. A strong land management system will foster a better environment for the private sector to encourage investment, entrepreneurship and innovation.

Arazi undertakes other actions, including strengthening land-titling systems, zoning and planning regulation, clarifying property rights, and improving the management of public land for noncommercial activities.

Arazi has an emphasis on industrial park development as a response to the difficulties investors face in acquiring land with a clear title for setting up production facilities. Industrial parks are also viewed as an effective means of focusing the provision of infrastructural and utility services, which are in short supply in Afghanistan. Other categories of land that are being leased support Enterprise and Market Development via, non-farming commercial usage, manufacturing, public service, and for agriculture, livestock and agri-business.

Increased and sustained economic development and growth in the above sectors require access to land. Arazi will work closely with the Ministry of Mines (MoM) as well as give priority to this sector's activities. Arazi will implement measures to facilitate access to land by clarifying property rights, simplifying procedures for the transfer of titles, and facilitating an environment for increased leasing.

Another challenge is lack of technical expertise with regards to land management systems in the country given that it is the first time that a process as specific and as technical as land management is being introduced.

Arazi aims to remove economic constraints, by improving access to governmental lands for commercial activities. Land is a very sensitive issue and has become a highly political topic in Afghanistan where the existing legislation, land management law, policies and procedures that are the main tools that Arazi can use to achieve its goals, are deficient, ineffective and contradictory. Law enforcement in relation to land faces many challenges and contributes to an ever-growing land mafia who utilise government lands for poppy cultivation.

\subsubsection{Scope}

The aim of this sub-component is to implement and enforce the Afghanistan Land Management law by making available Government-owned land for industrial use, providing equitable land access for subsistence farmers and the landless, and strengthening land enforcement mechanisms. 
This Sub-Component will primarily be implemented by the Afghanistan Land Authority (ARAZI). ARAZI was established to significantly increase the amount, quality and security of Goverment-owned land available for licit economic use and investment; its role includes land titling, zoning, planning and property rights. Initial activities will include land allocation for commercial purposes, mediation and arbitration support, mapping, survey and registration of land, land policy development and legislative reform.

\subsubsection{Deliverables}

ARAZI results and activities:

\begin{tabular}{|l|l|}
\hline Results & Activities \\
\hline \multirow{5}{*}{$\begin{array}{l}\text { Support and encourage economic } \\
\text { development }\end{array}$} & $\begin{array}{l}\text { Establish Industrial Parks and allocation of } \\
\text { land for other commercial purposes } \\
\text { Establish mediation and arbitration authority } \\
\text { Mapping, survey and registration of land } \\
\text { Draft commercial laws /amendments to } \\
\text { support private sector investment }\end{array}$ \\
\hline \multirow{5}{*}{ Develop Arazi institutional framework } & $\begin{array}{l}\text { Establish 3-person research unit } \\
\text { Establish 12 provincial offices } \\
\text { Provide guidelines, procedures and policies } \\
\text { on the internet for land management. }\end{array}$ \\
\hline & $\begin{array}{l}\text { Complete Land Management Law } \\
\text { amendments with Ministry of Justice (MOJ) } \\
\text { in 2012 } \\
\text { Identify capacity bottlenecks in court system } \\
\text { and police to resolve conflicts in land rights } \\
\text { Complete subsidiary land management laws } \\
\text { (wildlife, forests and national parks) with } \\
\text { MOJ } \\
\text { Complete National Land Strategy by end } \\
\text { 2013 }\end{array}$ \\
\hline
\end{tabular}




\section{ANNEXES}

\section{Annex: Component Budgets}

\subsection{FFL Budget}

\begin{tabular}{|c|c|c|c|c|c|}
\hline No. & Item & Year 2013 & Year 2014 & Year 2015 & Total \\
\hline 1 & Sub-Component 1: Data and Information Base & $1,500,000$ & $1,500,000$ & $1,200,000$ & $4,200,000$ \\
\hline 2 & Sub-Component 2: Cereals \& Legumes & $16,000,000$ & $42,000,000$ & $60,000,000$ & $118,000,000$ \\
\hline 3 & Sub-Component 3: Horticulture & $11,200,000$ & $28,000,000$ & $40,000,000$ & $79,200,000$ \\
\hline 4 & Sub-Component 4: Livestock & $16,000,000$ & $35,000,000$ & $50,000,000$ & $101,000,000$ \\
\hline 5 & Sub-Component 5: Food Nutrition & $1,000,000$ & $3,000,000$ & $4,500,000$ & $8,500,000$ \\
\hline 6 & $\begin{array}{l}\text { Sub-Component 6: Emergency Preparedness\& } \\
\text { Response }\end{array}$ & $10,000,000$ & $25,000,000$ & $25,000,000$ & $60,000,000$ \\
\hline 7 & $\begin{array}{l}\text { Sub-Component 7: Integrated Pest } \\
\text { Management }\end{array}$ & $1,600,000$ & $4,200,000$ & $4,800,000$ & $10,600,000$ \\
\hline 8 & Sub-Component 8: Dry Land Farming & $1,500,000$ & $2,500,000$ & $2,500,000$ & $6,500,000$ \\
\hline 9 & Program Operation Costs & $16,000,000$ & $28,000,000$ & $40,000,000$ & $84,000,000$ \\
\hline & Total Budget & $74,800,000$ & $169,200,000$ & $228,000,000$ & $472,000,000$ \\
\hline
\end{tabular}




\subsection{EMD Budget}

The table below presents the estimated consolidated budget for the EMD Component over the period $2012-2014$. This shows that the overall cost will be in the region of $\$ 580 \mathrm{~m}$, with CARD-F (under Sub-Component 1) the largest contributor at $\$ 301 \mathrm{~m}$. Current funding stands at $\$ 175 \mathrm{~m}$, leaving a shortfall of $\$ 405 \mathrm{~m}$. (All budgets will be reviewed when available funds are known).

EMD Component Consolidated Budget (2012-2014)

\begin{tabular}{|l|c|c|r|r|}
\hline Sub-Components & $\mathbf{2 0 1 2}$ & $\mathbf{2 0 1 3}$ & $\mathbf{2 0 1 4}$ & Total (USD) \\
\hline $\begin{array}{l}\text { Integrated Rural Economic Development and } \\
\text { Marketing (CARD-F) }\end{array}$ & $52,500,000$ & $123,250,000$ & $125,000,000$ & $\mathbf{3 0 0 , 7 5 0 , 0 0 0}$ \\
\hline Rural Enterprise Development (AREDP) & $14,500,000$ & $20,500,000$ & $15,000,000$ & $\mathbf{5 0 , 0 0 0 , 0 0 0}$ \\
\hline Sustainable Agriculture Credit (ADF) & $76,000,000$ & $56,000,000$ & $39,000,000$ & $\mathbf{1 7 1 , 0 0 0 , 0 0 0}$ \\
\hline Afghanistan Land Authority (Arazi) & $19,500,000$ & $19,500,000$ & $19,50 \mathrm{~m}$ & $\mathbf{5 8 , 5 0 0 , 0 0 0}$ \\
\hline Total Budget & $\mathbf{1 6 2 , 5 0 0 , 0 0 0}$ & $\mathbf{2 1 9 , 2 5 0 , 0 0 0}$ & $\mathbf{1 9 8 , 5 0 0 , 0 0 0}$ & $\mathbf{5 8 0 , 2 5 0 , 0 0 0}$ \\
\hline
\end{tabular}

While resources from international partners will be critical in meeting this funding requirement, emphasis will be placed during the EMD Component period on increasing the level of GIRoA's contribution through internally generated fiscal resources. Revenues from leasing activities, while not yet estimated in detail, will be expected to be significant in this regard.

\subsection{Food Zone AL Budget}

Funding requested for Food Zone interventions are limited to, and will be earmarked specifically for, AL activities. In September 2012, MCN signed a MoU with the US Government to further develop the Food Zone concept in Kandahar Province. The USG will provide \$10M in 2013 through off-budget funding and \$10M on-budget in 2014. USAID will implement the program beginning in May 2013 through another partner, while MCN will be fully engaged in $\mathrm{M} \& \mathrm{E}$ at the provincial and district level. MCN will be totally in charge of implementation in the second year. Assuming funding is assured to cover the Food Zone in Kandahar, MCN will need a total of \$60.84 Million to implement the program in the other $5 \mathrm{CN}$-priority provinces.

Budget (\$US) for Alternative Livelihood Sub-Component of Food Zone

\begin{tabular}{|r|l|r|r|r|r|}
\hline No & Province & \multicolumn{1}{|c|}{ Year-1 } & \multicolumn{1}{l|}{ Year-2 } & \multicolumn{1}{l|}{ Year-3 } & \multicolumn{2}{l|}{ Total } \\
\hline 1 & Kandahar* & 4.6 & 5.81 & 5.25 & 15.66 \\
\hline 2 & Farah & 3.22 & 4.06 & 2.73 & 10.01 \\
\hline 3 & Uruzgan & 1.84 & 2.6 & 1.64 & 6.08 \\
\hline 4 & Helmand & 5.12 & 6.03 & 3.78 & 14.95 \\
\hline 5 & Badakhshan & 6 & 4.62 & 3.5 & 14.12 \\
\hline 6 & Nangarhar & 4.22 & 6.88 & 4.6 & 15.7 \\
\hline & Total Budget & $\mathbf{2 5}$ & $\mathbf{3 0}$ & $\mathbf{2 1 . 5}$ & $\mathbf{7 6 . 5}$ \\
\hline
\end{tabular}




\section{Annex: Component Logical Frameworks}

\subsection{FFL Logical Framework}

\begin{tabular}{|c|c|c|c|c|}
\hline Goal & Impact & $\begin{array}{l}\text { Key Indicators } \\
\text { [Means of verification] }\end{array}$ & Baseline & Targets \\
\hline \multirow{10}{*}{$\begin{array}{l}\text { To increase agriculture } \\
\text { production and productivity } \\
\text { of cereals, legumes, oilseeds, } \\
\text { horticulture, and livestock in } \\
\text { an integrated and targeted } \\
\text { approach that will improve } \\
\text { rural livelihoods, thus } \\
\text { increasing the sustainability of } \\
\text { licit agriculture over narcotic } \\
\text { crops, and contribute to } \\
\text { national and household-level } \\
\text { food and nutrition security. }\end{array}$} & \multirow{10}{*}{$\begin{array}{l}\text { Increased production and } \\
\text { productivity in cereals and } \\
\text { legumes (wheat, rice, in } \\
\text { particular), horticulture } \\
\text { crops and livestock }\end{array}$} & $\begin{array}{l}\text { MT of Wheat Produced } \\
\text { [Agric. Prospects Report] }\end{array}$ & 20120: 4.53 Million MT & $\begin{array}{l}\text { 2015: 5.50 Million MT } \\
\text { 2022: } 7.00 \text { Million MT }\end{array}$ \\
\hline & & $\begin{array}{l}\text { Yield wheat } \\
\text { [Agric. Prospects Report] }\end{array}$ & $\begin{array}{l}\text { 2010: } \\
\text { Irrigated: } 2.65 \mathrm{MT} / \mathrm{ha}(2011) \\
\text { Rain-fed: 0.3 MT/ha (2011) }\end{array}$ & $\begin{array}{l}\text { 2015: Irrigated: } 3.10 \mathrm{MT} / \mathrm{ha} \\
\text { Rain-fed: } 1.50 \mathrm{MT} / \mathrm{ha} \\
\text { 2022:Irrigated: TBD } \\
\text { Rainfed: TBD }\end{array}$ \\
\hline & & $\begin{array}{l}\text { MT of Rice Produced } \\
\text { [Agric. Prospects Report] }\end{array}$ & 2010: 481,000 MT & $\begin{array}{l}\text { 2015: 700k MT } \\
\text { 2022: } 1.00 \text { Million MT }\end{array}$ \\
\hline & & $\begin{array}{l}\text { Yield of rice } \\
\text { [Agric. Prospects Report] }\end{array}$ & 2010: $2.31 \mathrm{MT} / \mathrm{ha}$ & $\begin{array}{l}\text { 2015: } 3.00 \mathrm{MT} / \mathrm{ha} \\
\text { 2022: } 4.00 \mathrm{MT} / \mathrm{ha}\end{array}$ \\
\hline & & $\begin{array}{l}\text { Increase in cereals surplus on Afghanistan } \\
\text { Cereals Balance Sheet } \\
\text { [Agric Prospects Report] }\end{array}$ & 2011: $-1,973$ & $\begin{array}{l}\text { 2015:TBD } \\
\text { 2022: TBD }\end{array}$ \\
\hline & & $\begin{array}{l}\text { Number of Livestock (Cows, Sheep, Goats) } \\
\text { [Agric. Prospects Report] }\end{array}$ & 2010: 20.29 Million & $\begin{array}{l}\text { 2015: } 27 \text { Million } \\
\text { 2022: } 37 \text { Million }\end{array}$ \\
\hline & & $\begin{array}{l}\text { Area under Horticulture }(\mathrm{Ha}) \\
\text { [Agric. Prospects Report] }\end{array}$ & 2010: 120,000 ha & $\begin{array}{l}\text { 2015: TBD } \\
\text { 2022: TBD }\end{array}$ \\
\hline & & $\begin{array}{l}\text { MT Production of Horticulture Produce } \\
\text { (Fruits \&Vegs) } \\
\text { [Agric. Prospects Report] }\end{array}$ & 2010: 2.78 Million MT & $\begin{array}{l}\text { 2015: } 3.50 \text { Million MT } \\
\text { 2022: 5.00 Million MT }\end{array}$ \\
\hline & & $\begin{array}{l}\% \text { increase in licit crop production (FZ } \\
\text { Target Provinces) }\end{array}$ & 0 & 2015: $15 \%$ \\
\hline & & $\begin{array}{l}\% \text { voluntary reduction in poppy cultivation } \\
\text { (FZ target Provinces) }\end{array}$ & 0 & 2015: $18 \%$ \\
\hline
\end{tabular}




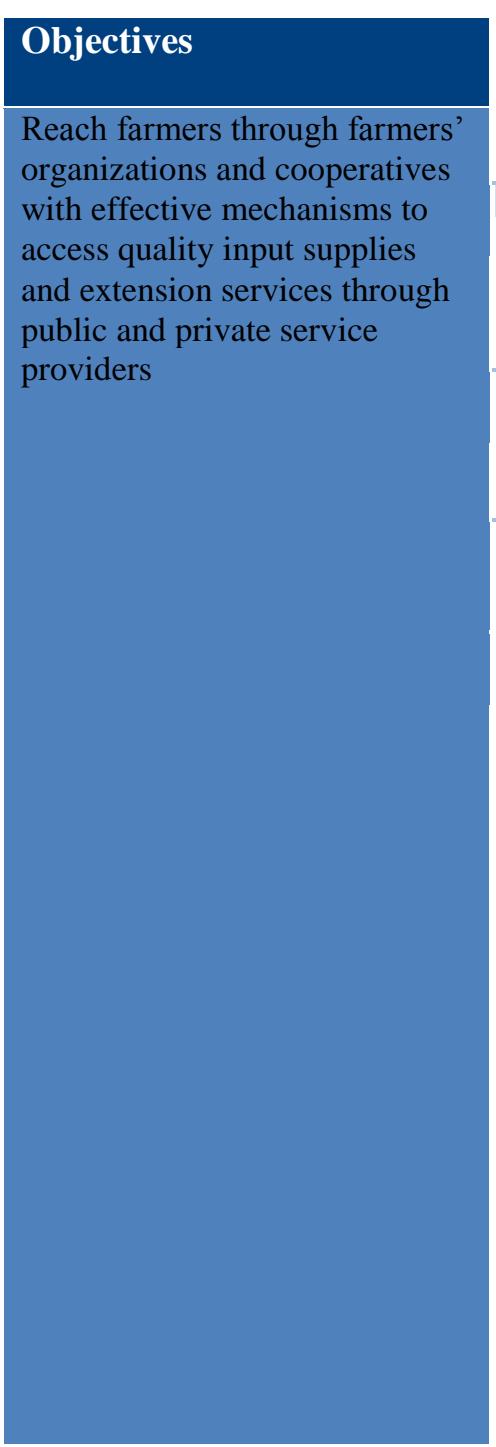

\section{Expected Outcomes}

Improved and adapted

inputs and service

available to the farmers

Increase in gross margin

(total revenue - total cost)

of selected agricultural

commodities

All indicators from MAIL

Farming Systems Survey]

Strengthened farmer

associations and

cooperatives

\section{Key Indicators}

[Means of verification]

Production of certified seed in MT

Agric. Prospects Report]

Number of improved dairy cows

[FAO Dairy Project]

Proportion of farmers using improved

cereal seed

[MAIL Farming Systems Survey]

Proportion of farmers using fertilise

[MAIL Farming Systems Survey]

Proportion of farmers using pesticides

[MAIL Farming Systems Survey]

Proportion of farmers using Integrated Pest

Management (IPM) Techniques

[MAIL Farming Systems Survey]

Hectares of land converted from poppy to

licit cultivation (FZ indicator)

Wheat - gross margin in AFG (with

percentage

Rice - gross margin in AFG (with

percentage increase)

Potato - gross margin in AFG (with

percentage increase)

Melon - gross margin in AFG (with

percentage increase)

Grapes - gross margin in AFG (with

percentage increase)

Apple - gross margin in AFG (with

percentage increase)

Almond - gross margin in AFG (with

percentage increase)

Famers belonging to a farmers'

organisations

\# of farmer cooperatives operating

effectively (FZ target provinces)

\section{Baseline}

18,081 MT (2011)

TBD

2012:10\%

2012: $90 \%$

2012: $100 \%$

2012: $3 \%$

2012: AFG ....... (0\%)

2012: AFG ....... (0\%)

2012: AFG ....... (0\%)

2012: AFG ....... (0\%)

2012: AFG ....... (0\%)

2012: AFG ....... (0\%)

2012: AFG ....... (0\%)

2012: $7 \%$

[MAIL Farming Systems

0

Targets

2015: 25,000 tonnes

2022: TBD

2015: TBD

2022: TBD

2015: TBD

2022: TBD

2015: TBD

2022: TBD

2012: TBD

2022: TBD

2012: TBD

2022: TBD

2015: 19,650

2015: $10 \%$

2022: $25 \%$

2015: $10 \%$

2022: $25 \%$

2015: $10 \%$

2022: $25 \%$

2015: $10 \%$

2022: $25 \%$

2015: $10 \%$

2022. $25 \%$

2015: $10 \%$

2022: $25 \%$

2015: $10 \%$

2022: $25 \%$

2015: $25 \%$

2022: 50\%

2015: 70 


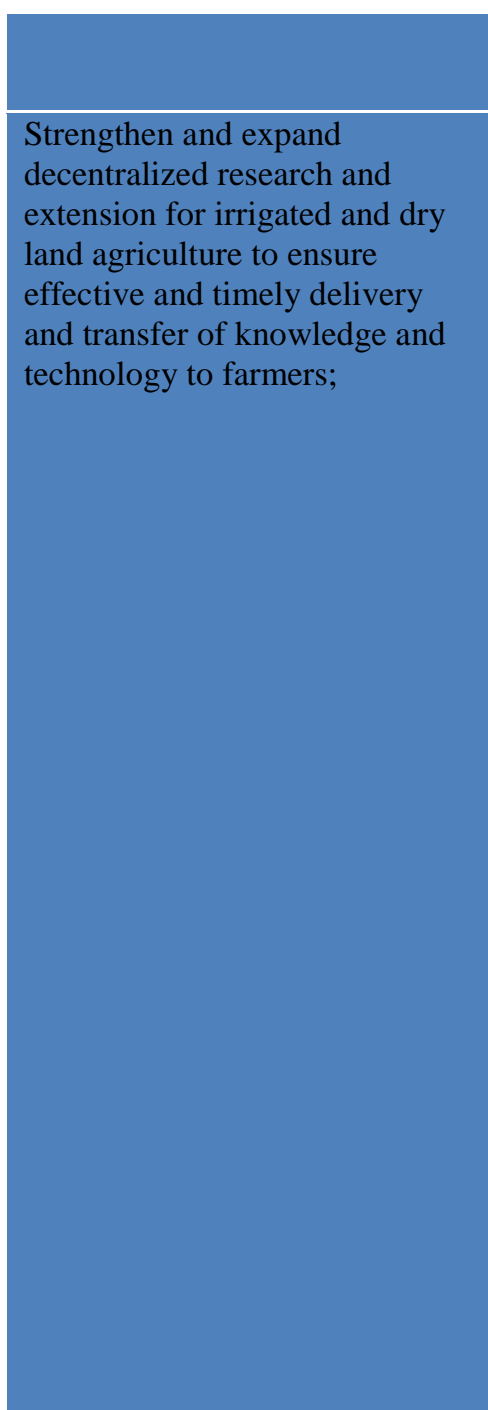

\begin{tabular}{|c|c|c|c|}
\hline & $\begin{array}{l}\text { Average of farmer coops per district (FZ } \\
\text { indicator) }\end{array}$ & 0 & 2015: 5 \\
\hline \multirow[t]{6}{*}{$\begin{array}{l}\text { Increased expansion of } \\
\text { research and extension } \\
\text { services around the country }\end{array}$} & $\begin{array}{l}\text { Number of active extension offices in } \\
\text { Provinces } \\
\text { [General Directorate of Extension] }\end{array}$ & TBD & $\begin{array}{l}\text { 2015: TBD } \\
\text { 2022: TBD }\end{array}$ \\
\hline & $\begin{array}{l}\text { Number of Rice Research Sub-Stations in } \\
\text { country } \\
\text { [GD of Agricultural Research] }\end{array}$ & TBD & $\begin{array}{l}\text { 2015: TBD } \\
\text { 2022: TBD }\end{array}$ \\
\hline & $\begin{array}{l}\text { Number of Dry Land research stations/sites } \\
\text { established } \\
\text { [GD of Agricultural Research] }\end{array}$ & 1 & $\begin{array}{l}\text { 2015: TBD } \\
\text { 2022: TBD }\end{array}$ \\
\hline & $\begin{array}{l}\text { Farmers Field Schools established through } \\
\text { IPM program/Number of farmers trained } \\
\text { [MAIL IPM Programme Reports] }\end{array}$ & $\begin{array}{l}\text { No. of FFS established: TBD } \\
\text { No. of Farmers trained: TBD }\end{array}$ & $\begin{array}{l}\text { 2015: } \\
\text { No. of FFS established: TBD } \\
\text { No. of Farmers trained: TBD } \\
\text { 2022: } \\
\text { No. of FFS established: TBD } \\
\text { No. of Farmers trained: TBD }\end{array}$ \\
\hline & $\begin{array}{l}\% \text { of farmers receiving IPM, post- harvest } \\
\text { and marketing support by competent } \\
\text { technical staff (FZ indicator) }\end{array}$ & 0 & 2015: $25 \%$ \\
\hline & $\begin{array}{l}\text { Average of greenhouse per district } \\
\text { construction (FZ indicator) }\end{array}$ & 0 & 2015: 10 Greenhouse/district \\
\hline \multirow{3}{*}{$\begin{array}{l}\text { Increased number of } \\
\text { private sector agriculture } \\
\text { service centres / } \\
\text { establishments }\end{array}$} & $\begin{array}{l}\text { Number of Ag Depots } \\
\text { [MAIL ......... ] }\end{array}$ & TBD & $\begin{array}{l}\text { 2015: TBD } \\
\text { 2022: TBD }\end{array}$ \\
\hline & $\begin{array}{l}\text { Seed production enterprises promoted } \\
\text { (number) } \\
\text { [MAIL Seed Project Reports] }\end{array}$ & TBD & $\begin{array}{l}\text { 2015: TBD } \\
\text { 2022: TBD }\end{array}$ \\
\hline & $\begin{array}{l}\text { Number of milk processing (chilling and } \\
\text { pasteurising) facilities } \\
\text { [ MAIL Farming Systems Survey / Diary } \\
\text { Project] }\end{array}$ & $\begin{array}{l}\text { TBD } \\
\text { (Currently a few facilities in } \\
\text { Herat and Nanghar) }\end{array}$ & $\begin{array}{l}\text { 2015: TBD } \\
\text { 2022: TBD }\end{array}$ \\
\hline \multirow{3}{*}{$\begin{array}{l}\text { Improved post-harvest } \\
\text { handling (processing, } \\
\text { storage, transportation, etc) } \\
\text { of produce }\end{array}$} & $\begin{array}{l}\text { Wheat - \% of post harvest loss } \\
\text { [MAIL Agric Marketing Study] }\end{array}$ & 2012: $15 \%$ & $\begin{array}{l}\text { 2015: } 10 \% \\
2022: 3.0 \%\end{array}$ \\
\hline & Rice - \% of post harvest loss & 2012: $15 \%$ & $\begin{array}{l}\text { 2015: } 10 \% \\
\text { 2022: } 3.0 \%\end{array}$ \\
\hline & Vegetable - $\%$ of post harvest loss & 2012: $15 \%$ & $\begin{array}{l}\text { 2015: } 10 \% \\
2022: 3.0 \%\end{array}$ \\
\hline
\end{tabular}




\begin{tabular}{|c|c|c|c|c|}
\hline & & Fruits - $\%$ of post-harvest losses & 2012: $15 \%$ & $\begin{array}{l}\text { 2015: } 10 \% \\
2022: 3.0 \%\end{array}$ \\
\hline \multirow{2}{*}{$\begin{array}{l}\text { Build and rehabilitate the } \\
\text { Strategic Grain Reserves and } \\
\text { establish a SGR network and } \\
\text { management system for an } \\
\text { efficient and effective } \\
\text { emergency response; }\end{array}$} & $\begin{array}{l}\text { Increased capacity of SGR } \\
\text { at national level }\end{array}$ & $\begin{array}{l}\text { Capacity of Strategic Grain Reserves at } \\
\text { national level } \\
{[\text { MAIL ...] }}\end{array}$ & 2012: $150,000 \mathrm{MT}$ & $\begin{array}{l}\text { 2015: } 200,000 \mathrm{MT} \\
\text { 2022: } 300,000 \mathrm{MT}\end{array}$ \\
\hline & $\begin{array}{l}\text { Improved emergency } \\
\text { preparedness and response } \\
\text { mechanism }\end{array}$ & $\begin{array}{l}\text { Time reduced in response to food shortage } \\
\text { response } \\
{[\text { MAIL ...] }}\end{array}$ & 2012: $0 \%$ & $\begin{array}{l}2015: 15 \% \\
2022: 50 \%\end{array}$ \\
\hline \multirow{3}{*}{$\begin{array}{l}\text { Strengthen coordinated } \\
\text { agriculture statistics and MIS } \\
\text { capacities to efficiently and } \\
\text { effectively collect, analyse and } \\
\text { disseminate required data for } \\
\text { public information, evidence- } \\
\text { based planning and decision- } \\
\text { making; }\end{array}$} & $\begin{array}{l}\text { Strengthened capacity of } \\
\text { MAIL in agriculture } \\
\text { statistics and MIS }\end{array}$ & $\begin{array}{l}\text { Number of DAIL offices have functioning } \\
\text { Statistics \& MIS System } \\
\text { [MAIL - Directorate of Agriculture and } \\
\text { Marketing Information] }\end{array}$ & 2011: 0 & $\begin{array}{l}\text { 2015: } 15 \\
\text { 2022: } 34\end{array}$ \\
\hline & $\begin{array}{l}\text { Improved evidence-based } \\
\text { planning and decision } \\
\text { making in MAIL and } \\
\text { among stakeholders }\end{array}$ & $\begin{array}{l}\% \text { of farmers have access to some market } \\
\text { information through a sustainable } \\
\text { mechanism } \\
\text { [USAID PAYWAD Project] }\end{array}$ & 2010: $15 \%$ & $\begin{array}{l}\text { 2015: } 35 \% \\
\text { 2022: } 70 \%\end{array}$ \\
\hline & & $\begin{array}{l}\text { Number of times MAIL GIS system is } \\
\text { accessed/visited in one year [MAIL] }\end{array}$ & 2012: TBD & $\begin{array}{l}\text { 2015: } 15 \\
\text { 2022: } 34\end{array}$ \\
\hline \multirow{4}{*}{$\begin{array}{l}\text { Promote diversification in food } \\
\text { production and consumption at } \\
\text { household level through } \\
\text { education and extension, in } \\
\text { cooperation with other } \\
\text { stakeholders. }\end{array}$} & $\begin{array}{l}\text { Increased awareness of } \\
\text { improved food and } \\
\text { nutrition needs and } \\
\text { practices }\end{array}$ & $\begin{array}{l}\text { Increased number of households provided } \\
\text { with nutrition education } \\
\text { [GD of Extension] }\end{array}$ & TBD & \\
\hline & $\begin{array}{l}\text { Increased number of } \\
\text { households with food and } \\
\text { nutrition security }\end{array}$ & $\begin{array}{l}\text { Proportion of population below minimum } \\
\text { level of dietary energy consumption }(<2100 \\
\text { cal./day) } \\
\text { [Afghanistan MDG Report] }\end{array}$ & $2010-29 \%$ & $\begin{array}{l}\text { 2015: TBD } \\
\text { 2022: TBD }\end{array}$ \\
\hline & & $\begin{array}{l}\text { Proportion of household with diversified } \\
\text { food consumption } \\
\text { [indicator being developed] }\end{array}$ & 0 & $\begin{array}{l}\text { 2015: TBD } \\
\text { 2022: TBD }\end{array}$ \\
\hline & & $\begin{array}{l}\text { Prevalence of underweight children under } 5 \\
\text { years of age } \\
\text { [Afghanistan MDG Report] }\end{array}$ & 2010: 39\% & $\begin{array}{l}2015: 25 \% \\
2022: 10 \%\end{array}$ \\
\hline
\end{tabular}




\subsection{EMD Logical Framework}

\begin{tabular}{|c|c|c|c|c|}
\hline Goal & Impact & Key Indicators & Baseline & Targets \\
\hline \multirow{6}{*}{$\begin{array}{l}\text { To sustain economic growth and poppy } \\
\text { reduction through improved employment } \\
\text { and income opportunities for rural } \\
\text { people by means of enterprise } \\
\text { development, credit and access to land }\end{array}$} & \multirow{5}{*}{$\begin{array}{l}\text { Improved employment opportunities } \\
\& \text { increased income of rural men and } \\
\text { women and the under-employed incl. } \\
\text { youth. }\end{array}$} & General unemployment rate & $40 \%$ & $\begin{array}{l}\text { 2015: } 30 \% \\
\text { 2022: } 20 \%\end{array}$ \\
\hline & & Youth unemployment rate & $50 \%$ & $\begin{array}{l}\text { 2015: } 40 \% \\
\text { 2022: } 25 \%\end{array}$ \\
\hline & & $\begin{array}{l}\% \text { female participation in economic } \\
\text { activity }\end{array}$ & $>5 \%$ & $\begin{array}{l}\text { 2015: } 5 \% \\
\text { 2022: } 20 \%\end{array}$ \\
\hline & & Increase in local income & 0 & $\begin{array}{l}2015:+20 \\
2022:+45\end{array}$ \\
\hline & & $\begin{array}{l}\% \text { increase in licit income (FZ target } \\
\text { provinces) }\end{array}$ & 0 & 2015: $15 \%$ \\
\hline & $\begin{array}{l}\text { Reduced area of land under illegal } \\
\text { crops }\end{array}$ & Land area under illegal crops & 0 & $\begin{array}{l}\text { 2015: }-20 \\
\text { 2022: }-50\end{array}$ \\
\hline Objectives & Expected Outcomes & Indicators & Baseline & Targets \\
\hline \multirow{8}{*}{$\begin{array}{l}\text { Improve on-farm and off-farm incomes } \\
\text { through the development of viable } \\
\text { community-based enterprises, small and } \\
\text { medium enterprises and larger agri- } \\
\text { businesses }\end{array}$} & \multirow{5}{*}{$\begin{array}{l}\text { Stimulate rural private sector growth, } \\
\text { to improve farm and off-farm } \\
\text { incomes thru community enterprises, } \\
\text { SMEs \& large agri-business }\end{array}$} & $\begin{array}{l}\text { Establishment of new community } \\
\text { enterprises }\end{array}$ & 0 & $\begin{array}{l}2015: 30 \% \\
2022: 100 \%\end{array}$ \\
\hline & & $\begin{array}{l}\text { \# of new community enterprises (in FZ } \\
\text { target provinces) }\end{array}$ & 0 & 2015: 35 \\
\hline & & Registration of new SME businesses & 0 & $\begin{array}{l}\text { 2015: } 30 \% \\
\text { 2022: } 100 \%\end{array}$ \\
\hline & & Registration of new agri- businesses & 0 & $\begin{array}{l}\text { 2015: } 20 \% \\
\text { 2022: } 80 \%\end{array}$ \\
\hline & & $\begin{array}{l}\% \text { of farmers gaining improved access to } \\
\text { markets though Coops, Associations and } \\
\text { Community-based Enterprises (FZ } \\
\text { indicator) }\end{array}$ & 0 & 2015: $25 \%$ \\
\hline & \multirow{3}{*}{$\begin{array}{l}\text { Provide business know-how for } \\
\text { sustainability of targeted local } \\
\text { enterprises }\end{array}$} & $\begin{array}{l}\text { Promotion of Enterprise Groups } \\
\text { (Cumulative) }\end{array}$ & 2,500 & $\begin{array}{l}\text { 2015: } 6,420 \\
\text { 2022: } 10,000\end{array}$ \\
\hline & & $\begin{array}{l}\text { Facilitating \& supporting SMEs } \\
\text { (Cumulative) }\end{array}$ & 300 & $\begin{array}{l}\text { 2015: } 640 \\
\text { 2022: } 1,200\end{array}$ \\
\hline & & $\begin{array}{l}\% \text { increase in the amount of investments } \\
\text { in the Farmers Coops' accounts (FZ } \\
\text { indicator) }\end{array}$ & 0 & $2015: 25 \%$ \\
\hline
\end{tabular}




\begin{tabular}{l} 
Support private-sector supply and \\
demand through investable surplus, \\
import substitution and export-led \\
economic growth \\
Improve linkages to domestic and export \\
markets \\
Improve and secure access to supportive \\
rural credit and inclusive land tenure \\
\hline
\end{tabular}

Improved the quality, quantity and value of agricultural production

Improved value chain linkages to domestic and export markets

\section{Improved access to credit}

mproved access to land
Product quality assessed by grading (no.

of schemes)

Business incomes from sale of products

Spread of buyers per producer

$\%$ of area's produce exported

Reduction of imports in basic agricultura

products

Volumes of credit transactions

(US\$ million)

No. of financial \& non-financial

intermediaries

Improved legal framework (no. of new

laws)

Regulatory \& procedural effectiveness

Area of new land coming into productive use (hectares) cumul.

\begin{tabular}{l|l}
0 \\
0 \\
0 \\
0
\end{tabular}

0

65

10

0

0

0

20,000
2015: 2

2022: 10

2015: $+30 \%$

2022: $+150 \%$

2015: $+25 \%$

$2022:+100 \%$

2015: $+100 \%$

2022: $+500 \%$

2015: $20 \%$

2022: $70 \%$

2015: 90

2022: 150

2015: 120

2022: 150

2015: 1

2022:

2015: In force

2022: In force

2015: 35,000

2022: 100,000 


\section{Annex: Monitoring \& Evaluation Framework}

\subsection{FFL M\&E Framework}

The monitoring and evaluation (M\&E) arrangements will build upon the Component's Log-frame (see Annex 2.1). The required strong supervision of Component activities will require establishing a functional M\&E system as part of a MAIL-wide joint/harmonised approach. Key parts of such system will be regular joint monitoring visits, a clear reporting format and schedule, regular presentations to inform management decisions, and to update implementation and financing partners.

In particular, in view of the Food Security and Nutrition Sub-Component objectives, the establishment of a systematic planning and reporting system for food security and nutrition, drawing on the integration of nutrition indicators in MAIL-wide M\&E systems will be important. The mapping of existing interventions, projects, programs in an established database, together with the regular and systematic review of on-going activities, extracting lessons learnt for the promotion of best practices will be integral parts of the FFL M\&E System.

\subsubsection{Monitoring Framework}

FFL constitutes a large area of MAIL functions that deals with the farmers at the sub-national level, agriculture cooperatives, farmer associations for improving production and productivity and increasing farm income; the households for increasing food and nutrition security; and with other national and international stakeholders for agriculture data and information. Therefore, the monitoring framework of this component will drive much of the on-going monitoring functions within MAIL with a collaborated and harmonized approach both in centre and the provinces.

The FFL monitoring framework will be built on program budgeting standards of MoF, which are already in place. The establishment of results-based planning and reporting for this component will strengthen the current Component Budgeting process and will further build upon the systems and approaches already introduced to departments in MAIL.

\section{Output Monitoring}

MIS unit in MAIL has already developed an output level planning and reporting mechanism. This system which will be available online - collects information on achieved outputs from DAILs and collates it at the national level under the NADF pillars and against the planned outputs. The aim of this mechanism is to train and kick-start project implementation accountability at the technical directorates of MAIL as well as at the sub-national DAIL levels.

The M\&E Department in MAIL which is tasked to physically monitor project progress in the field will be linked with the MIS system. This will ensure verification of progress reports generated by MIS department as central hub of monitoring and reporting for MAIL for all programs including FFL.

\section{Outcome Monitoring}

Building on the Sub-Component 1 "Data and Information base", FFL will focus on strengthening the capacity and roles of Agricultural Statistics and Information Directorate and the MIS Unit in particular in outcome monitoring. The FFL goals and expected outcomes are based on the NADF Pillar 1 - Agriculture Production and Productivity; linking up the Component outcomes to MAIL's strategic objectives and expected results outlined in NADF and ANDS.

Results-based monitoring and reporting at the outcome level will also be established identifying key outcome indicators to provide a clear picture of Component achievements on annual or bi-annual basis 
wherever applicable. Since the main goal of FFL is to increase production and productivity, increasing capacity of Statistics Directorate within MAIL to collect and analyse on time and accurate harvest data will be crucial.

Collaboration with Central Statistics Organization (CSO) will be established to mutually update MAIL with recent NRVA data on poverty, hunger and food security indicators. Where baseline data is not available for key outcome indicators, short surveys will be conducted or lead indicators will be used to fill the gap of monitoring and reporting.

\section{Impact Monitoring}

At the impact level, MAIL will rely on national surveys (such as NRVA) and strong coordination with the CSO to update the data within the MAIL MIS system, when available. Strengthening MAIL's capacity for analysis of data and information will be important; and that will be addressed in Sub-Component 1 of FFL.

\section{Monitoring and Reporting Hierarchy}

As with any other national program, FFL and its Sub-Components progress will be monitored by the aforementioned mechanisms at three levels: 1) Decision-making level; 2) Organizational level; and 3) Operational level.

At the decision-making level (i.e. ARD Cluster, JCMB and Cabinet), the Component progress will be monitored through periodic reports of outcome level achievements. However, during the early stages of implementation, where outcome data will not be available, interim output reports will be reported as appropriate.

At the organizational level, (i.e. H.E. Minister of MAIL, Deputy Ministers and Director Generals) higherlevel management will be provided with output reports, implementation challenges and bottlenecks and identifying mechanisms to better improve Component results.

At the operational level (i.e. Secretariat, Technical Directorates of MAIL and DAILs), monitoring will be done according to the implementation action plans set at the Sub-Component level. Director Generals and Deputy Ministers will closely supervise the operational level monitoring, and directions will be sought from MAIL Minister wherever necessary.

\subsubsection{Evaluation Framework}

The NPP will incorporate a high-level evaluation framework that will enable periodic assessment of SubComponents' relevance, performance, efficiency and impact in relation to stated objectives. The FFL evaluation will be based on two scales:

\section{Evaluation for Results}

In order to identify performance, efficiency and impact of FFL Sub-Components at national and subnational level, and to identify if we have achieved our targets as planned; mid-term and annual evaluation of the Sub-Components will be carried out. At this scale, the evaluation will enable the Secretariat and MAIL to refine and improve approaches and address any bottlenecks that hinder smooth and on-target Component implementation.

\section{Evaluation for Component Revision}

Annual and bi-annual revision of the Component will enable MAIL and the ARD Cluster to revise policies, and the Food For Life Component and its Sub-Components based on results. Component mid-term review that will be carried out during the third year of implementation will provide the chance to revise the Component and identify better implementation mechanisms, add and review Sub-Components and redefine targets. 
As part of its efforts to promote good governance and transparency, results and information emerging from the monitoring and evaluation exercises will not only be shared with all implementing and financing partners but information will be shared in an appropriate way with the intended beneficiaries and in their communities.

\subsection{EMD M\&E Framework}

\subsubsection{Monitoring of Overall Component}

A results-based management approach will apply to the EMDC Sub-Components. Appropriate performance monitoring and evaluation (M\&E) activity will be carried out both during the lifetime of the EMDC and at the end of the EMDC, feeding into the overall M\&E of NPP-2. This will specifically aim to draw lessons from experience and to use that experience for suggesting possible improvements in future approaches to this form of Technical Cooperation.

Key indicators, milestones and targets against the overall Component 1 and Component 2 objectives will be defined in an over-arching framework for measurement and evaluation of the NPP-2. Each Sub-Component within the EMDC (CARD-F, AREDP, ADF, Arazi) already has its own measurement framework that reflects its objectives and scope of work as defined in the relevant design document, as well as key indicators for performance and targets that are consistent with the overall NPP framework.

Due to the complexity, scope and size of the EMDC, there will be an overall monitoring framework to enable progress to be assessed transparently. Several tools are available in this regard:

- A Work Plan which will incorporate milestones against the desired attainment of agreed targets for each Sub-Component of the EMDC;

- Capacity assessments (reported periodically to the EMDC Inter-ministerial Committee) that consider development in staff capability and skills to autonomously deliver the EMDC;

- A consolidated monitoring report that summarises progress in the EMDC as it is being implemented;

- Independent annual reviews commissioned by donors to consider progress against the EMDC indicators and targets;

- A 'participatory field monitoring' approach will be employed for the joint monitoring of the Component.

\subsubsection{Monitoring of EMDC Sub-Components}

Responsibility for delivery of the Sub-Components within the EMDC will lie with the Implementing Ministries and, as such, reporting obligations against relevant high-level indicators will also lie with these ministries. Contracts for relevant works, goods and services will place an obligation on contractors to collect relevant data for the Sub-Components for which they are responsible. Base lining of data is also incorporated in the initial data-gathering activity, which precedes the full implementation of particular services, goods or works by contractors. In addition, data will be disaggregated by gender where appropriate.

Ongoing monitoring will be on the basis of periodic progress reporting at individual Component level against resource allocation and usage, as well as, against relevant high level performance indicators. This will be maintained by the Implementing Ministries and reported to the Inter-ministerial Committee. As well as resource management and implementation issues, these Implementing Ministries' reports will also capture progress against operational and key performance indicators.

Summary management reports will be prepared by each Sub-Component for assessment by the NPP InterMinisterial Committee on a periodic basis. 


\subsubsection{Component Evaluation}

The EMDC will incorporate a high level evaluation framework, embracing those of the existing SubComponents, which will enable periodic assessment of their relevance, performance, efficiency and impact in relation to stated objectives. Within each Component's time horizon there are two critical evaluation points:

- Annual reviews which offers an assessment of progress and analysis of the Component's likely impact, and is a means to identify necessary adjustments in its design;

- Ex-post/final evaluation, which gauges the Sub-Component's impact and sustainability, and provides insights and lessons for future intervention design.

As well as assessing Sub-Components individually, the evaluations will consider their consolidated impact in relation to the EMDC and NPP overall. In addition, the M\&E framework will be critical in developing the evidence base to support policy recommendations to the Inter Ministerial Committee.

\subsubsection{Key Performance Indicators}

As indicated earlier, the EMDC approach is directed at providing value chain-based development assistance, with the aim of directly assisting communities, entrepreneurs and other market intermediaries to exploit opportunities to generate income and subsequent employment.

On this basis, the impact of the EMDC assistance is therefore judged using operational concepts of growth in income and in employment. These measures constitute the primary target indicators of performance for the EMDC as a whole and at the Sub-Component level, where:

- Improved income performance is measured by incremental gross income generated by EMDC beneficiaries;

- Improved employment performance, given by number of full-time equivalent jobs created through EMDC interventions.

A number of other secondary operational performance indicators can be applied for the purposes of monitoring progress and performance of the EMDC as a whole. These indicators at Sub-Component level are already defined in the documents relevant to the four constituent Sub-Components of the EMDC.

The EMDC will also be required to develop a Management Information System (MIS) that will allow accurate assessment of performance against financial and Component indicators for the EMDC as a whole and the four Sub-Components. This MIS will integrate and build on the existing MIS and reporting systems in the Implementing Ministries as necessary and will directly link to Component 1 of NPP-2. The EMDC will maintain adequate resources to ensure that reporting requirements can be met.

\subsubsection{CARD-F Monitoring and Evaluation}

The CARD-F M\&E framework activities cover on-going monitoring and evaluation and contract verification requirements within the organisation. The skills required to undertake $M \& E$ are specialised and require the CARD-F team to work across several different donors' M\&E procedures and methodologies. However, the involved ministries will require a consolidated set of procedures from the donors to ensure that $\mathrm{M} \& \mathrm{E}$ is manageable.

In parallel, there is a requirement to undertake validation work to manage procurement contract obligations in order to meet contract and payment delivery schedules. This is less technically complex than the M\&E work, and in broad terms requires verifying that contractors are meeting delivery schedules and agreed technical standards. 
Operationally, the CARD-F project life-cycle generates a significant amount of information and data. CARD-F faces many unique issues with respect to managing the volume of information generated by its operations. This is especially true taking into account the trend in the international development sector to specifically link results to expenditures and budgets (financial performance). CARD-F is already developing a forward-looking IT-based Knowledge Management strategy to enable these issues to be addressed in a structured way as the programme progresses.

\subsubsection{AREDP Monitoring and Evaluation}

AREDP is in the process of establishing a robust M\&E system, combining continuous monitoring by inhouse M\&E specialists, and external evaluation. An MIS is being developed and aims to become operational to ensure timely feedback on both Sub-Component inputs/outputs and outcomes as determined in the results management framework. The Sub-Component will engage qualified institution(s) to carry out impact evaluation.

The Monitoring and Evaluation Unit of AREDP is responsible for identifying indicators and tasks for monitoring the progress of the Sub-Component and evaluating its outcomes and impact as it starts to support SMEs, Enterprise Groups and Savings Groups in the rural communities. The M\&E tasks are based on the Component's Logical Framework.

The monitoring process will be based on milestones established in the AREDP work plan. The data on the milestones will be cumulated, analysed and reported through graphs and texts on a monthly basis, to allow close supervision of progress. These reports will be available to donors.

The sustainability of AREDP activities will be monitored through a newly designed and implemented effective and efficient monitoring and evaluation system. Governance and Accountability, Gender and Third Party Audits will design and implement the Governance, Accountability and Gender Action Plans and carry out external and internal audits. The project will finance the establishment and staffing of eight offices, one at Headquarters level and seven Provincial Offices. These offices will oversee project implementation, provide coordination and leadership for the development of the rural economy, carry out project monitoring and evaluation, facilitate governance and ensure knowledge management that will facilitate participatory action learning, introspection and constant project improvement. Monthly, quarterly and annual reporting will be required re both the project lifecycle.

Evaluation Arrangements: In accordance with best practice, a mid-term evaluation will be conducted in 2013/2014 and a final evaluation will assess impacts at the end of the project for all components of NPP-2. The evaluation will measure progress against the baselines gathered in the starting phase of the programme through the individual components. Ex-post/terminal evaluation gauging the Sub-Components impact, and sustainability and provides the insights and lessons for future intervention design will be required.

\subsubsection{ADF Monitoring and Evaluation}

The Executive Agency is responsible for monitoring and reporting on physical and financial progress of the Sub-Component to the ADF Board of Directors and donor agencies. It is anticipated that the donor group will conduct regular supervision missions to assess agreed processes and achievement of the objectives outlined in the results framework.

A systematic monitoring and evaluation of Sub-Component activities and outcome indicators will be carried out to assess its effectiveness. The overall responsibility for assessing performance lies with an independent $\mathrm{M} \& \mathrm{E}$ agency. The $\mathrm{M} \& \mathrm{E}$ agency is responsible for delivering an updated baseline survey at the commencement of activities, a medium-term review, and a final impact assessment survey at completion.

The M\&E Manager within ADF will be responsible for the central collection and reporting of data on the progress and performance of ADF activities. The M\&E Manager will be supported by the M\&E Specialists in each region who will be responsible for data collection in their region, in accordance with the data collection schedule. 
ADF will also have responsibility for the internal monitoring by Regional Teams to ensure that borrowers' activities are in line with their lending agreements, and provide reports on lending progress to the Board of Directors.

\subsubsection{Arazi Monitoring and Evaluation}

The Arazi M\&E framework covers on-going monitoring and evaluation and contract verification requirements within the organisation. This falls into two distinct types, covering Sub-Component evaluation (i.e. the performance of Arazi), and procurement evaluation and verification.

Monitoring will contribute to making public spending by Arazi accountable. However it does not currently have the IT infrastructure to support the data needs for effective monitoring and evaluation, and this will be a priority to be addressed under the Sub-Component. The M\&E Directorate of Arazi plans to develop a new system to conduct monitoring across the new regional offices. This monitoring system is expected to generate quantitative data and provide feedback on implementation of measures, as well as facilitate corrections of deviations from operational objectives.

\subsubsection{An Integrated Approach to M\&E}

As is apparent from the above review of M\&E activities within the four Sub-Components of the EMDC, they are at varying stages of implementation and capability.

However, all have common long-term requirements in terms of verification of project and programme activity, validation of funds release, prior appraisal of projects, monitoring of progress, evaluations and the other aspects of programme assessment.

As the four Sub-Components are subsumed with the EMDC, their strategic high level objectives frameworks have been incorporated into a combined Log-Frame that demonstrates their clear relation to one another, demonstrating synergy rather than duplication. They will each have to be linked upwards to the new higher-level NPP objectives and measurement framework. Hence their approaches to data gathering, targets and measurement will need to be synchronised.

Additionally, future M\&E requirements are likely to become more sophisticated as they develop into monitoring and evaluation of community attitudes, beneficiary opinions and other societal responses to the EMDC. These more complex techniques will benefit from being developed centrally in collaboration for all, in a best practice approach, rather than drawn up individually in isolation in each of the four SubComponents' M\&E Units.

For the new EMDC, it is not proposed to replace current M\&E structures within CARD-F, AREDP, ADF or Arazi. Rather, it is proposed that they are strengthened by support from the centre through an M\&E oversight and advice office, and existing M\&E activities and intentions are validated and reinforced with specialist input where required.

The precise Terms of Reference of the proposed office, tentatively named the EMDC M\&E Support Office, will need to be drawn up, and its relationship with the four existing Sub-Component M\&E units will be established in dialogue. 


\section{Annex: NPP Linkages}

\subsection{NPP-2 Linkages}

\section{ARD NPPs}

NPP-1: Water Resources and Irrigation Developmen Component

NPP-1: Environmental
Conservation and

Management Component

(20)

NPP-2: FFL Component

NPP-2: EMD Component

NPP-3: National Rural Access

Programme

NPP-4: Strengthening Local Institutions
Areas that support FFL Component

Irrigation

Water storage

On-farm water management

Flood control

(2)

Rangelands and forests rehabilitation

and management

Renewable energy

$+1$

Input supply, technology, value

addition, agri-business development,

credit and market access

Roads for access to markets

CDCs for social mobilization and

emergency response
Linkages \&Areas supported by EMD Component

New technologies for better water use

Credit for improved irrigation services

Allocation of land for water resources

\section{Off-grid energy supply}

Non-agriculture SMEs

Credit for protected areas, forest rehabilitation \& renewable

energy

Land resettlement issues, rangelands policy support

Complements FFL activities for input provision, technology transfer, credit, land allocation, value addition, agro-business development and market access

Supplement road network to better markets, and enterprise development

CDCs for coordination and outreach 


\subsection{EMD Linkages}

\begin{tabular}{|c|c|c|}
\hline \multirow{4}{*}{$\begin{array}{l}\text { Water Resources \& } \\
\text { Irrigation } \\
\text { Development } \\
\text { Programme }\end{array}$} & CARD-F & $\begin{array}{l}\text { This program will be responsive to the irrigation needs, which are identified under the CARD-F district } \\
\text { analysis. Particular focus will include new technologies for better water use. Water harvesting could be a } \\
\text { good tool for CARD-F interventions. }\end{array}$ \\
\hline & AREDP & No major relationship. \\
\hline & $\mathrm{ADF}$ & $\begin{array}{l}\text { ADF will need to make credit facilities available for improved irrigation services and for OFWM } \\
\text { installations of new technology. }\end{array}$ \\
\hline & Arazi & $\begin{array}{l}\text { Water resources may require allocation of land to whole communities and is something that should be } \\
\text { feasible. }\end{array}$ \\
\hline \multirow{4}{*}{ Food For Life } & CARD-F & $\begin{array}{l}\text { All agricultural inputs, mechanization, research and extension, dry land farming have a direct relationship to } \\
\text { the production side of CARD-F activity. There needs to be significant coordination within the Program } \\
\text { rollout to avoid duplication of activity wherever possible. This removes the need for CARD-F buying in } \\
\text { services from NGOs etc. Even if services have to be bought in, it is important that they are embedded within } \\
\text { Ministry structures so that over time the need to buy services is reduced. }\end{array}$ \\
\hline & AREDP & $\begin{array}{l}\text { No major relationship, as AREDP should not be involved in agricultural focused SMEs. However, where } \\
\text { they are, the same applies to the services identified above with CARD-F. }\end{array}$ \\
\hline & $\mathrm{ADF}$ & $\begin{array}{l}\text { Farmers need credit to avail themselves of inputs and improved technology, particularly credit tailored to the } \\
\text { needs of farmers and agricultural calendars. }\end{array}$ \\
\hline & Arazi & $\begin{array}{l}\text { FFL requires additional land to increase production, assist landless farmers to have access to land and also } \\
\text { increase the land holdings for commercial farmers and international investors. FFL gives services to all } \\
\text { levels of farmers. }\end{array}$ \\
\hline \multirow{4}{*}{$\begin{array}{l}\text { Environmental and } \\
\text { Energy } \\
\text { Conservation }\end{array}$} & CARD-F & $\begin{array}{l}\text { In provinces with wild forests, these may be one of the best income-generating propositions, and sound } \\
\text { policies for management will need to be adopted. There is a major link with renewable energy, as CARD-F } \\
\text { often faces problems with energy supplies when off grid. ERDA will help overcome these problems. }\end{array}$ \\
\hline & AREDP & $\begin{array}{l}\text { AREDP is strongly attached to ERDA as it deals with non-agricultural SMEs that have high power } \\
\text { demands. }\end{array}$ \\
\hline & $\mathrm{ADF}$ & $\begin{array}{l}\text { ADF may need to fund communities for the building of protective walls around pistachio and other wild } \\
\text { forests. Funding may also be required for provision of renewable energy to agri-businesses. }\end{array}$ \\
\hline & Arazi & $\begin{array}{l}\text { There will be multiple land issues with rangeland and kuchis that require significant assistance from Arazi. } \\
\text { In the resource corridor it will be necessary for Arazi to consider environmental conservation when land } \\
\text { affected is either rangeland, forest or protected lands. }\end{array}$ \\
\hline
\end{tabular}




\section{Annex: EMD Risk Matrix}

The following chart provides the Risk Matrix for the EMD Component. This matrix provides an assessment of four critical aspects of risk that impact upon the success of the Program:

$£ \quad$ Financial risk - risk to cost control and project budget

T Time risk - danger of time over-run and late completion

$Q \quad$ Quality risk - risk to the quality of the completed project

$\boldsymbol{R} \quad$ Reputational risk - risk to the reputation of stakeholders and donors

\begin{tabular}{|c|c|c|c|c|c|c|c|}
\hline Risk & $£$ & $\mathbf{T}$ & $\mathbf{Q}$ & $\mathbf{R}$ & Impact & Probability & Mitigating Actions \\
\hline Lack of coordination - Ministers & & $\checkmark$ & $\checkmark$ & $\checkmark$ & High & Medium & Regular communication \\
\hline Lack of coordination - Organisations & $\checkmark$ & $\checkmark$ & $\checkmark$ & $\checkmark$ & Low & High & Regular communication \\
\hline Lack of coordination - Donors & $\checkmark$ & $\checkmark$ & & & Low & Medium & Regular communication \\
\hline Inadequate funding - Quantity & $\checkmark$ & & & & High & Low & $\begin{array}{l}\text { Proposal quality and } \\
\text { accountability systems }\end{array}$ \\
\hline Inadequate funding - Timing & & $\checkmark$ & & & High & Medium & $\begin{array}{l}\text { Contingency and scenario } \\
\text { planning }\end{array}$ \\
\hline Implementation obstacles & $\checkmark$ & $\checkmark$ & $\checkmark$ & $\checkmark$ & High & Medium & $\begin{array}{l}\text { Contingency and scenario } \\
\text { planning }\end{array}$ \\
\hline Absorptive capacity of beneficiaries & . & $\checkmark$ & $\checkmark$ & 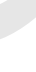 & High & High & $\begin{array}{l}\text { Selection procedures and } \\
\text { training }\end{array}$ \\
\hline Fiduciary risk & $\checkmark$ & & & $\checkmark$ & High & Medium & $\begin{array}{l}\text { Accountability systems and } \\
\text { independent controls }\end{array}$ \\
\hline Organisational capacity & $\checkmark$ & $\checkmark$ & $\checkmark$ & $\checkmark$ & Medium & Medium & Staffing and training \\
\hline Security & $\checkmark$ & $\checkmark$ & $\checkmark$ & & High & High & $\begin{array}{l}\text { Contingency and scenario } \\
\text { planning }\end{array}$ \\
\hline
\end{tabular}




\section{Annex: Comprehensive Strategic Framework for Food and Nutrition Security}

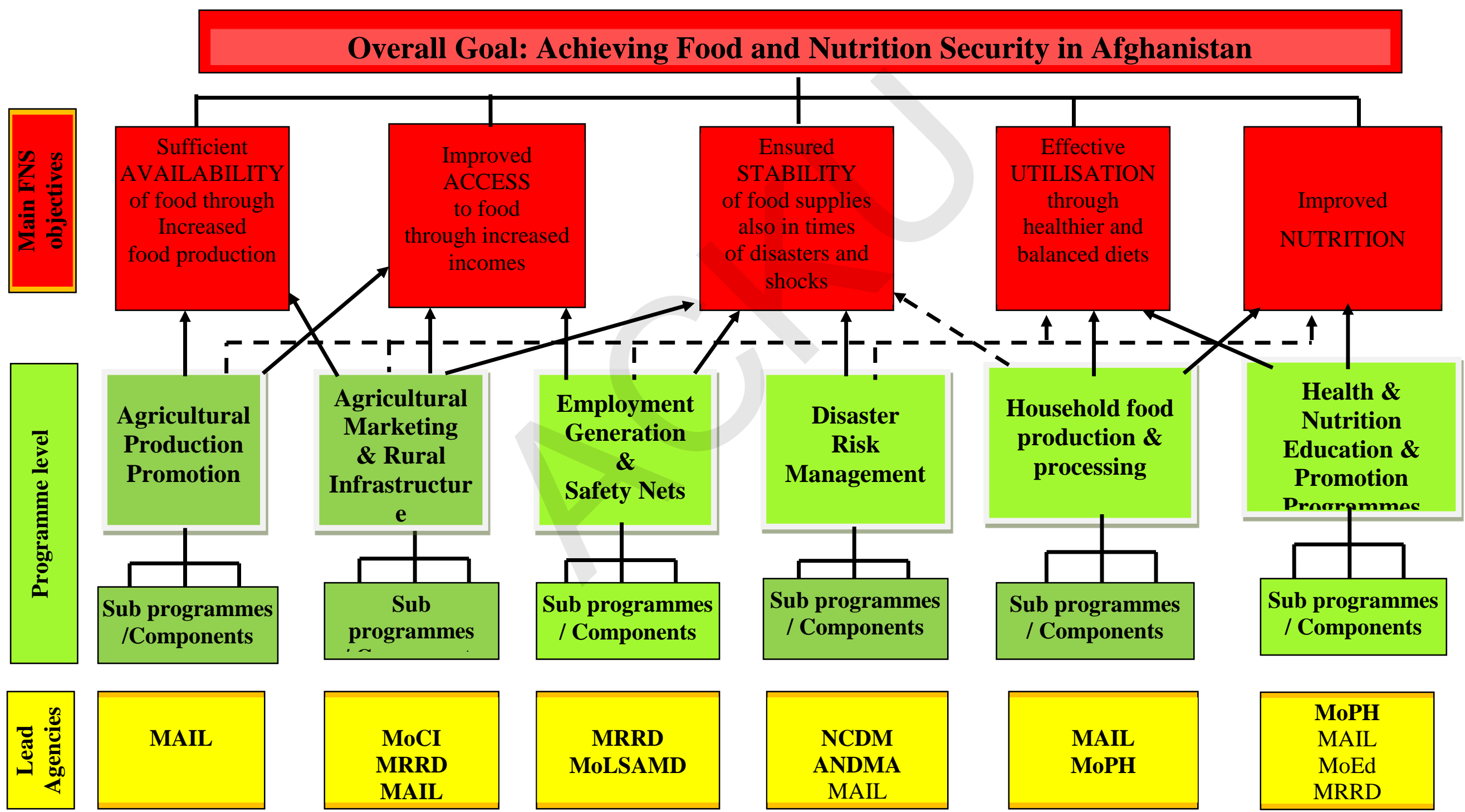

FFL-programme components, $\longrightarrow \quad$ Primary objectives / direct effects; $\longrightarrow$ 